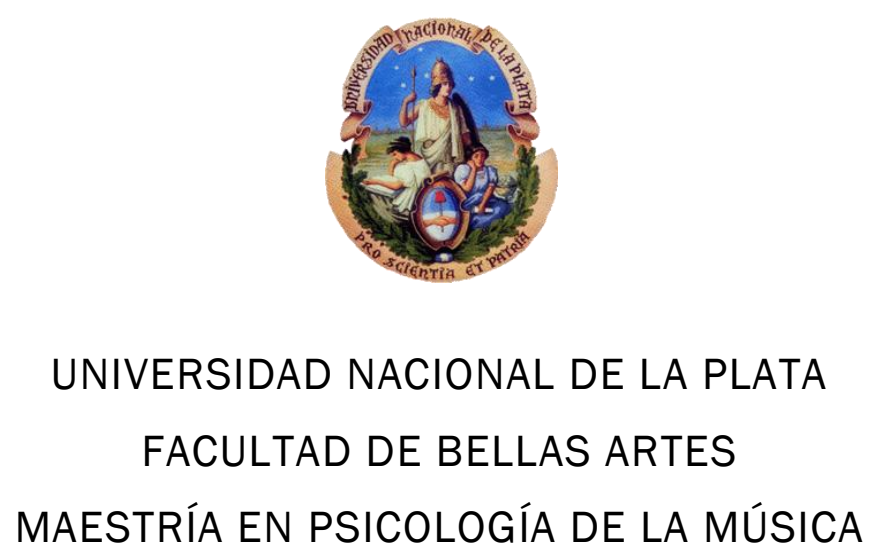

\title{
TESIS:
}

\section{Realidad perceptual de la nota como unidad operativa del pensamiento musical}

\author{
Maestrando: Prof. María Inés Burcet \\ Director: Dr. Favio Shifres
}

La Plata, Agosto de 2014 



\section{Índice}

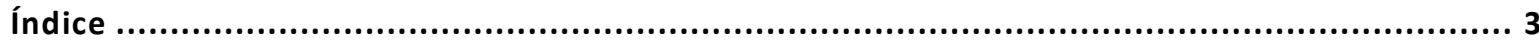

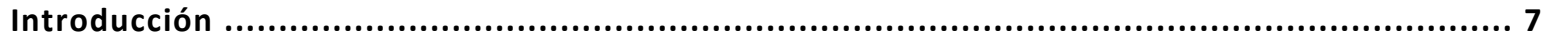

PRIMERA PARTE: FUNDAMENTOS TEÓRICOS .......................................... 15

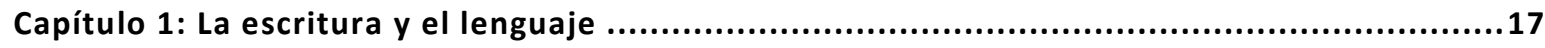

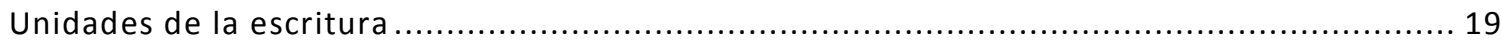

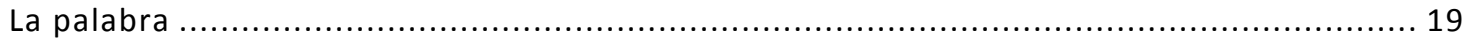

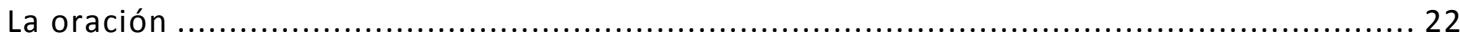

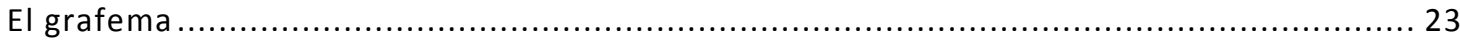

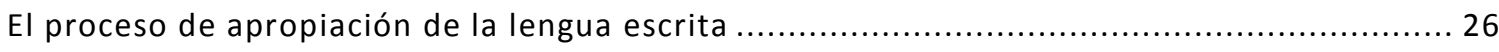

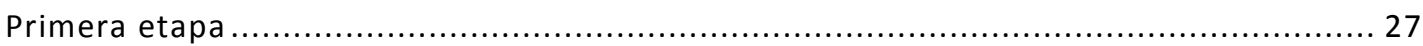

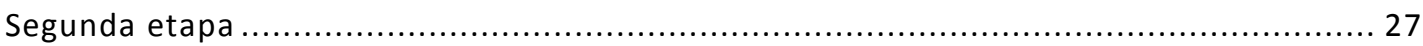

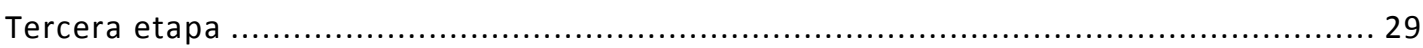

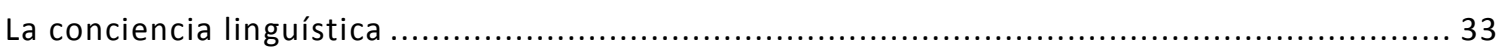

¿La conciencia fonológica se desarrolla espontáneamente? ........................................ 34

¿La conciencia fonémica, se desarrolla espontáneamente? ...................................... 35

¿Es suficiente estar alfabetizado para tener conciencia de los fonemas? ....................... 36

¿Desarrollar la conciencia de los fonemas, es un prerrequisito para iniciar el aprendizaje de

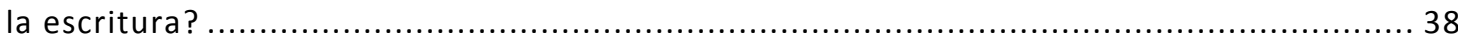

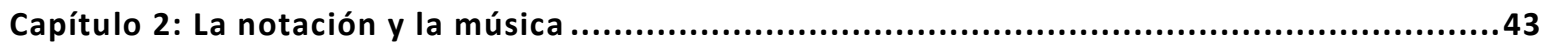

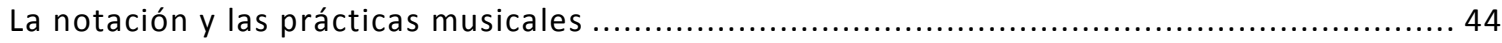

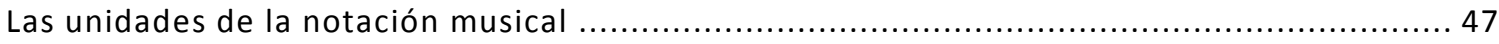

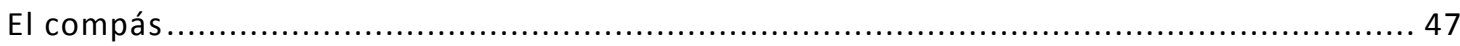

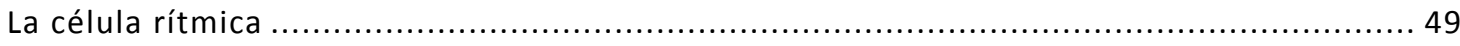

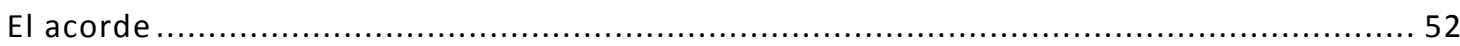

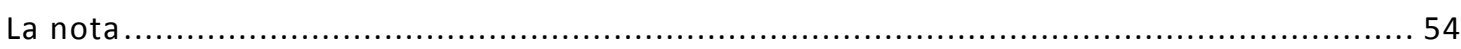

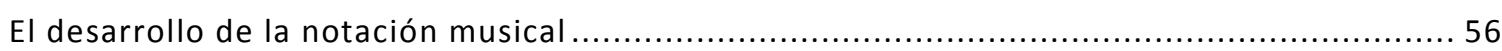

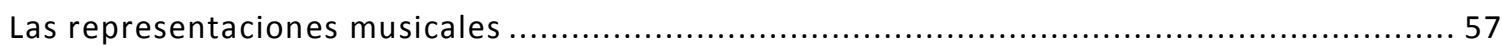

Representaciones pre figurativas, figurativas y formales .......................................... 59

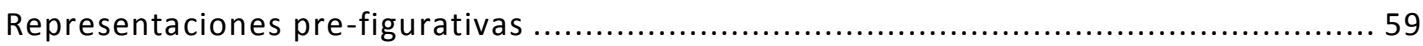

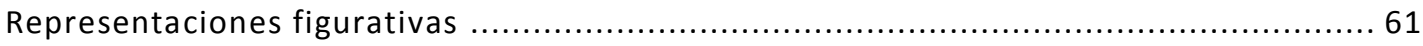




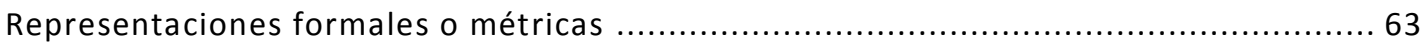

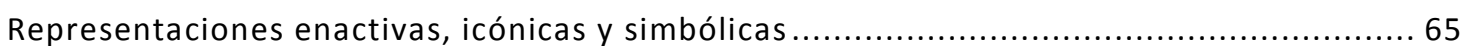

SEGUNDA PARTE: EVIDENCIA EMPÍRICA................................................. 71

Capítulo 3: La influencia del conocimiento de la notación musical en la identificación de la nota

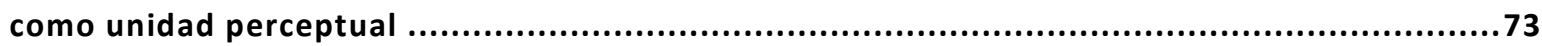

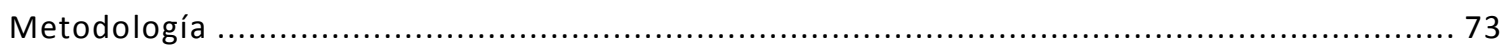

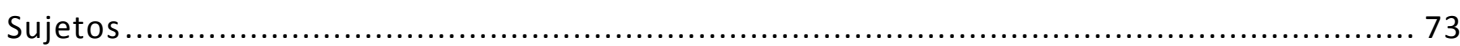

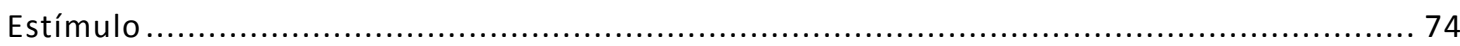

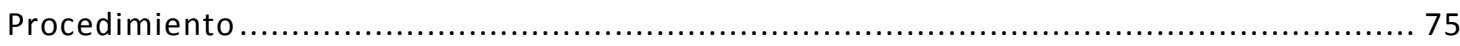

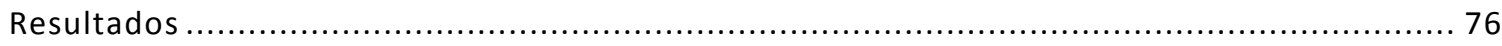

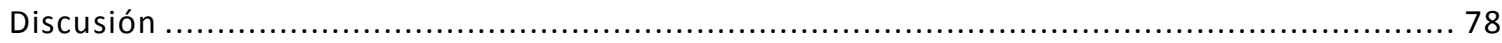

Capítulo 4: La unidad espontánea de análisis musical por audición en niños de 6 años ...........81

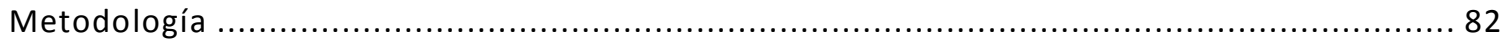

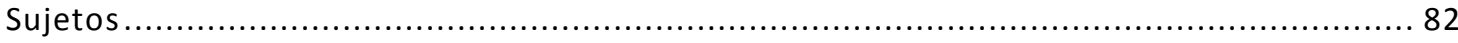

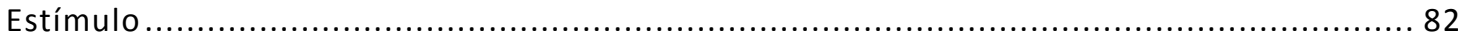

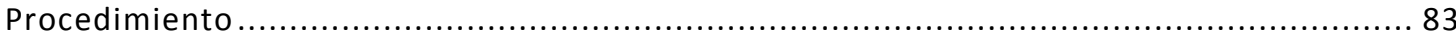

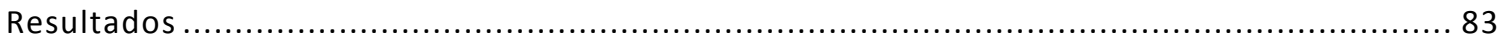

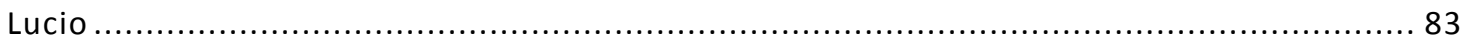

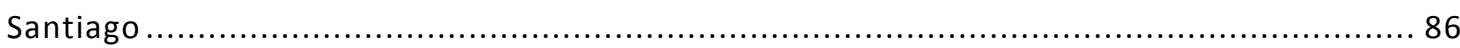

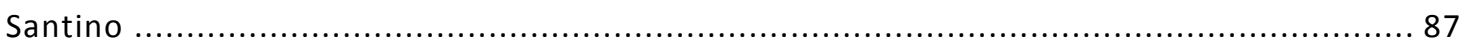

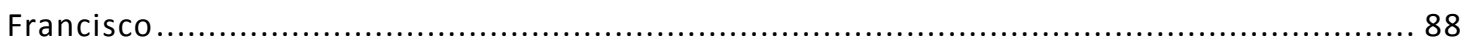

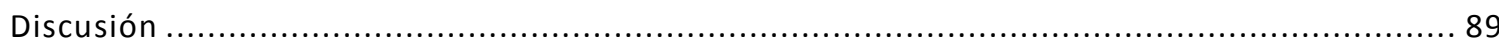

Capítulo 5: El conocimiento de la notación musical y la identificación de la nota como unidad

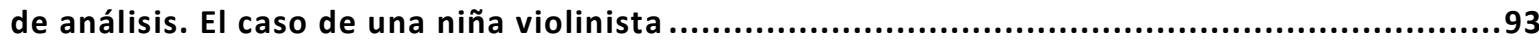

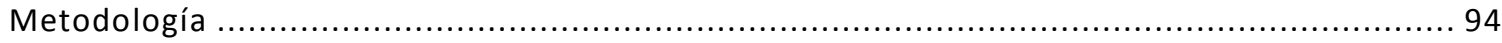

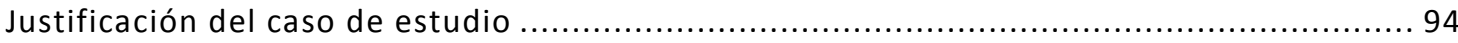

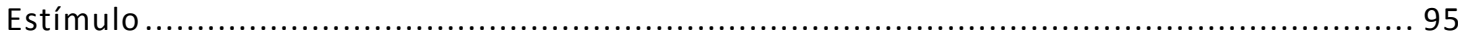

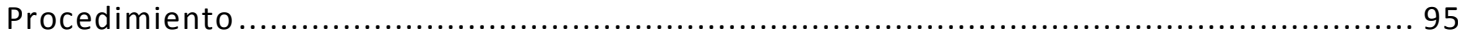

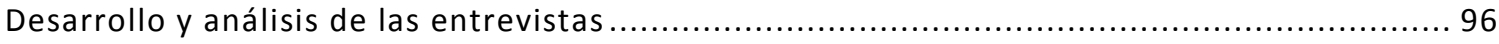

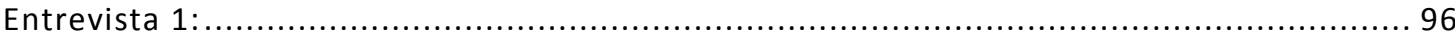

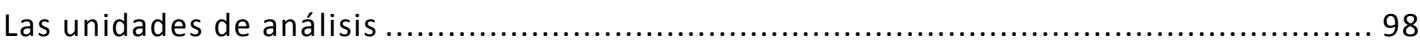

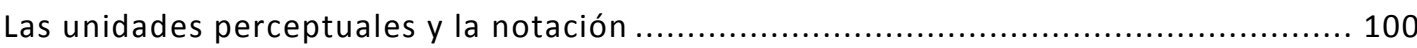




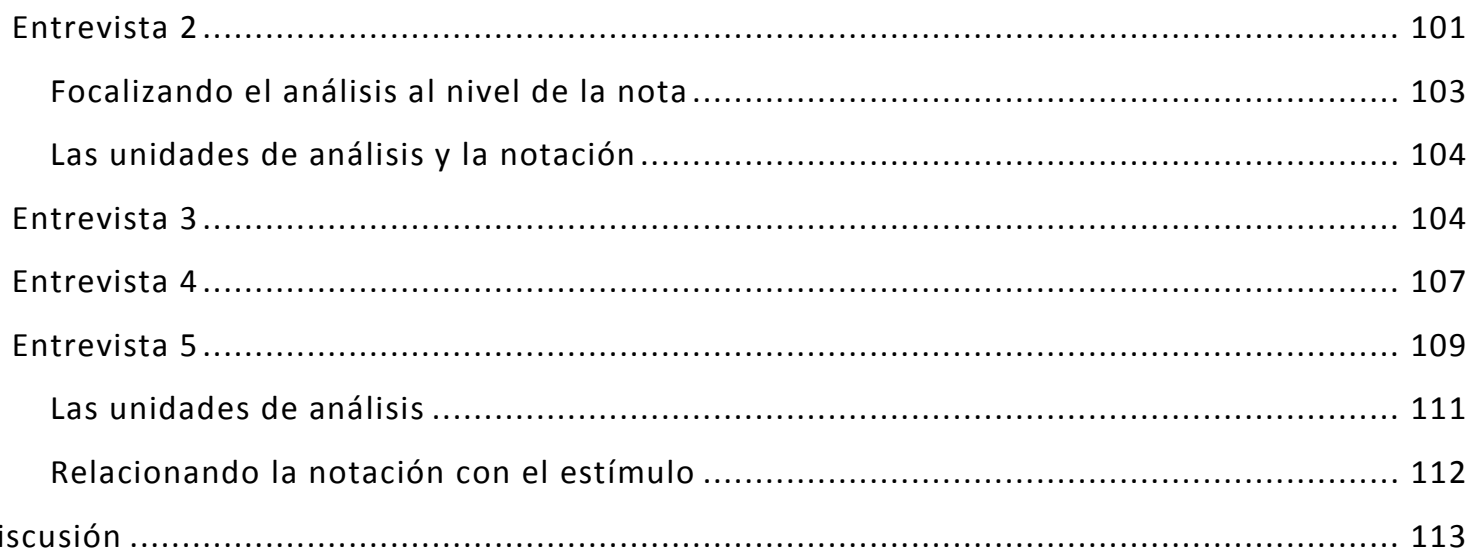

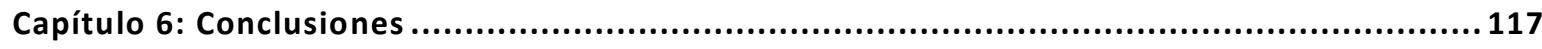

La nota como unidad de análisis, ¿̇surge de modo espontáneo? ................................. 119 ¿Es el conocimiento de la notación musical condición de posibilidad para la conciencia de tales unidades?

¿Es necesaria una intervención para acceder a las notas perceptuales, como unidades básicas de análisis?

Referencias. 129

Referencias bibliográficas .................................................................. 129

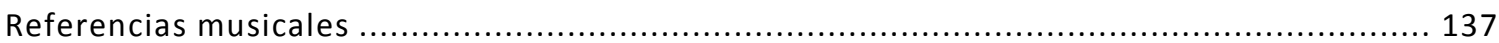

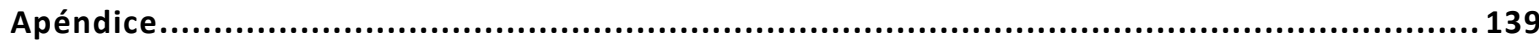

Transcripción de los fragmentos de Los Miserables .......................................... 139

Grabación de los fragmentos de Los Miserables ........................................ 140

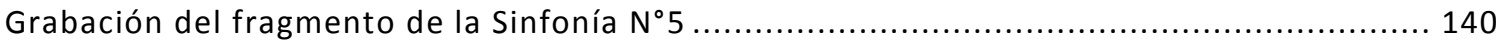





\title{
Introducción
}

\author{
“La escritura ha dado un soporte material a \\ una reflexión que difícilmente hubiera \\ podido desarrollarse de la misma manera \\ frente a un objeto en perpetua \\ transformación y evanescencia."
}

(Emilia Ferreiro 2002, p. 151)

Esta tesis problematiza la realidad perceptual de la nota como unidad de análisis y descripción de la música. Considerando que la nota es la unidad mínima de escritura en el sistema de notación musical, se propone cuestionar su realidad perceptual como unidad espontánea de análisis auditivo. Asimismo, se propone explorar la tipología de las unidades utilizadas por sujetos con y sin conocimiento de la lectoescritura en diferentes tareas que demanden el análisis del discurso musical.

El interés en el tema surge a partir de la experiencia docente en el contexto de la enseñanza formal de la música, tanto en niños como en adultos, donde el conocimiento del sistema de escritura musical es una habilidad ampliamente valorada. En estos contextos, la teoría ha encontrado en el sistema de notación musical las estructuras básicas para elaborar un modelo que permita explicar y describir la música. Estas estructuras teóricas básicas o prototeóricas (Shifres 2007), como la nota, el intervalo, el acorde, entre otras, han sido aplicadas para el desarrollo de las capacidades auditivo-musicales. Así, en la segunda parte del siglo $X X$, los principales enfoques de la formación auditiva orientaron la modalidad de audición hacia la producción de respuestas en términos de la teoría de la práctica musical (Wason 2002).

Si bien, los conceptos prototeóricos permiten realizar descripciones de la música en términos objetivos, y aunque, actualmente su relación con el desarrollo del oído musical ha planteado nuevas perspectivas de análisis para su abordaje, el problema 
consiste en que estos conceptos no sólo fueron tomados como normativos de la experiencia musical, sino que, además, fueron considerados como altamente compatibles con las unidades perceptuales. Tanto la pedagogía como la psicología clásica de la música han presupuesto que escuchamos notas, acordes e intervalos, porque estas unidades están disponibles tanto en la música como en la conciencia del oyente. En particular, la nota, que es la unidad mínima de escritura en el código de notación musical, ha sido considerada como la unidad de la dimensión melódica a la cual el oyente accede de modo espontáneo. Así, segmentar una melodía en unidades equivalentes a la nota se presenta como una habilidad de acceso directo. Un ejemplo de esta concepción son las grafías analógicas utilizadas habitualmente en el contexto de las prácticas musicales iniciales, incluso cuando el sistema de notación musical ni siquiera es contenido de estudio. Estas grafías utilizan, con frecuencia, la nota como unidad de representación que es representada con puntos, dando por supuesto que los sujetos establecen espontáneamente un correlato entre la grafía y la música a ese nivel. Incluso, en las prácticas iniciales del desarrollo de la lectoescritura, la habilidad para segregar el discurso musical en unidades que luego serán traducidas a notas no aparece siquiera problematizada.

En la experiencia docente, especialmente en la Facultad de Bellas Artes, donde el conocimiento de la lectoescritura musical no es requisito para el ingreso a las carreras de música, hemos observado que las unidades que propone el sistema de notación musical no resultan igualmente accesibles para quienes han desarrollado prácticas musical vinculadas a otros sistemas de escritura como las tablaturas o los cifrados. Particularmente, en la tarea de transcripción de enunciados musicales, en las prácticas iniciales del desarrollo de la lectoescritura, resulta frecuente encontrar diferencias entre las transcripciones realizadas por los estudiantes y la transcripción esperada por el docente. Es frecuente encontrar discrepancias, no sólo en el contorno melódico o en los grados de la escala involucrados, sino también entre la cantidad de notas escritas por los estudiantes y la cantidad de notas esperada. Algunas transcripciones suelen omitir o agregar notas. La observación sistemática de diferencias entre la cantidad de notas escritas y la cantidad de notas esperada, nos llevó a considerar que no se trataría de errores fortuitos.

El objetivo de esta tesis es cuestionar la realidad perceptual que tiene la nota como unidad de análisis e indagar en la tipología de las unidades utilizadas por niños y 
adultos, con diferente experiencia en el dominio del sistema de notación musical convencional, para resolver tareas de descripción y representación gráfica de diseños melódicos. Se espera que los aportes puedan redundar en una mayor comprensión de las habilidades que forman parte del proceso de aprendizaje de la lectoescritura musical, como así también proporcionar un antecedente en la discusión de los supuestos epistemológicos que definen los contenidos para el desarrollo de habilidades auditivas.

Esta tesis se organiza en dos partes. La Primera Parte presenta los fundamentos teóricos que enmarcan el problema de estudio y comprende el Capítulo 1, "La escritura y el lenguaje verbal" y el Capítulo 2, "La notación y el lenguaje musical"

El Capítulo 1 desarrolla un conjunto de conceptos teóricos derivados del lenguaje que permitirán situar el problema que será objeto de estudio a partir de reflexiones que han sido planteadas en el ámbito del lenguaje. El capítulo comienza con una descripción de las unidades de escritura y su diferenciación respecto a las unidades de la oralidad desde la perspectiva de Claire Blanche-Benveniste $(1998,2002)$ y Marie-José Béguelin (2002). A partir de esta diferenciación, respecto a los principios de delimitación que subyacen a tales unidades, en el siguiente capítulo se hará un planteo similar en el contexto de la música. Luego, se desarrolla la perspectiva que propone la psicogénesis para describir el proceso de apropiación de la escritura, se definen las etapas que se suceden y las problemáticas que va enfrentando el sujeto durante la adquisición de la escritura desde la mirada de Emilia Ferreiro y Ana Teberosky (1979). De esta perspectiva se rescatará el interés por la actividad espontánea que realiza el sujeto con el fin de comprender la escritura como objeto de conocimiento, así como las particularidades propias del pensamiento del sujeto prealfabetizado durante ese proceso. Finalmente se presentan diferentes investigaciones que han abordado el desarrollo de la conciencia fonológica, como habilidad metalingüística que aparece íntimamente relacionada con el proceso de alfabetización. Este concepto ha sido especialmente acuñado por la psicología cognitiva para aludir a la conciencia de las unidades constitutivas de las palabras, y el desarrollo de esta habilidad se ha instaurado como predictor del futuro desempeño de los niños en el aprendizaje de la lectura y la escritura alfabética. Sin embargo, y a pesar de los largos debates que se han planteado alrededor de la relación entre el desarrollo de la conciencia fonológica y el proceso de alfabetización, en el contexto 
de la tesis presentaremos algunos estudios experimentales que provienen de las diferentes perspectivas con la finalidad de poner en evidencia las particularidades que conlleva el acceso a las unidades de escritura en el contexto del lenguaje, así como las variables que son estimadas en los estudios de tales problemáticas. Todo ello, con la finalidad última de problematizar las particularidades que presentaría el acceso a las unidades del sistema de notación musical.

En el Capítulo 2 se plantea un recorrido en el ámbito del lenguaje musical. El capítulo comienza analizando el rol que el sistema de notación musical ha asumido en el desarrollo de las habilidades de ejecución y audición, donde las unidades derivadas de la escritura musical han definido tanto los contenidos de estudio como los problemas de investigación y han sido consideradas como altamente compatibles con las unidades de pensamiento musical. Luego se describen las unidades que la teoría y la notación musical han establecido y se presenta evidencia empírica obtenida a partir de estudios previos a esta tesis los cuales indicarían que estas unidades no serían de acceso espontáneo para quienes no manejan el sistema de notación musical. Seguidamente se presentan estudios de las representaciones musicales espontáneas realizados en niños y adultos, especialmente los enfoques de Jeanne Bamberger $(1982,1988,1991)$ y Lyle Davidson y Larry Scripp $(1988,1989)$ que han sido referencia de numerosas investigaciones posteriores. Los autores explican el desarrollo del pensamiento musical en términos de un proceso madurativo con etapas que se suceden por franjas etáreas. Desde ambas perspectivas, la unidad mínima de análisis no aparece como un problema durante en el proceso. Tanto las representaciones realizadas por los niños pequeños, como así también las realizadas por niños mayores y adultos, presentan un correlato directo entre cantidad de elementos graficados y cantidad de eventos sonoros. Sin embargo, es necesario resaltar que, mientras Bamberger desarrolla sus estudios a partir de la escritura de fragmentos rítmicos palmeados, donde la cantidad de elementos escritos podría derivar directamente de la cantidad de acciones motoras para producirlos; Davidson y Scripp lo hacen a partir de una canción popular cantada con presencia de un texto, por lo tanto la cantidad de notas graficadas podría derivar de la identificación de unidades de texto (sílabas). Considerando estas particularidades, es comprensible que el problema de la unidad no surgiera en tales estudios. Se propone entonces la necesidad de abordar esta problemática a partir de estímulos musicales reales, interpretados por músicos profesionales, en versiones grabadas. 
La Segunda Parte de la Tesis se presenta la evidencia empírica y comprende tres estudios que conforman los capítulos 3,4 y 5 .

El Capítulo 3 desarrolla el estudio "La influencia del conocimiento de la notación musical en la identificación de la nota como unidad perceptual". Este trabajo propone indagar la relación entre el desarrollo de la notación musical y la conciencia de la nota. Para estimar en qué medida, la habilidad para identificar en una melodía unidades equivalentes a la nota sería dependiente del conocimiento del sistema de notación musical, se solicitó a un grupo de estudiantes de música iniciales adultos que contaran la cantidad de sonidos que presentaban diferentes fragmentos melódicos que habían sido previamente memorizados. Las respuestas fueron analizadas en relación con el conocimiento de lectoescritura musical que poseían los sujetos. El estudio permitió considerar que, para quienes habían desarrollado experiencias musicales iniciales no basadas en la notación musical, la nota no constituía una entidad de acceso espontáneo.

A partir de los resultados obtenidos en el estudio del Capítulo 3, y estimando los resultados de los estudios de las representaciones espontáneas, los cuales muestran que a partir de los 5 o 6 años los niños están en condiciones de representar tantas unidades gráficas como eventos contienen los estímulos musicales, se llevó a cabo, en el Capítulo 4, el estudio denominado: "La unidad espontánea de análisis musical por audición en niños de 6 años". En este trabajo se realizaron entrevistas individuales a 5 niños en las cuales, en primer lugar se solicitó que contaran los sonidos de un fragmento musical a partir de su audición y luego, en caso que los sujetos no accedieran a la nota como unidad de análisis de manera espontánea, se formularon diferentes preguntas con el fin de propiciar la segmentación en dichas unidades. La estrategia metodológica utilizada resultó clave para el abordaje del problema de estudio porque, a partir de las intervenciones del investigador pudo advertirse, si esta unidad era accesible aun cuando los sujetos no la habían estimado inicialmente para resolver la tarea. Los resultados mostraron que ninguno de los sujetos entrevistados estimó la nota como unidad espontánea de análisis. Asimismo, la unidad de análisis pudo vincularse con diferentes atributos de la música. Estos resultados difieren de los expresados por Bamberger, Davidson y Scripp, quienes mostraron que a los 6 años los niños representaban gráficamente tantas unidades como notas presentaban los estímulos musicales. 
Partiendo de estos resultados, y también con el propósito de contrastar con el estudio del Capítulo 3, realizado en sujetos con insuficiente desarrollo en el dominio de la música, se llevó a cabo el estudio del Capítulo 5, denominado: "El conocimiento de la notación musical y la identificación de la nota como unidad de análisis. El caso de una niña violinista". En esta investigación se presenta el caso de una niña de 6 años, con un gran desarrollo del lenguaje musical basado en un entorno familiar musicalmente rico y en una intensa práctica instrumental precoz, durante el proceso de adquisición de la escritura del lenguaje y el aprendizaje del sistema de notación musical. En una entrevista inicial, a un cuando descontábamos que el nivel de acceso a la nota sería para ella una habilidad resuelta, la niña mostró un desempeño similar al de niños sin conocimientos musicales específicos. Se seleccionó este caso para indagar en las particularidades del pensamiento en ausencia del conocimiento del sistema de escritura musical.

Por último, el Capítulo 6 presenta las conclusiones. Se discuten algunos supuestos teóricos a la luz de los hallazgos de los estudios empíricos presentados y finalmente se expresan algunas reflexiones finales.

\section{$* * *$}

\section{Agradecimientos:}

Quiero agradecer especialmente a mis alumnos, niños y adultos, que constantemente motivan mis reflexiones acerca de la complejidad, y al mismo tiempo, la simplicidad, que implica desarrollar habilidades musicales.

A los docentes de la cátedra de Educación Auditiva de la Facultad de Bellas Artes, Universidad Nacional de La Plata, con quienes permanentemente reflexionamos acerca de las instancias iniciales de la educación musical formal: Victoria Assinnato, Romina Herrera, María de la Paz Jacquier, Gabriela Martínez, Pablo Musico, Alejandro Pereira Ghiena, Martín Remiro, Violeta Silva y Vilma Wagner.

A los docentes que generaron en mí inquietudes teóricas: Favio Shifres, Silvia Malbrán, Silvia Furnó, Isabel Cecilia Martinez y Susana Romé.

A quienes me ofrecieron su colaboración durante el desarrollo de la tesis: Guadalupe Segalerba, Orlando Musumeci y especialmente a Jeanne Bamberger que me 
proporcionó sus escritos y me dio la posibilidad de intercambiar reflexiones a través del correo electrónico.

Por último, especialmente mi agradecimiento a Favio Shifres por su presencia incondicional, sus apreciados y relevantes comentarios, aportes y sugerencias; por su constante seguimiento y por compartir su tiempo de manera generosa durante el desarrollo del presente trabajo. 



\section{PRIMERA PARTE: FUNDAMENTOS TEÓRICOS}





\section{Capítulo 1: La escritura y el lenguaje}

Numerosos filósofos, antropólogos y lingüistas han reflexionado acerca de la relación que existe entre la manifestación escrita y oral de la lengua. Dos posiciones antagónicas se han desarrollado respecto al rol de la escritura en dicha relación.

Por un lado una perspectiva clásica, que comprende las ideas desde Aristóteles hasta el primer estructuralismo de Saussure (1983) y Leonard Bloomfield (1933), entiende la escritura como un dispositivo gráfico con la finalidad de transcripción del habla. De acuerdo con este enfoque, la escritura representa los patrones fónicos del habla a través de marcas visibles y considera que son esos patrones fónicos, y no la escritura, los que conllevan de manera directa los significantes, por ello este enfoque es denominado fonocéntrico. Desde esta perspectiva la historia de la escritura ha sido entendida como una serie de intentos progresivos hacia la representación de los fonemas, considerando que el conocimiento de la estructura de la lengua es anterior al hecho de representarla en tanto que la evolución de la escritura consiste en encontrar los medios para traducir su estructura en unidades de escritura sin ambigüedades. En este contexto, los sistemas de base fonológica son considerados como los sistemas más evolucionados.

Por el otro lado, una perspectiva autonomista que ha valorado la escritura como un modo de existencia de la lengua, un medio lingüístico por derecho propio, que ejerce efectos decisivos en procesos cognitivos vinculados con el habla. Es a través de la escritura que el habla se convierte en objeto de pensamiento y análisis. Desde este enfoque, el origen de la escritura es anterior o contemporáneo a la conciencia de unidades de representación. Al respecto, David Olson (1994) explica que son los sistemas de escritura los que proporcionan los conceptos y categorías para pensar el lenguaje oral, y no a la inversa. Y agrega que "la conciencia de la estructura lingüística es un producto del sistema de escritura, no una condición previa para su desarrollo" (1994, p.92). Desde esta perspectiva, el sistema de escritura es 
comprendido como la consecuencia de manifestaciones de la conciencia de los aspectos del lenguaje representados que exhiben diversas propiedades y funciones.

Algunos lingüistas, como Roy Harris (1986) y Geoffrey Sampson (1985), han objetado la supremacía del sistema alfabético, considerando que la representación de componentes fonológicos no es un requisito indispensable para desarrollar una teoría lingüística y reconociendo las ventajas de otros sistemas de notación, como por ejemplos aquellos con componentes ideográficos, los cuales no han sido un impedimento para el desarrollo de las sociedades que los utilizan.

La lingüística contemporánea ha rechazado la jerarquía entre las manifestaciones escritas y orales, considerando que tanto lo escrito como lo oral son expresiones complementarias de una lengua. El interés se ha centrado especialmente en el estudio de las particularidades de cada una de esas manifestaciones, así como de sus mutuas influencias. En particular, Claire Blanche-Benveniste $(1998,2002)$, Marie-José Béguelin (2002) analizaron los procesos de segmentación y las funciones que cumplen las unidades derivadas de esos procesos en la oralidad y en la escritura. Las autoras estudiaron la relación entre las unidades de la lengua escrita y las unidades de la lengua hablada, focalizando especialmente en los principios que subyacen en su delimitación y han coincidido en considerar que las unidades que derivan de la escritura presentan principios de organización diferentes a las unidades derivadas de la oralidad.

La delimitación de las unidades de la oralidad ha sido muy discutida por los lingüistas, sin embargo hay acuerdo en considerar que éstas no guardan relación con las unidades de escritura. Blanche-Benveniste y Béguelin sostienen que la escritura elabora unidades propias como son la palabra, la oración o el párrafo, que no tienen una correlación directa con las unidades del habla. En el mismo sentido, Emilia Ferreiro (2002) propone hacer una diferenciación entre letras y fonemas, como así también entre palabra gráfica y palabra oral.

A continuación se presentan algunas definiciones de las unidades derivadas de la escritura, en particular la palabra, la oración y el grafema; se exponen las diferencias que presentan estas unidades respecto a las unidades de la oralidad. 


\section{Unidades de la escritura}

\section{La palabra}

Como han señalado Paul Saenger (1997) y Francois Desbordes (1990) la segmentación gráfica es un hecho relativamente reciente en la historia de la escritura occidental. Si bien los griegos y latinos utilizaban la palabra como una unidad cuando realizaban clasificaciones gramaticales, la distinción en la escritura fue introducida recién hacia fines del S. X. Hasta entonces la scripto continua presentaba la cadena de letras de corrido y requería de un experto para poder hacer una lectura adecuada.

La implementación de los espacios en blanco facilitó la lectura porque permitió separar el discurso en palabras. Aun sin conocer una lengua, es posible contar la cantidad de palabras que están escritas. Sin embargo, los espacios blancos no tienen un correlato desde la oralidad, como afirma Guy Cornillac, "en la cadena hablada, no hay aire entre las palabras, que el blanco sería susceptible de denunciar" (citado por Blanche-Benveniste 1998, p.71).

Segmentar un enunciado en unidades que se corresponden con las palabras escritas no es una habilidad de acceso espontáneo. Entre otras cosas porque, como consideraba Gustave Guillaume, "para que una oración cobre sentido, las palabras deben dejar de distinguirse" (citado por Blanche-Benveniste 1998, p.68); entonces, en la medida en que el discurso se percibe como un flujo continuo no permite aislar directamente unidades que se correspondan con las palabras escritas. BlancheBenveniste explica que los escritores inexpertos, niños o adultos, utilizan principios de segmentación en palabras que no tienen correspondencia con la lengua escrita. Por ejemplo cuando escriben, sin separación, un artículo con el sustantivo “lamanzana", dos pronombres clíticos contiguos "sela comió" o bien cuando separan en segmentos una única palabra, como "en tonces".

Los lingüistas se han interesado profundamente por definir el concepto de palabra, sin embargo, como asegura Béguelin, siempre han tropezado con definiciones incompletas. Se ha definido la palabra como unidad de acentuación, como unidad con autonomía sintáctica y como unidad de designación, encontrando ciertas limitaciones en cada una de las definiciones. 
De acuerdo con el criterio de unidad de acentuación, cada segmento que está provisto de un acento es una palabra. Esta definición ha permitido delimitar la unidad, pero no ha abarcado aquellas palabras que no tienen acento, como por ejemplo los artículos o algunas preposiciones. Blanche-Benveniste explica que otro inconveniente de esta definición resulta cuando se presentan palabras de 4 sílabas o más, las cuales suelen percibirse con un acento secundario que llevaría a la posibilidad de confundir esa unidad con una serie de dos palabras, por ejemplo "mariposa" como "mari-posa".

De acuerdo con el criterio de unidad con autonomía sintáctica, se considera que la palabra es portadora de un sentido propio y resulta posible aislar cada palabra de un enunciado sin que ésta pierda el sentido. Esta definición no ha alcanzado a definir las palabras que no son autónomas, como las preposiciones o los artículos. Incluso, resulta frecuente que los niños tiendan a aislar un grupo de palabras más que una única palabra como unidad de sentido debido a su autonomía, por ejemplo: “la mariposa estaba posada en la flor" podría segmentarse como "lamariposa estaba posada enlaflor". Emilia Ferreiro (2002) explica que antes de los 6-7 años los niños presentan dificultades para asumir como "palabras" aquellas que no tienen un sentido semántico pleno, en tanto que, la aceptación de artículos y preposiciones como "palabras" es contemporánea al inicio de la alfabetización.

De acuerdo con el criterio de unidad de designación, "nombre” sería la definición más cercana para la palabra. Los nombres propios resultan el prototipo de palabra, así también los sustantivos comunes que remiten a "cosas", luego le siguen ciertos adjetivos y adverbios, ciertos verbos, y finalmente preposiciones, artículos y verbos auxiliares presentan mayor dificultad para ser comprendidos por esta definición. Aun así, incluso en los sustantivos comunes, palabras como ice cream (helado), pomme de terre (patata), quedan exceptuadas de esta definición por tratarse de unidades de designación que se escriben utilizando dos o tres palabras separadas. Por lo tanto esta definición tampoco a alcanza para definir la palabra. "Por lo tanto" es un ejemplo de tres palabras gráficas que representan una sola idea de consecución (Ferreiro, 2002).

Para Béguelin la palabra, como unidad, es una construcción social, con todo lo aproximativo y arbitrario que esto pueda acarrear. La autora explica que se trataría de una unidad configurada en el saber práctico, sin fundamento científico. Estudios 
en antropología desarrollados por Jack Goody (1977) han permitido identificar lenguas que utilizan un mismo término que puede traducirse por palabra, morfema, frase, proverbio, entre otros, designando porciones de enunciado que pueden corresponderse con una o con más palabras ${ }^{1}$. Incluso, el autor también ha señalado que ciertas lenguas sin tradición escrita no tienen ningún término para designar la palabra.

La ambigüedad en la designación, en su definición y delimitación, condujo a considerar que no se trataría de una unidad propia del lenguaje oral. Para BlancheBenveniste, aislar porciones de discurso que se corresponden con la palabra escrita demanda una serie de operaciones complejas que se desarrollan a partir del aprendizaje de la escritura. La autora explica que la palabra conlleva una definición gramatical y contextual, es por ello que, la posibilidad de segmentar el discurso en estas unidades, surge como consecuencia de conocer la escritura, la lengua, su gramática y su ortografía.

Con el propósito de estudiar la habilidad para segmentar el discurso en palabras, Ferreiro (2000) desarrolló un estudio en niños alfabetizados con edades comprendidas entre los 7 y 8 años. Allí, se solicitó a los niños que contaran la cantidad de palabras que presentaba un refrán, considerando que los refranes corresponden a expresiones que deben repetirse literalmente, ya que cualquier paráfrasis puede afectar su significado. Los niños debían escuchar el refrán grabado, repetirlo, contar las palabras escuchadas (diciendo cuáles eran), escribirlo y contar (subrayando) las palabras escritas. Los datos permitieron observar que la mayoría de las respuestas presentaban discrepancias entre el conteo oral y el conteo escrito con una tendencia a contar más "palabras" desde el conteo oral; diferencias que, en algunos casos eran del orden de 15 palabras desde el conteo oral y 7 desde el conteo escrito. Se observó que el $65 \%$ de los niños tendían a contar sílabas al buscar palabras a nivel oral, asimismo en las escrituras se observaron también hiposegmentaciones, es decir uniones de palabras como por ejemplo "ojosquenoven".

\footnotetext{
1 En griego rhema, lexis, logos y en latin verbum, dictum, dictio, vox, pueden traducirse por palabra, emisión de voz, habla expresión, frase, sentencia o discurso, resultando ampliamente polisémicos. (Reichler-Begelin, 1990 citado por Blanche Benveniste 1998).
} 
La autora explicó que los sujetos tendían a utilizar la misma designación de "palabra" para referirse a segmentaciones diferentes en lo oral y en lo escrito, incluso aceptando, ante la evidente discrepancia entre ambos conteos, que el término palabra podía no tener el mismo referente cuando se aplicaba a lo oral o a lo escrito. Esta dificultad para conceptualizar indicaría que el simple hecho de estar alfabetizados no es suficiente para segmentar el discurso en palabras, que no se trata simplemente de asimilar el modelo que la escritura propone sino de construir un nuevo observable, de encontrar y elaborar el propio referente conceptual para definir el término "palabra” (Ferreiro 2000a).

\section{La oración}

Al igual que la palabra, la oración parece ser una unidad derivada de la escritura. Las oraciones son unidades que, en el texto escrito, están delimitadas por puntos. Sin embargo, la puntuación de los textos impresos, en el sentido moderno, se instaló en Europa a fines del siglo XV. En las tradiciones antiguas era el lector quien, comprendiendo primero el contenido de un texto, debía proponer las segmentaciones en grupos de palabras. El lector producía las pausas fundándose en el sentido que él mismo le otorgaba al texto. En nuestros días, el procedimiento se da de modo inverso: las demarcaciones que proporciona el texto conforman referencias de segmentación que colaboran para su compresión (Blanche-Benveniste 1998).

En la escritura, las mayúsculas y los puntos segmentan el texto en oraciones, pero estas unidades no encuentran correspondencia directa en la oralidad. Para BlancheBenveniste, algunas unidades que hemos aprendido en la escritura, como la oración, nos resultan incuestionables. En la oralidad, las pausas se realizan en lugares donde la sintaxis no invitaría a puntuar, por ejemplo entre un verbo y su complemento: "ellos llamaban... a cada una de las personas que estaban allí".

Cuando transcribimos una producción oral no nos basamos en las pausas para localizar los puntos y segmentar en oraciones, más bien nos basamos en los indicios dados principalmente por la entonación. Es la entonación la que desempeña un papel primordial como indicador de agrupamientos y separaciones en la oralidad (BlancheBenveniste 1998). Sin embargo, “la puntuación es un sistema autónomo de demarcaciones gráficas, que no tiene correspondencia directa con los hechos de entonación" (Blanche-Benveniste 1998, p.60). Si bien, cuando hay un punto escrito 
se produce una pausa en lo oral, esto ocurre solamente en la lectura de un texto, no ocurre en las demás situaciones de lengua hablada. En los discursos orales, fenómenos como los titubeos, enmiendas o fallos resultan corrientes y producen pausas en diferentes lugares del discurso que no se corresponden con la puntuación. Incluso en el habla se puede producir de corrido, sin pausas, un enunciado que en la escritura se traduciría en varias oraciones.

Al igual que la palabra, la oración parece ser una unidad compuesta de múltiples criterios, para Emilia Ferreiro "la oración sólo se justifica al nivel de la grafía" y resulta ser una "unidad del saber práctico" (2002, p.48).

\section{El grafema}

El grafema es la unidad mínima e indivisible de la escritura de una lengua (Real Academia Española, 2001). Esta unidad puede representar una idea, como ocurre en una escritura logográfica; o bien puede representar los sonidos de la pronunciación, como es el caso de la escritura alfabética. En la escritura alfabética, el grafema es comúnmente denominado "letra" (Alarcos Llorach 1968).

Numerosas discusiones se han desarrollado en orden a definir la unidad de discurso que en la escritura se traduce en grafema. Por lo general se considera que, en una escritura alfabética, los grafemas representan a los fonemas (Catach 1988). El fonema es un sonido del habla que permite distinguir palabras en una lengua. Por ejemplo, en el español, "b" y "p" son fonemas diferentes, porque podemos encontrar palabras como "bote" y "pote" que sólo difieren en ese sonido y significan cosas diferentes. En el español hay una alta correspondencia entre grafemas (o letras) y fonemas, sin embargo, un fonema pueden corresponderse también con una combinación de grafemas, como por ejemplo: "gn" en italiano, "nh" en portugués, "ch" en español; o bien un mismo fonema puede representarse con dos grafemas diferentes como ocurre en español con la "g" y la "j" o con la "b" y la "v". Incluso un grafema puede no corresponderse con ningún fonema, como ocurre en el español con el grafema " $h$ ". Claire Blanche-Benveniste y André Chervel (1974) explican que los sistemas alfabéticos incluyen a través de la utilización de recursos ortográficos, algunos componentes ideográficos. Por ejemplo "casa" y "caza" tienen los mismos fonemas pero diferente significado a partir de su ortografía. Allí, la escritura presenta una diferencia gráfica que no corresponde a una diferencia sonora. 
A su vez, el lenguaje oral comprende unidades menores al fonema, estas unidades se denominan fonos. Cada fono presenta características acústicas particulares y es representado con un signo gráfico de acuerdo al Alfabeto Fonético Internacional2 (AFI). El AFI comprende un signo gráfico, y sólo uno, por cada unidad sonora de la lengua. Sin embargo, como explica Blanche-Benveniste (2002), existe una gran diferencia entre hacer una "notación" de la lengua en términos de este alfabeto y "escribir" una lengua. Esa diferencia, explica la autora, comprende factores históricos y culturales. Esto ocurre porque, como explica Geoffrey Sampson (1985), dentro de cualquier lengua hablada, no todas las diferencias entre fonos son significantes o distintivas. Así es que, del universo de fonos posibles, hemos aprendido a identificar aquellos que resultan necesarios para comprender nuestra lengua. En cada lengua hay fonos diferentes que son representados con una misma letra por considerárselos como alófonos. Por ejemplo, en el español, el fono que corresponde a la letra "s" en "castillo" es físicamente diferente al que corresponde a la letra "s" en "casa". Estas diferencias corresponden a dos fonos que son considerados alófonos, sus diferencias nos resultan irrelevantes y no determinantes para diferenciar significados, por lo tanto en español son representados con la misma letra. Sin embargo, en otras lenguas los fonos que son considerados como alófonos pueden ser diferentes. Por ejemplo, en chino mandarín la [b] y la [p] son alófonos de un mismo fonema y se escriben con la misma letra, mientras que otros fonos que en español se consideran como alófonos del fonema que corresponde a la letra "p" que son [p] y [ph], son considerado fonos diferentes en el chino mandarín. Como aducen Morais, Alegria y Content (1987), las letras se corresponden aproximadamente con los fonemas y es por ello que se requiere de un conjunto de reglas de conversión grafema-fonema para poder acceder a la lectura de palabras nuevas o poco conocidas.

Los fonos no se encuentran representados en la escritura. Como explica Blanche Benveniste (2002), las escrituras no conservan las diferencias fónicas por debajo del umbral de los fonemas. Los adultos alfabetizados están entrenados para no percibir esas diferencias, mientras que los niños todavía las perciben antes de conocer la escritura. David Olson (1994) explica que el alfabeto no constituye una teoría fonológica y señala, al igual que Roy Harris (1986), que los griegos, inventores del alfabeto, describieron patrones de sonidos que resultaban de una reflexión directa

2 International Phonetic Alphabet (IPA). Propuesto en 1925 por la Conferencia de Fonética celebrada en Copenhague y revisado en diversas ocasiones. 
del alfabeto de modo tal que "los griegos Ilegaron a ignorar las diferencias fonéticas que no se reflejaban en la ortografía griega" (p.86). Habitualmente en los letrados, el conocimiento de los fonemas contribuye a oscurecer algunas distinciones fonéticas. Charles Read (1978) sostiene que, quienes estudian la fonética deben hacer un esfuerzo para adquirir, o volver a adquirir, los juicios que los niños de preescolar pueden hacer espontáneamente. Lo que hemos aprendido, quienes conocemos la escritura alfabética, es a representar el discurso conscientemente como una secuencia de fonemas en lugar de fonos y, al mismo tiempo, utilizar las diferencias entre fonos que resultan pertinentes para expresar los significados referenciales en nuestra lengua. Incluso, en ocasiones, el alfabeto puede operar como modelo a tal punto que nos condiciona el modo de percibir los fonemas. Un estudio realizado en niños alfabetizados demostró que tendían a contar más "sonidos" en la palabra "pitch" que en la palabra "rich" (Ehri 1985) aun cuando los fonoaudiólogos les explicaban que son equivalentes. Esto ocurre porque, quienes están alfabetizados tienden a hacer introspección de la lengua utilizando su alfabeto.

Comprender la naturaleza fonológica del lenguaje y comprender que los símbolos escritos representan fonemas, resultan habilidades complejas, entre otras cuestiones, por la imposibilidad de pronunciar de manera aislada cada uno de los fonemas, como ocurre especialmente con los fonemas que corresponden a las letras "t", “p”, "b", "c" o “d”. Alvin M. Liberman y sus colaboradores (Liberman, et al. 1967) explican que, en el lenguaje oral, existe una relación de superposición o coarticulación entre fonemas. Particularmente, algunas consonantes y vocales se solapan en el habla y es por ello que no podemos identificar el instante certero donde finaliza una y comienza la otra (Mattingly, 1972). Por ejemplo, en la palabra "bag" las dos consonantes y la vocal que la conforman se coarticulan produciendo un solo segmento de sonido. Por lo tanto, el número de segmentos sonoros que se perciben, no es igual al número de segmentos que la estructura fonológica transmite. Si bien esto no es un problema para producir el lenguaje oral, ya que el oyente recupera automáticamente los gestos coarticulados (Liberman y Mattingly 1989), dada la compleja relación entre la estructura fonológica y el automatismo con que esta relación se aborda en el habla, planteará una dificultad en los futuros lectores quienes deberán encontrar esos segmentos en la fonología subyacente, y no en la apariencia superficial del sonido (Liberman et al 1967). 
De acuerdo con las diferentes argumentaciones presentadas hasta aquí, podemos observar que los principios de organización y delimitación que proponen las unidades de la escritura, difieren de los principios de segmentación espontánea que se producen en la oralidad. Por lo tanto, la correspondencia entre unidades de escritura y unidades de oralidad va a requerir el conocimiento de la lengua, la escritura, su gramática y su ortografía.

A los fines de esta tesis nos interesa analizar el modo en que se accede a la segmentación del habla en la unidad mínima de escritura, es decir, la relación grafema-fonema, o bien letra-fonema. Dado que, la letra es la unidad de acceso a la lectura y escritura, el principio de correspondencia entre esta unidad y los fonemas ha sido especialmente problematizado en los estudios sobre la adquisición y desarrollo de la alfabetización. En virtud de analizar el modo en que los sujetos establecen correspondencia entre unidades sonoras y unidades escritas (al nivel de la letra), y con la finalidad última de problematizar esta relación en la música (al nivel de la nota); consideraremos el enfoque de Emilia Ferreiro y Ana Teberosky (1979) sobre la adquisición de la escritura.

\section{El proceso de apropiación de la lengua escrita}

Emilia Ferreiro y Ana Teberosky (1979) proponen que los niños toman contacto con la escritura mucho antes de entrar a la escuela. La escritura no sólo está presente en los libros de su entorno o en carteles callejeros, la escritura aparece también en sus juguetes, sus vestimentas, en los alimentos y en la televisión. Con frecuencia, los niños están expuestos a situaciones donde sus padres resuelven problemas a través de la escritura, como anotar una lista de cosas para recordar, escribir un mensaje en un papel o en una computadora. Los adultos protegen y muestran preocupación por ciertos documentos escritos demostrando que guardan un valor especial. Por lo tanto, desde pequeños los niños observan situaciones en las cuales los adultos producen lenguaje a partir de las letras, e inclusive, advierten que ese lenguaje contiene palabras que son diferentes a las que utiliza para comunicarse de manera oral, con un modo de organización y una entonación que no es la habitual de una conversación.

Ferreiro (1997, 2000, 2002) concibe el desarrollo de la lectoescritura como el proceso de apropiación de un objeto socialmente constituido, y no como la 
adquisición de una técnica de transcripción. Considera que el niño, por estar inmerso en una cultura con escritura, elabora ciertas hipótesis acerca del modo en que el sistema está organizado y propone que las escrituras infantiles, en diversas lenguas, situaciones educativas y medios culturales, siguen una línea de evolución que comprende una serie de etapas. Como dice la autora:

Esta evolución indicaría que estamos en presencia de una psicogénesis real que tiene su propia lógica interna, lo que quiere decir que las informaciones provenientes del medio son incorporadas en los sistemas interpretativos cuya sucesión no es aleatoria, aunque la duración de los cambios de cada momento de organización -y por consecuencia de las edades de aparición- depende de un conjunto de influencias diversas (sociales, familiares, educativas, individuales, etc.) (2000, p.32).

Bajo esta perspectiva, las etapas del desarrollo de la escritura no presentan una correspondencia rígida en cuanto a la edad, sino que van apareciendo cronológicamente en cada individuo de acuerdo al contexto.

\section{Primera etapa}

La primera etapa está caracterizada por la búsqueda de parámetros distintivos entre las marcas gráficas figurativas y las marcas gráficas no-figurativas, es decir, entre dibujar reproduciendo la forma del objeto, y escribir utilizando formas arbitrarias, aunque no necesariamente convencionales y ordenadas de modo lineal. En esta etapa los niños comienzan a diferenciar entre el objeto (o su imagen) y el texto escrito, y para marcar la diferencia recurren a la utilización del artículo indefinido, por ejemplo para describir la imagen dicen "unos zapatos", en cambio para describir lo que está escrito bajo la imagen dicen: "zapatos". Como indican Emilia Ferreiro y Ana Teberosky (1979), esta diferenciación sutil al nivel del lenguaje es una de las indicaciones más seguras de la constitución de las letras dispuestas en serie, como objetos sustitutos. Los niños conceptualizan la escritura como un conjunto de formas arbitrarias, que sirven fundamentalmente para representar aquella propiedad de los objetos que el dibujo no consigue atrapar: el nombre.

\section{Segunda etapa}

La segunda etapa se caracteriza por el establecimiento de ciertas condiciones formales para la legibilidad. Con el fin de que una serie de letras pueda "decir algo" 
se establecen criterios de diferenciación intra-relacionales. Se proponen dos hipótesis básicas: una en el eje cuantitativo, según la cual la serie de letras debe tener una cantidad mínima, generalmente de tres; y otra en el eje cualitativo, según la cual debe haber cierta variación interna entre las letras que componen la serie. En esta etapa un niño que observa una palabra con dos letras considera que allí no puede decir nada y lo mismo ocurre si aparecen tres letras repetidas.

Posteriormente y como parte de un proceso más extenso, se buscan modos de diferenciación inter-relacionales, donde las escrituras deben diferenciarse para decir cosas diferentes. Se considera, por ejemplo, que los nombres de los objetos más grandes deberían escribirse con más letras que los nombres de los objetos pequeños, e igualmente para los más gruesos, los más pesados, los más numerosos, o los más viejos. Esto surge por la necesidad de encontrar principios formales de diferenciación.

Ferreiro propone dos problemas cognitivos que estarían en el centro de la evolución entre la segunda y la tercera etapa: (i) la relación entre la totalidad y las partes constitutivas y (ii) la correspondencia término a término.

\section{La relación entre la totalidad y las partes constitutivas}

Desde el momento en que la escritura es comprendida como una serie de partes, comienza a problematizarse la relación entre las partes y su totalidad. En un principio las propiedades atribuidas al todo son igualmente atribuidas a las partes, así los niños consideran que dice su nombre tanto en la totalidad que se conforma con las letras que lo componen, como también en cada una de sus letras. Esta solución entra en contradicción con la hipótesis de cantidad mínima, a partir de la cual sólo con tres letras puede decirse algo.

Entonces aparece el siguiente razonamiento: a una totalidad incompleta al nivel de lo escrito debe corresponderle otra totalidad incompleta al nivel de la emisión oral. Y este paso marca el inicio de la segmentación silábica. Aquí la autora plantea que son los problemas cognitivos derivados de la comprensión de la escritura, y en particular por el problema de la relación entre la totalidad y las partes, los que conducen al niño al descubrimiento de la posibilidad de descomposición silábica como la mejor forma de resolver tales problemas (Ferreiro 2002b). Entonces, la segmentación en sílabas 
surgiría como respuesta a problemas planteados por la comprensión de la escritura y no solamente la aplicación de un saber-hacer obtenido en el contexto del habla.

\section{La correspondencia término a término}

Antes de ingresar a la tercera etapa del desarrollo, el niño ha comenzado a realizar diferentes correspondencias entre dibujos y escritura, como por ejemplo cuando los niños dibujan la cantidad de letras (o bolitas, o marcas) como objetos hay en una imagen. Esta es una primera relación término a término. Luego esa correspondencia, por la exigencia de la cantidad mínima, se transforma en una relación de muchos a uno, tanto en la producción como en la interpretación de textos: como por ejemplo cuando consideran que, para que diga algo, son necesarias, al menos, tres letras.

Finalmente surge otra relación uno a uno cuando el nombre es susceptible de ser segmentado en tantos "pedacitos" como unidades comprende la escritura. A partir de la correspondencia entre unidades de escritura y unidades de pronunciación, correspondencia que se da en el nivel silábico especialmente en lenguas como el español o el italiano en las que el límite silábico está bien marcado, se inicia la fonetización de la escritura. Esta correspondencia se da del siguiente modo: a cada sílaba pronunciada le corresponde una letra escrita, aunque sin importar qué letra sea. Por ejemplo, un niño de 6 años (Ferreiro 2000a) escribe "mariposa”, "caballo", "gato" y "pez" del siguiente modo: "ieif", "aei”, "ei", "i". Esto ocurre en la medida en que el niño acepta que una letra puede representar un fragmento de una enunciación y, además, como se observa para la palabra "pez", también una letra puede representar un enunciado, es decir que va dejando de lado la hipótesis de cantidad mínima, tanto para representar a un fragmento de enunciado como a un enunciado completo. La correspondencia término a término entre elementos evoluciona hacia una correspondencia entre los elementos cualificados en el curso de la tercera etapa del desarrollo.

\section{Tercera etapa}

La tercera etapa se inicia cuando los niños comienza a buscar una relación entre lo que se escribe y los aspectos sonoros del habla. El niño descubre que la forma lingüística hablada tiene partes, que la escritura representa esas partes y lo escrito comienza a estar regulado por las semejanzas y diferencias de los componentes sonoros. Ferreiro distingue tres modos de representación en esta etapa: silábico, 
silábico-alfabético y alfabético. Los tres modos se corresponden con las diferentes hipótesis que construye el niño para dar uso a la escritura. Si bien el niño accede espontáneamente a la hipótesis silábica, para elaborar una hipótesis alfabética es necesaria una intervención que, generalmente, suele coincidir con el inicio de la escuela primaria.

\section{Modos de representación silábicos}

La sílaba resulta una unidad de segmentación accesible en las lenguas que tienen unidades silábicas claramente marcadas como en el español, el portugués, el italiano y el catalán. Ferreiro explica que la conciencia de la sílaba puede considerarse como un hecho evolutivo, ya que ha sido reiteradamente constatada en niños de 4 y 5 años sin formación específica (Ferreiro 2002). Aunque no resulta igualmente accesible en el francés y el inglés, es interesante subrayar que en esta etapa, el niño descubre que la palabra tiene unidades menores, por lo tanto descubre la noción de constituyente lingüístico. En este momento del desarrollo, el niño intenta dar una correspondencia término a término, en la cual la serie ordenada de letras se corresponde con la serie ordenada de sílabas. Esta correspondencia, letra con sílaba de enunciado en principio es azarosa: cualquier letra puede corresponderse con cualquier sílaba.

A partir de esta hipótesis los niños comienzan a regular la cantidad de letras, pueden anticiparlas y justificarlas, pero los problemas se generan particularmente en las palabras con pocas sílabas. Por ejemplo, un niño de 5 años y 10 meses cuenta con sus dedos la cantidad de sílabas, luego escribe tantos puntitos sobre la hoja como sílabas ha contada y finalmente escribe las letras sobre los puntos. Procede así para la palabra vaca, mariposa y elefante, pero al momento de llegar a las palabras monosílabas pan y sol, suspende el conteo y escribe dos letras, sin poder justificarlo (Ferreiro 2000b). Se observa que, cuando una sílaba está inserta en una palabra, una letra basta para representarla, pero cuando la sílaba es equivalente a la palabra, una letra no alcanza para representarla. En algunos casos justifican la presencia de dos letras creando un bisílabo donde hay un monosílabo, por ejemplo al escribir "sol" utilizando dos letras lo justifican como "so-ol" (Ferreiro 2000b).

Esta hipótesis conlleva sus propios conflictos, uno de ellos es el de la representación de las palabras con una sílaba y el otro es la exigencia de una cantidad mínima de 
letras. Por otra parte su explicación del sistema no alcanza para comprender las escrituras que están presentes en su medio. Cuando quieren leer las escrituras, siempre sobran letras. Pero además, un nuevo conflicto aparece cuando el niño no puede explicar la escritura de su propio nombre. Los niños proponen muchas soluciones ingeniosas a este problema, en algunos casos intentan hacer correspondencia entre dos letras por sílaba.

\section{Modos de representación silábico-alfabéticos}

Este período se caracteriza por la necesidad del niño de abandonar el sistema anterior y reemplazarlo por uno nuevo. Esta necesidad surge a partir de la imposibilidad de utilizar la hipótesis silábica para explicar la escritura de su propio nombre: cada vez que intenta hacerlo le sobran letras. Como explica Ferreiro, "el nombre propio es fuente tanto de información como de conflicto" (Ferreiro 1982, p.152). Este conflicto en la correspondencia de unidades orales y escritas será resuelto a partir de la instrucción formal en lectoescritura que recibirá el niño en la escuela y que dará inicio a una nueva etapa centrada en la relación sonora de las letras (Sinclair 1982).

En un principio los niños comienzan a escribir en un sistema que no es totalmente silábico ni tampoco alfabético. Prácticamente todas las letras utilizadas son correctas, pero suelen faltar. Algunos ejemplos son, "maiosa" para mariposa, "cayo" para caballo. Las escrituras silábico-alfabéticas han sido tradicionalmente consideradas como "escrituras desviantes" por las omisiones de letras, sin embargo, Ferreiro (2000a) explica que, si bien estas escrituras presentan diferencias con la escritura alfabética, especialmente omisiones de letras, desde el punto de vista de la psicogénesis es exactamente lo contrario, ya que, con relación a las escrituras silábicas precedentes, lo que ocurre es que el niño comienza a agregar letras.

\section{Modos de representación alfabéticos}

Finalmente el niño se apropia de los principios de la escritura alfabética, es decir, comprende sus reglas de producción, y entonces inicia el último período. La escritura alfabética responde básicamente al siguiente principio: a diferente secuencia sonora, diferente secuencia gráfica, y a semejante secuencia sonora, semejante secuencia gráfica. Sin embargo, estas reglas de correspondencia sonora no llegan a explicar la 
escritura, ya que, en numerosos casos, la identidad de sonido no garantiza la identidad de letras, así como la identidad de letras no garantiza la cantidad de sonidos. El problema, más allá de la correspondencia, será comprender la naturaleza del sistema de escritura. Para ello deberá comprender otros aspectos, tales como el uso de los espacios en blanco para la separación entre palabras, los signos de puntuación, la distribución de mayúsculas y minúsculas, y las diferentes alternativas gráficas para diferencias sonoras. Esto va a derivar en nuevos conflictos, especialmente vinculados a la ortografía.

Como vimos hasta aquí, Ferreiro y Teberosky, consideran que el aprendizaje de la escritura es un proceso de construcción que surge a partir de la necesidad del sujeto de explicarse y comprender la naturaleza de este objeto de conocimiento. Las autoras proponen una serie de etapas que atraviesa el sujeto durante ese proceso, en las cuales elabora diferentes hipótesis acerca del modo en que la escritura se organiza. Primero las hipótesis se orientan a explicar las condiciones de interpretabilidad de la escritura, luego intentan explicar la relación entre el todo y las partes constitutivas, finalmente buscan relacionar lo escrito con los aspectos sonoros del habla. En esta última etapa los sujetos elaboran hipótesis del tipo: a semejanza de sonidos, semejanza de letras; a diferencia de sonidos, diferencia de letras.

En oposición al enfoque psicogenético, que comprende el conocimiento de la escritura como un proceso similar al del conocimiento de la lengua oral, Ignatius Mattingly (1972) propone que es necesario hacer una distinción entre ambos procesos. Para este autor, la adquisición del lenguaje oral es una actividad lingüística primaria que se desarrolla espontáneamente sin que medie una enseñanza sistemática. En cambio, la adquisición de la lengua escrita requiere el aprendizaje sistematizado e implica el desarrollo de la conciencia lingüística, es decir, de un conocimiento metalingüístico de ciertas características o aspectos de la actividad lingüística primaria, es por ello que la denomina actividad lingüística secundaria. La conciencia lingüística es la habilidad para tratar el lenguaje de un modo objetivo y su desarrollo implica la desviación de la atención desde el significado del lenguaje hacia la estructura. Asimismo, implica la capacidad para poder reflexionar y manipular la estructura o forma de lenguaje independientemente de su función comunicativa. La habilidad para manipular segmentos del habla inferiores a la palabra se denomina 
conciencia fonológica, e implica la habilidad para comprender que las palabras están formadas por elementos deslindables en el continuo del habla (Mattingly 1972).

Numerosos debates se han planteado en relación al desarrollo de la conciencia fonológica y sus implicancias. Sin embargo, aquí expondremos simplemente algunos estudios experimentales que nos permitan poner en evidencia las particularidades que conlleva el acceso a las unidades de escritura en el contexto del lenguaje.

\section{La conciencia lingüística}

Como dijimos antes, Mattingly (1972) define la conciencia lingüística como la habilidad para reflexionar y manipular la estructura o forma del lenguaje independientemente de su significado. Particularmente, propone el concepto de conciencia fonológica para referirse a la habilidad para manipular segmentos del habla inferiores a la palabra. Ahora bien, los segmentos del habla inferiores a la palabra incluyen una variedad de unidades, entre ellas los morfemas, las sílabas y las letras. Por su parte, Joseph Torgensen y Patricia Mathes (2000) proponen hacer una diferenciación entre dos habilidades que derivan de la conciencia lingüística, y que refieren a la conciencia de diferentes segmentos del lenguaje: la conciencia fonológica y la conciencia fonémica. Los autores explican que, mientras la primera refiere a la habilidad para acceder a la estructura sonora de la palabra, tanto la segmentación en sílabas como la identificación de rimas, la segunda refiere a la identificación de los fonemas individuales. Aquí nos proponemos abordar la conciencia lingüística valiéndonos de dicha diferenciación.

Las investigaciones sobre el desarrollo de la conciencia fonológica y la conciencia fonémica, realizadas en los últimos 40 años, han intentado dar respuesta a algunos de los siguientes interrogantes: ¿se desarrollan espontáneamente? ¿Es suficiente estar alfabetizado para tener conciencia fonémica? ¿Desarrollar la conciencia fonémica, es un prerrequisito para iniciar el aprendizaje de la escritura?

Presentamos aquí algunas consideraciones que proponen dar respuesta a cada uno de estos interrogantes. 


\section{¿La conciencia fonológica se desarrolla espontáneamente?}

A partir de la observación del comportamiento lingüístico de los niños en edad preescolar, se ha advertido que, cierto conocimiento de la estructura fonológica de la lengua, podría desarrollarse antes del aprendizaje formal de la lectura y escritura. En particular, este conocimiento inicial se ha manifestado en la habilidad de los niños de edad preescolar para identificar rimas de un modo espontáneo. Sin embrago existen posiciones controvertidas respecto a la consideración de la identificación de rimas como manifestación del desarrollo de la conciencia lingüística. Por un lado, se considera que se trataría de un proceso perceptivo básico que no implicaría necesariamente una habilidad metacognitiva, y por otro, una postura opuesta entiende que tal identificación surgiría como consecuencia de la capacidad para aislar y comparar los segmentos fonológicos finales, es decir, como una habilidad metalingüística (Naremore, Densmore y Harman 2001). Desde esta última perspectiva, la identificación de rimas sería la resultante del desarrollo de la conciencia fonológica que aparecería como consecuencia de la maduración y/o la experiencia lingüística misma.

En relación con la segmentación en sílabas, Ferreiro (2012) explica que el niño accede a estas unidades de un modo espontáneo en ciertos contextos. Se trata de unidades fácilmente aislables en el lenguaje oral porque las mismas suelen cumplir funciones comunicativas, por ejemplo, los niños las utilizan habitualmente cuando quieren remarcar un enunciado: "quiero cho-co-la-te". La autora explica que el niño accede espontáneamente a las sílabas, como unidades mínimas de segmentación entre los 4 y los 5 años. Del mismo modo, estudios realizados en diferentes lenguas han constatado que las tareas de identificación de las sílabas resultan más fáciles para los niños de 5 años que aquellas en las que deben identificar fonemas (Liberman, Shankweiler, Fischer y Carter, 1974 para el inglés; Lundberg, Olofsson y Wall, 1980 para la lenguas escandinavas y Jiménez, 1992 y Carrillo, 1994 para el español).

Es así que, tanto la identificación de rimas, como la segmentación en sílabas, se consideran habilidades que surgen de un modo espontáneo en los niños de entre 4 y 5 años. Sin embargo, en el desarrollo de la conciencia fonémica, el proceso resulta más complejo. 


\section{¿La conciencia fonémica, se desarrolla espontáneamente?}

Con el propósito de indagar el conocimiento de los fonemas de la lengua, las investigaciones pusieron el énfasis en la manipulación de segmentos dentro de palabras o pseudo palabras, como por ejemplo solicitando a los niños que quitaran, agregaran o cambiaran segmentos vocálicos o consonánticos a partir de palabras dadas. En tal sentido, Victoria Fromkin y Robert Rodman (1988) asumieron que la capacidad para segmentar una palabra en los sonidos que la componen era una habilidad compartida por los hablantes de esa lengua, por lo cual, un hablante de inglés 'sabe' que hay tres sonidos en la palabra "cat": el sonido inicial representado por la letra “c”, el segundo por la letra "a", y el sonido final por la letra "t" y por lo tanto, podrá segmentar esa palabra en esas 3 partes. A partir de esa hipótesis los autores desarrollaron pruebas de supresión y adición de fonemas donde, por ejemplo, se estimaba que, si los sujetos podían segmentar "cat" en "c + a + t", entonces podían suprimir el fragmento "c" y obtener "at", suprimir el fragmento "t" y obtener "ca", o agregar el fragmento "a" y obtener "cata". Estas pruebas se aplicaron en inglés y luego en diferentes idiomas y en ningún caso se confirmó el planteo realizado por Fromkin y Rodman.

Si bien las pruebas de supresión de fonemas fueron fácilmente resueltas por quienes sabían leer y escribir el inglés, los desempeños no fueron iguales para quienes aun no habían aprendido a leer. En una serie de estudios posteriores, reportados por Robert Scholes y Brenda Willis (1991), se observó que los adultos hablantes nativos, analfabetos, del inglés eran incapaces de efectuar supresión de fonemas en tareas como eliminar la "f" de "flat" (volar), eliminar la "s" de "past" (pasado), entre otros. Por otro, lado estas mismas tareas resultaban sencillas de resolver para los hablantes de inglés alfabetizados, incluso los niños de hasta 3er grado de la escuela primaria (Scholes y Willis 1987). Así, los desempeños en estas pruebas arrojaron fuertes indicios de que los fonemas eran un componente de la conciencia de la lengua que tiene un hablante sólo si sabe leer una escritura alfabética en su lengua. Los autores asumieron que es a través de la adquisición de la representación alfabética de la lengua que el hablante puede transferir este modo de representación al análisis del habla. En definitiva, tenemos conocimiento de los fonemas porque tenemos conocimiento de las letras (Scholes y Willis 1991). 
Mientras que el desarrollo de la conciencia fonológica no precisaría del aprendizaje de la lectoescritura, en las investigaciones psicolingüísticas contemporáneas fue surgiendo la convicción de que, el desarrollo de la conciencia fonémica estaría ligado al proceso de alfabetización. Desde esta perspectiva, la capacidad para manipular fonemas no surgiría como un simple hecho madurativo sino más bien como consecuencia del desarrollo de la alfabetización y la habilidad para deletrear. Los estudios anteriores consideraron la edad de los sujetos como variable para el estudio del desarrollo de la conciencia fonológica intentando determinar el momento en que se evidenciaba. Para abordar el desarrollo de la conciencia fonémica, el proceso de alfabetización fue introducido como variable de estudio.

\section{${ }_{\mathrm{d}}$ Es suficiente estar alfabetizado para tener conciencia de los fonemas?}

Una limitación que suelen tener los estudios que comparan desempeños entre sujetos analfabetos y alfabetizados es la imposibilidad de aislar esa diferencia respecto a otros componentes como el contexto socio económico o la edad. En tal sentido, es interesante observar el estudio realizado por José Morais y sus colaboradores (Morais et al. 1979) quienes, con el fin de estudiar el vínculo entre el desarrollo de la conciencia fonémica y el proceso de alfabetización en adultos provenientes de un contexto socio económico similar, desarrollaron una serie de pruebas en analfabetos de Portugal, que nunca habían asistido a la escuela y en sujetos de similar edad y origen social que habían asistido a la escuela a partir de la adolescencia, aprendiendo a leer en clases especiales. Ambos grupos habían estado igualmente expuestos a las palabras escritas alfabéticamente en el medio donde vivían y pertenecían al mismo contexto socio económico.

A los fines del estudio los sujetos debían repetir una emisión eliminando o agregando un segmento inicial. En algunos casos la tarea daba por resultado una palabra y en otros daba por resultado una no-palabra. Por ejemplo, "alhaco" se convirtió en "palhaco" (payaso) y "purso" se convirtió en "urso" (oso). Los resultados mostraron que los sujetos analfabetos no podían resolver adecuadamente la tarea. Por ello, los autores concluyeron que no es la mera exposición a la lengua escrita la que proporciona la habilidad para segmentar el lenguaje, ya que los analfabetos portugueses carecían de la capacidad segmentaria aun cuando habían tenido 
similares oportunidades que los sujetos alfabetizados de encontrarse con el lenguaje escrito y sus usuarios. Se consideró que esa experiencia de exposición no era suficiente para desarrollar en ellos habilidades de segmentación, y que sólo quienes habían desarrollado habilidades de lectura y escritura podían operar con esas unidades.

Un estudio posterior realizado por Read y sus colegas (Read et al. 1986) mostró que el análisis segmentario no sólo se desarrolla en quienes están alfabetizados. Los autores compararon lectores no alfabéticos y alfabéticos en China. Es decir, sujetos que utilizaban la escritura tradicional (logográfica) y otros que, además de la escritura tradicional, manejaban en sistema pinyin, que transcribe el chino con alfabeto latino. Las pruebas y procedimientos fueron exactamente los mismos utilizados por Morais y sus colaboradores (Morais et al. 1979) y los resultados fueron muy similares. Quienes sabían sólo el sistema de escritura tradicional (logográfico) obtuvieron los mismos resultados que los portugueses analfabetos, es decir, ambos mostraron por igual la imposibilidad de analizar discurso en el nivel e los fonemas. Mientras que, quienes conocían el sistema pinyin mostraron la habilidad para acceder al nivel de los fonemas al igual que los portugueses alfabetizados. Ello permitió considerar que es aprender a leer en un sistema alfabético lo que permite desarrollar las capacidades de análisis segmentario. Como expresan Scholes y Willis, "los fonemas son un componente de la conciencia de la lengua que tiene un hablante sólo si éste sabe leer una representación alfabética de su lengua" (1991, p.291). Es decir que tenemos conciencia de los fonemas porque tenemos conocimiento de las letras. Del mismo modo, Olson (1994) afirma que "quienes no están familiarizados con un alfabeto simplemente no oyen los fonemas" (p.189).

En tal sentido, se ha considerado que las habilidades de segmentación en fonemas no se adquieren espontáneamente en el curso del desarrollo cognitivo del ser humano, por el contrario, es necesaria una intervención específica, que para la mayoría de las personas se desarrolla al aprender a leer y escribir en un sistema de escritura alfabética (Morais et al. 1979). Jesús Alegría (1985) explica que:

El ser humano no llega espontáneamente a descubrir la estructura fonética de la lengua. Para que esto ocurra, una intervención externa es indispensable y esa intervención es generalmente el hecho de tener que aprender a leer en un sistema alfabético (p. 91). 
En otras palabras, no es suficiente para un iletrado el contacto con el lenguaje oral o la exposición en un medio con escritura para desarrollar la conciencia de los fonemas. Es necesaria una intervención externa para comprender que las palabras tienen una conformación fonémica.

\section{¿Desarrollar la conciencia de los fonemas, es un prerrequisito para iniciar el aprendizaje de la escritura?}

En torno a este interrogante hay posiciones controvertidas, especialmente, desde la psicogénesis y la psicología cognitiva. Particularmente la polémica se centra en establecer si la conciencia fonológica es un prerrequisito o una consecuencia de la adquisición de la lectoescritura.

La perspectiva cognitivista ha estimado que el desarrollo de la conciencia fonémica requiere de instrucción explícita para conocer las letras a las cuales refieren los fonemas. El desarrollo de esta habilidad ha sido considerado como prerrequisito para el aprendizaje de la escritura alfabética (Stanovich y Stanovich 1995, Lundberg 1991; Stanovich, Cunningham y Cramer 1984; entre otros). En tal sentido, numerosas investigaciones mostraron que el desarrollo del conocimiento fonológico, a través de la enseñanza explícita en niños de nivel preescolar, conduce a un mayor rendimiento en lectura y escritura en los primeros años de la escuela primaria (McCardle y Chhabra 2004; Alegría, 2006). Es por ello que, basándose en estos resultados, las prácticas educativas promovieron actividades que permitieron desarrollar y entrenar la conciencia de los fonemas como requisito previo para abordar la lectura alfabética. Incluso, se consideró que la resolución de tareas a partir de la manipulación de los componentes fonológicos de las palabras, podría no sólo colaborar en la resolución de problemas de lectura sino también instaurarse como un predictor de dicha habilidad (Lundberg, Frost y Petersen 1988; Goswami y Bryant 1990; Ball y Blachman 1991; Defior y Tudela 1994).

Desde esta perspectiva, los estudios sobre el desarrollo de la conciencia fonológica se diseñaron en torno a la resolución de tareas de: (i) comparación de sonidos, por ejemplo, indicar qué palabra comienza con el mismo sonido que otra palabra dada; (ii) segmentación en fonemas, por ejemplo contar, pronunciar, quitar, adicionar o invertir fonemas individuales de una palabra; (iii) unión de fonemas, por ejemplo 
pronunciada una serie de sonidos aislados se solicita al niño que los una para formar una palabra.

Desde la psicogénesis, el enfoque de estos estudios, tanto como los supuestos que subyacen a ellos, ha recibido numerosas críticas. Para Ferreiro (2002) hay tres problemas que se plantean en la relación entre las unidades y los niveles de análisis en las investigaciones sobre conciencia fonológica. El primero reside en que sostienen implícitamente, aunque a veces explícitamente también, una noción de escritura como codificación de la oralidad, considerando que la escritura refleja las unidades de análisis de la oralidad. Por lo tanto, si alguien no tiene conciencia de los fonemas, no podrá reconocerlos en la escritura. Esta idea es caracterizada por la autora como reduccionista y aplicacionista, considerando que conlleva la idea de prerrequisitos y desestima toda posible interacción entre unidades previas (fónicas aunque no necesariamente fonológicas) y unidades gráficas, que permita el surgimiento de una nueva unidad no preexistente. El segundo problema reside en que, los estudios sobre el desarrollo de la conciencia fonológica (y fonémica), han desestimado las variables dialectales de los sujetos considerando la conciencia sobre los fonemas sin plantear las diferentes habilidades que esta habilidad implica a los hablantes particulares y en sus contextos específicos. Y el tercer problema reside en que esta perspectiva ha considerado que los fonemas existen en un nivel inconsciente antes que el sujeto pueda tomar conciencia de ellos y entonces son esas mismas las unidades las que pasan al nivel de la manipulación voluntaria. En este sentido, Ferreiro sostiene que no se trataría de la misma unidad ya que el fonema no preexiste a la toma de conciencia, la autora explica que "el fonema es el producto de un nuevo nivel de reorganización de las unidades del habla, permitido (sugerido, impuesto quizá) por la escritura" (Ferreiro 2002, p. 161).

Desde la psicogénesis se realizaron estudios para analizar la conciencia fonológica, pero, en este caso, analizando la relación entre tal habilidad y la etapa de desarrollo de la escritura en que se encontraba cada sujetos. En un estudio experimental (Vernon 1997; Vernon y Ferreiro 1999) se propuso a niños con edades cercanas a los 6 años y con niveles de conceptualización de la escritura diferentes (de pre-silábicos a alfabéticos) realizar tareas de segmentación de palabras a partir de estímulos escritos y de imágenes de los mismos. Por ejemplo "luna" fue segmentada en "Iu na”, “Iu - u - na”, “I - u - na”, “lu - n - a” y “I - u - n - a”. El nivel de segmentación tuvo 
una alta correlación con la etapa de la conceptualización. Quienes escribían silábicamente, es decir escribiendo una letra por sílaba, podían aislar en la emisión oral las sílabas; quienes comenzaban a dejar de lado las sílabas e incorporaban algunas letras en la escritura, podían aislar sílabas, vocales y algunas consonantes (por ejemplo “lu-u-na"); mientras que, quienes escribían alfabéticamente tenían la capacidad de separar en la emisión las vocales y consonantes, aunque no siempre de modo exhaustivo. Con ello quedó en evidencia la directa relación entre el desarrollo de la conciencia fonémica y el nivel de conceptualización de la escritura. Asimismo, las segmentaciones más exhaustivas, para cada uno de los niveles de conceptualización de la escritura, se obtuvieron cuando el estímulo era una palabra escrita en lugar de una imagen. Por lo tanto, el soporte escrito podría funcionar como un andamiaje (en términos de Bruner) que favorecería el acceso a las unidades de análisis (Hohn y Ehri 1983; Vernon y Ferreiro 1999).

Ambas perspectivas, psicogenética y cognitivista, coinciden en considerar que la habilidad para acceder a los fonemas, como unidades de segmentación del habla, estaría estrechamente vinculada al aprendizaje de una escritura alfabética. Aprender a leer en un sistema alfabético estaría colaborando en el desarrollo de la conciencia fonológica y, a su vez, el desarrollo de habilidades de análisis segmentario sería decisivo para el dominio de las reglas de conversión grafema-fonema. Esto también fue estimado por autores como Liberman y Shankweiler (1985) o Liberman, Shanweiler y Liberman (1989), quienes consideraron que la relación entre la conciencia fonológica y el aprendizaje de la escritura es causal recíproca. Es decir que, las habilidades fonológicas colaboran en el aprendizaje de la escritura y al mismo tiempo, el aprendizaje de la escritura beneficia el desarrollo de la conciencia fonémica. Aunque, como vimos, el enfoque cognitivista considera que la escritura refleja las categorías de análisis preexistentes en el habla y el enfoque psicogético considera que es a través de la escritura que el habla se convierte en objeto de análisis.

$* * *$

A lo largo de este capítulo se desarrolló la perspectiva planteada por Claire BlancheBenveniste y Marie-José Béguelin acerca de la relación entre las unidades de escritura y las unidades de la oralidad. Se propuso que la delimitación de unidades 
como palabra, oración y grafema, no presenta un problema desde la escritura, sin embargo, desde la oralidad implica procesos cognitivos complejos que se encuentran estrechamente relacionados con el desarrollo de la alfabetización.

Luego, presentamos el enfoque de Ferreiro y Teberosky quienes describen las diferentes hipótesis que elaboran los niños acerca del modo en que funciona el sistema de escritura. De acuerdo con las autoras, el proceso de apropiación de la escritura se desarrolla de un modo espontáneo y sin intervención directa, a excepción de la transición que hay entre el modo de representación silábico y el alfabético, donde, a través de la interacción con la familia o maestros, el niño accede a los principios de la escritura alfabética.

Finalmente presentamos algunas consideraciones vinculadas al desarrollo de la conciencia fonológica y fonémica como habilidades íntimamente relacionadas con el proceso de alfabetización. Si bien existen posturas controvertidas respecto al rol que el desarrollo de esas habilidades tiene en el proceso de alfabetización, esa problemática excede el planteo de esta tesis. Es necesario precisar que, en el ámbito del lenguaje musical, los estudios sobre el proceso de alfabetización, especialmente acerca del conocimiento del sistema de notación musical, se encuentran en instancias iniciales respecto al estudio de las habilidades involucradas para su adquisición. Tal es así, que se considera que las categorías que proporciona el sistema de escritura musical, en particular la nota, son categorías de acceso espontáneo; consideración que será discutida en el contexto de esta tesis. Por lo tanto, la presentación de las particularidades de cada enfoque respecto al desarrollo de la conciencia fonémica, tiene como finalidad echar luz a una incipiente problematización que se irá desarrollando el contexto de esta tesis. 



\section{Capítulo 2: La notación y la música}

El desarrollo histórico del sistema de escritura musical podría considerarse como una serie de intentos progresivos hacia la representación explícita de todos los aspectos del fenómeno musical, o al menos, todos aquellos que resultaban, en cada período, indispensables para que la música fuera exitosamente comunicada. Las categorías representadas cambiaron históricamente en relación con los aspectos de la música que se querían representar y a las funciones que esos sistemas debían cumplir. Las partituras reunieron una creciente cantidad de detalles que se incorporaron a la escritura como consecuencia de una progresiva cantidad de variables de la música que comenzaron a hacerse explícitas.

Si bien, la notación musical surgió como un modo de registrar gráficamente la música con el fin de alivianar la memoria, y permitió la transmisión de todo un patrimonio cultural, hacia el siglo XVIII el sistema de escritura se estableció como el modo de representación preferencial y privilegiado de hacer y de pensar la música, perfilando un modelo de música y de músico. Un modelo de músico que accede a la obra musical solamente a partir de la lectura y un modelo de música para la cual la partitura es su privilegiado modo de existencia. Desde esta perspectiva, el desarrollo de habilidades musicales de ejecución como así también las habilidades de audición, en los ámbitos de enseñanza formal, estuvieron atravesadas por el aprendizaje de la lectoescritura.

Más recientemente la musicología ha valorado la naturaleza temporal de la música considerando que la música es comprendida en tiempo real (Cook, 2003) resultando la ejecución un factor central en su ontología. Bajo esta consideración, se entiende como obra musical no su partitura sino la síntesis de todas las ejecuciones que la representan (Kivy 1995). Sin embargo, la ejecución musical no es solamente una representación de una ontología abstracta sino que resulta también un medio para acceder a ella en tanto modo de conocer. Un ejemplo de esto tiene lugar cuando se conoce una pieza musical a través de la imitación. Es por ello que, desconocer el 
sistema de notación musical no resulta excluyente para desarrollar habilidades de ejecución y el acceso a la música está garantizado también a través de ella.

Desde esta perspectiva, el modelo pedagógico basado en la ontología de la obra musical como texto, está siendo problematizado, tanto en sus contenidos de estudio como en sus prácticas. Por ejemplo, los contenidos de estudio de las disciplinas que abordan la enseñanza de la ejecución instrumental, comienzan a describirse en tanto habilidades de ejecución antes que como la enumeración de partituras, y algo similar ocurre en el desarrollo de habilidades de audición donde el enfoque tradicional comienza a suscitar diversas críticas y comienzan a plantearse nuevas líneas de desarrollo que proponen valorar otros modos de descripción y análisis de la música (Shifres 2007, 2009; Burcet y Shifres, 2013; Shifres y Holguín Tovar, en prensa). Aun así, el enfoque que domina actualmente las prácticas pedagógicas, en el contexto de la enseñanza formal, es aquel que entiende la escritura musical como epicentro del desarrollo de las habilidades musicales. Bajo este enfoque, tanto las prácticas de ejecución como las prácticas de audición conforman sus contenidos de estudio, como así también definen los criterios de dificultad alrededor de las categorías y conceptos derivados del sistema de notación musical tradicional.

\section{La notación y las prácticas musicales}

El aprendizaje del sistema de notación musical ha estado tradicionalmente vinculado al desarrollo de habilidades de ejecución, asumiendo un rol central en el desarrollo de tales habilidades. En las instituciones de enseñanza formal, aprender a tocar un instrumento implica, entre otras habilidades, aprender a decodificar partituras en él. La mayor parte de los métodos de iniciación a la ejecución instrumental proponen el desarrollo conjunto de habilidades de ejecución y lectura: el alumno aprende a tocar lo que aprende a leer. Desde el inicio se pone énfasis en contar y medir bien la duración de cada nota. Así, resulta frecuente que quienes se han formado en torno a ciertos repertorios, especialmente el repertorio académico, sólo tocan aquello que pueden leer. Esto ocurre, generalmente porque han desarrollado sus capacidades musicales a partir de la partitura.

Asimismo, el conocimiento del sistema de notación musical ha adquirido gran prestigio. Resulta frecuente distinciones del tipo: "aprendió a tocar piano, pero no sabe música", considerando "saber música" al conocimiento del sistema de notación 
musical. Sin embargo, las habilidades de ejecución y de lectura no parecen tener un desarrollo paralelo. Hay músicos que han desarrollado habilidades específicas, tanto vocales como instrumentales, participan en prácticas de conjunto como bandas, grupos, coros, o incluso componen temas para bandas o para películas, y nunca han aprendido a leer música. Un ejemplo de ello es el de Paul McCartney quien luego de varios intentos por aprender a leer música, primero cuando era un niño, luego cuando tomaba clases de piano y finalmente cuando era uno de los Beatles, dijo en una nota para la revista The New Yorker "Ahora ni siquiera quiero aprender", "las notas no parecen ir con lo que voy escuchando" (Colapinto 2007, p. 58).

A su vez, en los ámbitos de enseñanza formal, el interés en el conocimiento del sistema de notación musical se ha centrado en la lectura como única dimensión del proceso de alfabetización musical. Los estudiantes han aprendido a establecer correspondencias entre signos de escritura y destrezas motoras. Es por ello que muchos ejecutantes, pueden leer tocando una canción pero encuentran dificultades al transcribir enunciados musicales. Esto último quedó en evidencia en los estudios realizados por Lyle Davidson, Larry Scripp y Patricia Welsh (1988) donde se solicitó a un grupo de estudiantes que ingresaban a un conservatorio superior, que transcribieran la canción Felíz Cumpleaños sin utilizar su instrumento. Los resultados mostraron que el $90 \%$ de los estudiantes no logró hacerlo, incluso muchos de ellos leían la melodía transcripta sin percatarse de las diferencias que había entre lo que cantaban y su escritura. Los resultados Ilevaron a considerar la importante disparidad que puede haber entre el desarrollo de habilidades de ejecución instrumental y el conocimiento del sistema de notación musical.

El aprendizaje del sistema de notación musical también ha estado tradicionalmente vinculado al desarrollo de habilidades de audición. Tanto la pedagogía como la psicología de la música han planteado los problemas del desarrollo auditivo alrededor de las categorías teóricas derivadas del sistema de notación musical, y estas categorías se han consolidado como la base para pensar y analizar la música especialmente en los ámbitos de enseñanza formal. Numerosos estudios de la tradición cognitivo-estructuralista de la psicología de la música sostienen que la representación mental de la música se basa en las mismas categorías teóricas que se ponen en juego y sustentan la escritura. En tal sentido, algunos investigadores (Deutsch 1992; Dowling 1994; Krumhansl 1990; Lee 1991) consideran que las 
representaciones mentales son congruentes con las categorías de la teoría de la música. Estos autores analizan las problemáticas de la audición basándose en categorías como: acorde, intervalo, patrones rítmicos, contorno melódico, respectivamente. Considerando que los músicos se representan el ritmo en corcheas, negras y semicorcheas; las alturas como notas, que escuchamos acordes, intervalos y compases. Las categorías y los conceptos por los cuales se analiza auditivamente la música se corresponden con los signos de escritura que son comprendidos como altamente compatibles con las propiedades y relaciones inherentes a la música misma.

La habilidad para representarse la música en los términos de la escritura es considerada una habilidad de alta complejidad, y es por esta valoración, que el oído absoluto es una aptitud sumamente reconocida en los ámbitos de enseñanza formal de la música. Sin embargo aunque el término absoluto remite a total o a completo, el alcance habitual que se le da a esta expresión como habilidad, se vincula a la identificación por audición del nombre de las notas. La valoración que tiene la habilidad del oído absoluto sobre el campo de las denominaciones de las alturas es un ejemplo de la valoración que pensar en términos de la escritura conlleva. Por eso, para la cultura escrita, tener oído absoluto equivale a tener un oído ideal, quien lo posee tiene la suerte de poder escuchar la música haciendo una anotación mental de las notas.

En los ámbitos de enseñanza formal de la música, los contenidos teóricos se vincularon al desarrollo de capacidades auditivo-musicales. Y en este correlato entre teoría y audición, las categorías de análisis fueron las derivadas de la teoría y particularmente de la escritura. Desarrollar habilidades auditivas consistió, básicamente, en aprender a escuchar la escritura: escuchar las notas, el compás, las corcheas y las semicorcheas. Los conceptos derivados de la escritura pasaron, de ser un modo descriptivo de la realidad musical, a ser normativos de la experiencia musical, que pasó a ser indagada de acuerdo con las categorías emergentes de la teoría musical (Shifres, 2013). En este contexto, no sólo las problemáticas de la audición se redujeron a las categorías de la escritura (compás, grupo rítmico, acorde, nota, entre otros) sino que además, se las tomó por categorías naturales para pensar la música. 


\section{Las unidades de la notación musical}

En este apartado se desarrollan las unidades derivadas del sistema de notación musical que suelen considerarse como normativas de la experiencia de audición. Se presenta evidencia empírica a partir de la cual se propone hacer una diferenciación similar a la planteada en el campo de la lingüística (ver Capítulo 1) entre unidades de escritura y unidades de lengua. Se hipotetiza que las unidades compás, célula rítmica, acorde y nota, corresponden a categorías derivadas de la escritura, unidades que no tienen un correlato perceptual desde la audición.

\section{El compás}

El compás es un concepto teórico derivado del sistema de notación musical que refiere a una unidad gráfica delimitada por barras. Las barras de compás segmentan la partitura en unidades de duración equivalentes de acuerdo con la cifra indicadora de compás. Esta cifra proporciona información acerca de las relaciones métricas que estarán implícitas en la ejecución de esa pieza.

En una partitura podemos observar o contar la cantidad de compases pero no percibimos los compases cuando escuchamos una pieza musical. Cuando escuchamos una pieza podemos identificar pulsos y establecer relaciones entre esos pulsos para caracterizar la estructura métrica. Si bien la estructura métrica está representada en la partitura por la cifra indicadora de compás y luego es traducida a la escritura de la melodía utilizando barras de compás y agrupando las figuras rítmicas de un modo determinado, las relaciones métricas que percibe el oyente no segmentan el flujo musical en unidades equivalentes a los compases. Es decir que, a pesar de que percibimos la estructura métrica, y que ésta tiene un correlato en la escritura con el compás, la estructura métrica divide la música en partes.

En la práctica musical, la segmentación en compases se utiliza con frecuencia para localizar un punto en la partitura, por ejemplo para retomar la lectura en una práctica de ejecución grupal: "tomemos del 5to compás". Como consecuencia de ello, también ha sido utilizada frecuentemente para segmentar la lectura en la práctica instrumental en estrategias como "repetir tal compás" o inclusive "estudiar por compás". En algunas prácticas de dictado se ha utilizado para dosificar la melodía en estrategias como "dictar por compás" y también se utiliza frecuentemente como 
unidad de medida, al decir "esta melodía dura 4 compases" o "debe componer una pieza de no más de 16 compases". Es importante señalar que, en los casos mencionados, la segmentación en compases se origina a partir de la partitura, por lo tanto no son decisiones que necesariamente se ajusten a criterios lingüísticos sino metalingüísticos.

Los oyentes perciben espontáneamente agrupamientos y estos constituyen la base a partir de la cual se configurarán las representaciones formales, es decir el dominio del sistema de notación musical. Los principios por los cuales se generan esos agrupamientos han sido analizados por la Teoría Generativa de la Música Tonal desarrollada por Fred Lerdahl y Ray Jackendoff (1983). Esta teoría propone una serie de reglas que el oyente utiliza de manera intuitiva para organizar sus representaciones internas del discurso musical en términos de agrupamientos.

Cuando la estructura de agrupamiento se encuentra en desfase respecto a la estructura métrica como ocurre con los agrupamientos con comienzo acéfalo o anacrúsico, segmentar por compás es un criterio contradictorio con el fraseo musical, ya que la segmentación por compases genera unidades incompletas. Obsérvese el ejemplo de la figura 2.1, en este ejemplo la segmentación de la melodía en compases genera unidades diferentes a las unidades que se corresponden con los agrupamientos señalados con arcos.

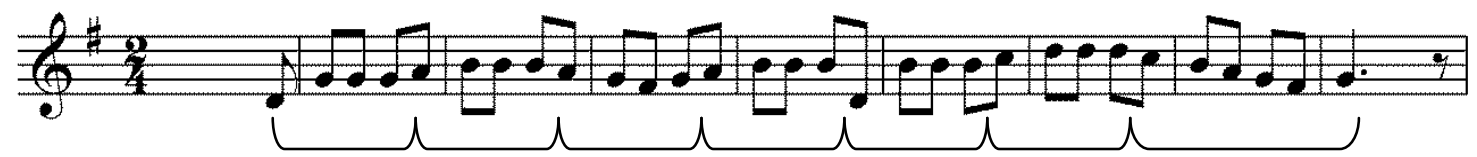

Figura 2.1. Contradicción entre las unidades que corresponden a los compases y las unidades que corresponden a los agrupamientos indicados con arcos.

Con el objetivo de indagar las unidades utilizadas espontánea mente por estudiantes iniciales en la tarea de enseñar cantando una melodía aprendida desde la lectura, se desarrolló un estudio (Burcet 2010) en el cual se solicitó a estudiantes adultos, ingresantes a carreras de música de nivel universitario, que memorizaran una melodía que era presentada en una partitura, para luego enseñarla a otro estudiante. La melodía que debían leer en la partitura presentaba ritmo de corcheas con 
agrupamientos anacrúsicos por lo tanto, como se explicó arriba, el compás segmentaba la melodía en unidades incompletas y diferentes a las unidades de los agrupamientos. Los resultados permitieron observar que, los sujetos que emplearon más tiempo para resolver la tarea, fueron aquellos que utilizaron el compás como unidad de segmentación para enseñar la melodía. En estos casos se observó una mayor dificultad para realizar la tarea por parte del sujeto que aprendía la melodía como así también gran dificultad por parte de quien enseñaba para retomar el canto cada vez que lo necesitaba.

El compás parece ser una unidad exclusiva del pensamiento ligado a la escritura cuya utilización estaría restringida a decisiones vinculadas con la segmentación de la partitura y no tanto del discurso musical como entidad oral.

\section{La célula rítmica}

En la escritura del ritmo, las figuras que representan valores de duración menores que el tiempo, como la corchea o la semicorchea; tienen asignado un modo de organización gráfico preestablecido por el código de escritura según el cual se agrupan conformando unidades que habitualmente se denominan grupos o células rítmicas. Estas unidades gráficas surgen de reemplazar con una barra los ganchillos de las corcheas o las semicorcheas, entre otras figuras menores a la negra. Así, cada célula rítmica queda integrada por un conjunto de figuras equivalentes a un tiempo (o tactus), tal como se ejemplifica en la figura 2.2 para el pie binario y ternario.

PIE BINARIO

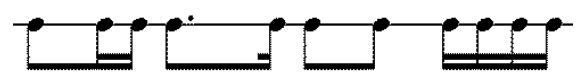

PIE TERNARIO

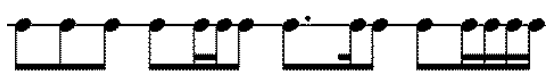

Figura 2.2. Células rítmicas en pie binario y ternario.

Las células rítmicas se ajustan a ciertas reglas de ortografía de la escritura musical, en este caso, la regla consistiría básicamente en agrupar con una barra superior el conjunto de 2 o más notas equivalentes a una unidad de tactus. Así es que, si una melodía presenta un ritmo isócrono con valores de nivel de división del tiempo en pie 
binario, el ritmo se traducirá a la escritura agrupando las corcheas de a dos, mientras que en pie ternario se agruparán de a tres, aun cuando estos grupos no coincidan con los grupos perceptuales.

En el ámbito del lenguaje verbal, y en vinculación con las reglas de ortografía Olson (1994) explica que "no todas las características gráficas necesitan verbalizarse y no todas las diferencias verbalizadas necesitan aparecer en la escritura" (p.101). EI factor decisivo en la elaboración de la escritura no son los modelos verbales, sino más bien el intento de una representación funcional, sin ambigüedades (Gaur 1987; Harris 1986). Por ejemplo: una palabra que comienza con mayúscula no se lee diferente de una que se escribe con minúscula, la convención sólo facilita la interpretación. De la misma manera, en la escritura musical, el modo en que las notas se agrupan dando lugar a las células rítmicas, tendría por finalidad desambiguar la escritura para facilitar la interpretación. Es probable que, en el sistema de notación musical, la escritura rítmica sea la que más reglas de ortografía implique.

La célula rítmica conforma una unidad de notación que no implica una entidad perceptual relacionada directamente. Cuando observamos una partitura, la escritura del ritmo se encuentra organizada gráficamente en esas unidades, pero cuando escuchamos música el ritmo no se perciben directamente escindidos en esas unidades.

En relación con las representaciones y el procesamiento interno de los fenómenos rítmicos de la música, Lerdahl y Jackendoff (1983) identifican dos componentes cuyas estructuras se organizan jerárquicamente: la estructura de agrupamiento y la estructura métrica. La estructura de agrupamiento está conformada por unidades o grupos (motivos, temas, secciones) que son organizados a partir de indicios en la superficie musical. Y la estructura métrica está conformada por esquemas regulares de pulsaciones fuertes y débiles que son asignados por el oyente. Aunque nuestra comprensión del ritmo está organizada a partir de la interacción de ambas estructuras, la escritura del ritmo está fuertemente condicionada por la estructura métrica.

El modo en que el ritmo se organiza en la notación, en ocasiones, puede generar contradicciones con los agrupamientos mínimos que, de acuerdo con Lerdahl y Jackendoff (1983), son percibidos por el oyente. Esta contradicción se evidencia, por 
ejemplo, en el fragmento del Menuet de la Suite Orquestal Nro 2 de J. S. Bach que muestra la figura 2.3. En la notación se observa que las corcheas de los compases 5 , 6 y 7 están agrupadas de a dos, sin embargo cuando escuchamos la pieza, los agrupamientos perceptuales pueden organizarse como lo señalan los corchetes.

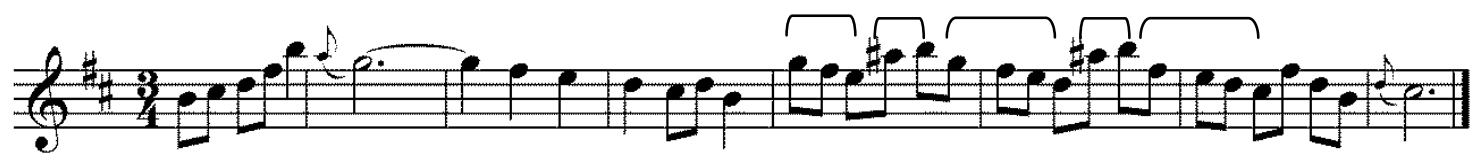

Figura 2.3. Menuet de la Suite Orquestal Nro 2 de J. S. Bach.

En un estudio realizado con estudiantes adultos en instancias iniciales de su formación musical formal, se realizó un análisis detallado de las transcripciones rítmicas realizadas a partir de una melodía previamente memorizada con la finalidad de poner en evidencia la contradicción antes explicada (Burcet y Jacquier 2007). En el panel superior de la figura 2.4 se encuentra la melodía seleccionada para realizar la transcripción, la misma presenta un encadenamiento de motivos anacrúsicos que están remarcados con arcos. En el panel inferior de la misma figura se encuentra una transcripción realizada por un estudiante.

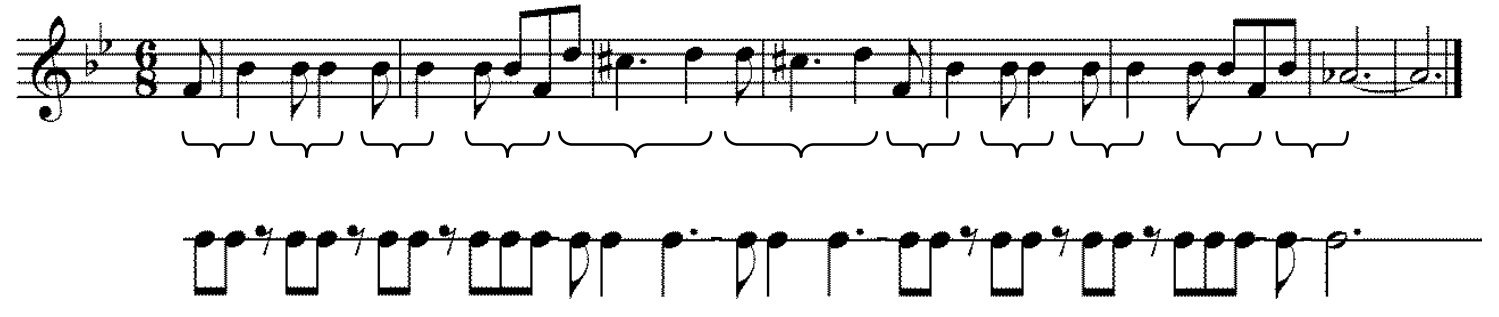

Figura 2.4. Melodía original (arriba) con los agrupamientos indicados con arcos y transcripción rítmica de un estudiante (abajo).

A simple vista, podría considerarse que el ritmo transcripto por el estudiante es incorrecto porque no se ajusta adecuadamente a la estructura métrica del ejemplo original. Sin embargo, la relación que hay entre los agrupamientos que están representados con los arcos y las células rítmicas transcriptas por el estudiante nos permite comprender que, en gran medida estas distorsiones se deben a la necesidad de forzar la notación para representar la estructura de agrupamiento. 
Podemos observar que el estudiante no representó en su transcripción el nivel de base de la estructura métrica (el tactus), que en la escritura se traduce en la selección de células rítmicas (en este caso, negra-corchea) y tampoco representó en su transcripción el metro, que en la escritura se traduce en la ubicación de las barras de compás. Sin embargo, los valores rítmicos en términos de intervalos de ataque son correctos (con algunas excepciones) como así también los agrupamientos, aunque esto último no se registre en el sistema de notación musical. Ocurre que, para anotar un ritmo, muchas veces es preciso separar lo que la percepción agrupa o agrupar lo que la percepción separa tal como ocurre en el ejemplo descripto.

Lo expuesto pone en evidencia algunas dificultades que plantea la escritura rítmica en las instancias iniciales del aprendizaje de la escritura rítmica especialmente cuando la información proveniente de las experiencias internas rivaliza con la proveniente de las convenciones de escritura. En muchos casos las dificultades en la representación del ritmo a través del sistema de notación se suscitan por la incapacidad de los sistemas gráficos para capturar todas las variables que inciden en las representaciones internas.

\section{El acorde}

El acorde es una unidad que no deriva exclusivamente de la escritura pero implica conocimientos teóricos derivados de ella. Según la teoría de la música, el acorde es una unidad conformada por dos o más notas que se presentan de modo simultáneo.

Cuando realizamos el análisis armónico de una pieza en una partitura, inferimos los acordes a partir de las decisiones que tomamos al agrupar notas. Por ejemplo, si en el primer compás de una pieza tenemos las notas do-mi-sol, lo traducimos a un acorde de do mayor. Si en el compás siguiente tenemos las notas fa-do, lo traducimos a un acorde de fa mayor, aun cuando la nota la no forma parte del mismo, estimamos que esa nota estará implícita en ese fragmento de la pieza. Ahora bien, si en el segundo compás tenemos las notas fa-la-si, tal vez estimemos que se trata del acorde de fa mayor en las dos primeras notas y luego analicemos qué rol se adjudica al si ¿un acorde de sol mayor? ¿una nota de paso?. Todas estas decisiones forman parte de los procesos de análisis armónico que se dan exclusivamente desde el examen de la partitura. Pero desde la audición el análisis armónico implica habilidades diferentes. 
Imaginemos una partitura para dos flautas con una textura contrapuntística. A partir del análisis de la partitura podríamos inferir los acordes y cifrarlos (tal vez un acorde por compás) Pero esos acordes ¿se perciben? Seguramente podamos percibir dos líneas melódicas que se entrecruzan y generan diferentes relaciones de tensión y reposo, pero no percibimos entidades similares a los acordes, y menos aun, que se articulen uno por compás. Tal vez un músico experimentado pueda describir esas tensiones y distensiones en términos de funciones armónicas pero esto no implica que perciba acordes propiamente dichos.

Aun cuando las notas se articulan en simultáneo no tenemos certeza de que el oyente perciba una única entidad. Tal vez el oyente perciba un sonido, quizá el más agudo, o tal vez perciba 2 sonidos, 3 sonidos o bien 2 intervalos, ya que no existe ningún fenómeno de fusión que involucre los sonidos a ese nivel. Por el contrario, la conformación del acorde parecería, más bien, un fenómeno cultural, una prueba de ello es el hecho de que la teoría musical lo enunciara siglos después de que la simultaneidad de sonidos existiera en la música. Por lo tanto, si aun cuando las notas que conforman el acorde se articulan de manera simultánea no hay razón para suponer que el oyente percibe una unidad única, resulta mucho menos parsimonioso considerar que puedan percibirse auditivamente entidades como los acordes cuando la textura presenta realidades todavía más complejas.

En la práctica de la enseñanza ocurre con frecuencia, que la habilidad para identificar las funciones armónicas mediante la audición adjudicándole un rótulo a cada una de ellas resulta una habilidad notoriamente más sencilla para aquellos estudiantes cuyas prácticas musicales han estado vinculadas a instrumentos armónicos, que para aquellos sujetos cuyas prácticas musicales estuvieron vinculadas a instrumentos melódicos. Es posible que los primeros hayan establecido asociaciones entre la "sonoridad general" y el concepto de acorde al amparo de la unidad de ejecución, es decir la unidad de acción por la cual el acorde suena. Sin embargo, ésta no sería una categoría igualmente accesible para quienes no establecieron esa asociación. Incluso, muchos estudiantes de música identifican las funciones armónicas con estrategias analíticas más complejas, como por ejemplo: “si identifico que el bajo articula la dominante y la melodía el segundo grado, entonces infiero que se trata de un acorde de dominante". Este tipo de pensamiento, que 
remite al tipo de análisis que se puede realizar desde la partitura, no implica que el oyente perciba el acorde como una entidad.

Por lo tanto, el acorde también parecería una construcción teórica cuyo correlato perceptual no sería directo y por lo tanto, se accedería a él a través de algún tipo de intervención, y no de un modo espontáneo.

\section{La nota}

La nota es la unidad mínima de escritura en el sistema de notación musical. Esta unidad es frecuentemente asociada a la unidad mínima de acción y de percepción.

En primer lugar, es preciso aclarar que, con la finalidad de diferenciar entre la nota como unidad de escritura y su referente perceptual, en el contexto de esta tesis, utilizaremos los términos nota gráfica y nota perceptual. La primera hará referencia a la nota escrita mientras que la segunda hará referencia a su correlato perceptual. Esta distinción ha sido establecida en el idioma inglés utilizando dos palabras diferentes: "note" para la nota gráfica y "tone" para la nota perceptual; sin embargo en el idioma español, dado que la palabra tono remite a una relación interválica, se ha empleado la palabra nota para aludir indistintamente a ambos significados.

Si bien la nota gráfica ha sido relacionada con la unidad mínima de acción, ya que una nota escrita indica una acción, a menudo son varias las acciones que se corresponden en la ejecución con lo que en la notación corresponde a una única nota, desde acciones anticipatorias o preparatorias a complejos de acciones en el sostén de la nota como el vibrato o el portamento. Asimismo, la multiplicidad de acciones que dan como resultado un vibrato o un portamento son percibidas por el oyente, aunque a menudo como un complejo único de acción. Es decir que la nota gráfica no necesariamente se corresponde con la unidad mínima de acción ni con la unidad mínima de percepción.

La pedagogía y la psicología de la música no han problematizado la realidad perceptual de la nota, probablemente porque el desarrollo de habilidades musicales ha estado estrechamente vinculado al aprendizaje de la notación. Así, del mismo modo que los estudios sobre la adquisición del lenguaje verbal proponen que "los fonemas son un componente de la conciencia de la lengua que tiene un hablante 
sólo si éste sabe leer una representación alfabética de su lengua" (Scholes y Willis, 1991, p.291), puede hipotetizarse que las notas perceptuales son un componente de la conciencia del lenguaje que tiene un músico sólo si éste sabe leer utilizando el sistema de notación musical convencional. Por lo tanto, si los sujetos están alfabetizados musicalmente, es decir, conocen el sistema de notación musical porque han desarrollado prácticas musicales a partir de la lectura, entonces la nota, como unidad de análisis, no presentará un problema de delimitación.

Ahora bien, ¿es posible considerar que quienes desconocen el sistema de notación musical no tienen conciencia de las notas? $Y$ ¿qué ocurre cuando los sujetos desarrollan habilidades musicales utilizando otros sistemas de notación tales como cifrados o tablaturas? ¿Cuáles son las unidades mínimas de análisis que utilizan?

En otros sistemas de escritura musical la unidad mínima presenta una dimensión completamente diferente a la nota. Por ejemplo, en el cifrado americano, "A7" representa un conjunto de sonidos e incluso, en muchas prácticas performativas, conlleva implícitamente un determinado patrón rítmico, y una organización particular de la textura, como ocurre en el acompañamiento de una chacarera. En ese contexto, la unidad de escritura representa un conjunto de acciones que el oyente percibe como un conjunto de sonidos, allí donde la escritura registra una única unidad. Las personas que han desarrollado prácticas musicales a partir de estos códigos de escritura ¿desarrollan una correspondencia gráfico-perceptual uno a uno al nivel de la nota?

Tal como vimos en el capítulo precedente, en las leguas con escritura alfabética, a cada sonido (fonema) le corresponde una letra escrita (grafema), del mismo modo, en el lenguaje musical, la correspondencia entre la unidad del discurso y la unidad de escritura se da al nivel de la nota, correspondiéndole a cada nota articulada en una pieza musical, una nota escrita. Para escribir música es necesario identificar cada una de estas unidades y manipularlas, habilidad que en lenguaje verbal se denomina conciencia fonémica. En el aprendizaje de la notación musical, esta habilidad no ha sido indagada. Los estudios que han abordado el desarrollo de la notación musical lo han hecho a partir del estudio de las representaciones espontáneas realizadas por niños y adultos (Bamberger 1982, 1988, 1991; Davidson y Scripp 1988, 1992) y no han problematizado la nota como unidad de análisis, en tanto que, sostienen que la identificación de esta unidad parece surgir como consecuencia de un proceso 
madurativo hacia los 5 o 6 años de edad. Esta perspectiva será especialmente cuestionada en el desarrollo de la tesis.

\section{El desarrollo de la notación musical}

A diferencia del lenguaje verbal, los niños no toman contacto con el sistema de notación musical antes de entrar a una institución de enseñanza formal. La escritura musical no suele aparecer en los libros que tienen en su entorno, ni en los carteles callejeros que forman parte del paisaje urbano. Tampoco suele aparece en sus juguetes, ni en sus vestimentas, ni en los alimentos, ni en la televisión y cuando lo hacen, es tan sólo como íconos que representan la música como un todo (como una clave del sol o figuras rítmicas sueltas). Generalmente los padres no resuelven problemas a través de la notación musical, como anotar una melodía para recordarla - leer una melodía que no conocen y tampoco suelen tener partituras, si las tienen, están guardadas en el estante más alto de la biblioteca como un recuerdo familiar. La escritura musical no está al alcance de la mayoría de los niños, ni de los adultos, por lo cual no hay oportunidades para elaborar las propias hipótesis acerca del modo en que la escritura musical se organiza. Por el contrario, generalmente se advierte que la escritura musical es algo misterio e incomprensible que sólo entienden quienes estudian música.

En la Argentina, los métodos de educación musical en la Educación Primaria y Secundaria, donde la asignatura Música forma parte del currículo escolar, no contemplan la enseñanza del sistema de notación musical. Los niños desarrollan habilidades vocales, realizan prácticas de conjunto, e incluso aprenden a tocar instrumentos como por ejemplo la flauta dulce, utilizando anotaciones analógicas con números, colores, u otras representaciones gráficas. Asimismo, algunos métodos de enseñanza de instrumento como guitarra, bajo o piano, utilizan otros códigos de escritura para registrar la música que no son la notación tradicional. En estos casos, las habilidades de lectura y ejecución se desarrollan a partir de estas escrituras. Así es que, muchos jóvenes que inician sus estudios musicales en la universidad, cuentan con variadas experiencias tanto de ejecución como de práctica de conjunto pero estas prácticas no incluyen necesariamente el conocimiento del sistema convencional de escritura musical. Por lo tanto, para ellos, el dominio de la 
representación de la música en los términos que plantea el sistema de notación musical convencional es una habilidad no desarrollada.

En el ámbito universitario, y especialmente en las universidades donde leer música no es un requisito para el ingreso a las carreras de música, se ha observado un porcentaje considerable de estudiantes que ingresan sin conocimiento del sistema de notación musical. Una encuesta desarrollada por docentes de la Universidad Nacional de La Plata en 2009 (Saint Pierre 2010), permitió observar que los porcentajes de alfabetización musical, esto es, el porcentaje de alumnos con conocimiento de la lectoescritura al momento de ingresar a la universidad resultaba notoriamente bajo. Ante la pregunta ¿lees música?, más del $65 \%$ de los estudiantes declararon que no leían nada o lo hacían en forma deficiente. Estos estudiantes, por lo tanto ingresan a la universidad con ciertas destrezas de ejecución vocal o instrumental, práctica de conjunto, etc. pero con escasos conocimiento de lectoescritura. Esto significa que, en su mayoría, han desarrollado habilidades de ejecución (vocal o instrumental) desde la audición, o en algunos casos utilizando otros códigos gráficos como los cifrados (cifrado americano o tablaturas) y por lo tanto han configurado otras relaciones entre lo que tocan y lo escrito.

\section{Las representaciones musicales}

Dado que los sujetos no acceden al sistema de escritura musical de manera espontánea, elaborando sus propias hipótesis sobre los principios que la organizan, particularmente porque el sistema de escritura musical no suele formar parte del entorno, los estudios acerca de las representaciones escritas se han basado en el análisis de las notaciones espontáneas. Con la consigna de transcribir estímulos musicales, para poder recordarlos o registrarlos con motivo de que otra persona pudiera recuperarlos, se ha inducido a niños y adultos a crear sus propias notaciones las cuales han sido motivo de estudio. Se han analizado tanto los aspectos implicados en las representaciones, como así también el proceso de hacerlas, entendiendo que ambos, producto y proceso, estarían comunicando aspectos de la comprensión y el pensamiento musical (Barret 2005) y que proporcionarían, según Lyle Davidson y Larry Scripp $(1988,1992)$, una "ventana" para observar el desarrollo del conocimiento musical. Es a través del estudio de las representaciones que 
podemos encontrar evidencia acerca de la creciente comprensión que los niños y adultos tienen acerca de las alturas y los ritmos, explican los autores.

Los estudios iniciales sobre las representaciones fueron desarrollados por Mira Stambak (1951) quien solicitó a niños, con edades comprendidas entre los 6 y 12 años, que percutieran un ritmo a partir de una serie de puntos escritos. Las notaciones comprendían series de puntos con diferentes separaciones espaciales similares a las graficadas en la figura 2.5 y se esperaba que, la diferente dimensión de los espacios en blanco entre los puntos escritos, derivara en diferente intervalo de tiempo entre los sonidos ejecutados. La autora observó que si bien los niños más pequeños no podían resolver la tarea como se esperaba, la mayoría de los niños mayores lo hacían adecuadamente.

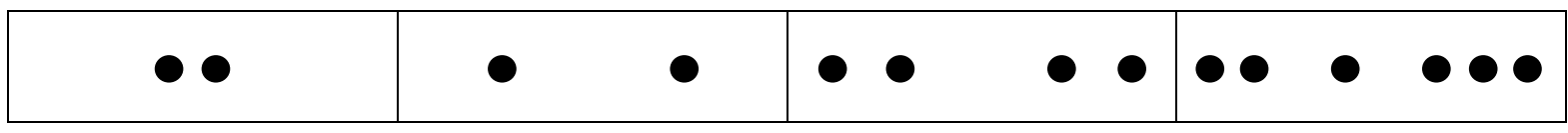

Figura 2.5. Series utilizadas en los estudios de Stabak (1951)

En la misma dirección pero, invirtiendo la tarea, Jacqueline Goodnow (1977) solicitó a los niños que transcribieran secuencias rítmicas palmeadas a partir de la audición. La autora observó que los niños preescolares no representaban espacialmente los intervalos de tiempo, sino que sólo dibujaban puntos o círculos por cada golpe, o bien dibujaban una colección (no contada). Sin embargo, a los 5 años los niños comenzaban a producir lo que denominó "equivalentes activos" de las secuencias. Los niños dibujaban el primer grupo de puntos, luego hacían una pausa y dibujaban el siguiente grupo de puntos sin dejar espacio entre ambos grupos. Como señala la autora, en algunos casos la cantidad de puntos no era necesariamente la correcta. Luego, entre los 5 y los 7 años, los niños comenzaban a representar los intervalos de tiempo, observándose además diferencias entre el tamaño, la posición y la separación de las unidades graficadas.

Posteriormente se han desarrollado numerosos estudios de las representaciones espontáneas realizadas por los niños a partir de diferentes estímulos musicales, ya sea ritmos palmeados por el investigador (Bamberger 1982; Upitis 1987a), canciones populares (Davidson y Scripp 1988, 1989, 1992), o las propias composiciones realizadas por los niños (Barret 1997, Upitis 1992). En general, los diferentes 
estudios han coincidido en considerar que tanto el desarrollo musical como la edad influyen en el resultado de los aspectos representados. Los diferentes autores propusieron descripciones de la trayectoria de desarrollo de la comprensión musical a partir del análisis de las estrategias notacionales utilizadas. Aquí se presentan especialmente los hallazgos de Jeanne Bamberger y los estudios de Davidson y Scripp por tratarse de dos enfoques que explican el desarrollo de las representaciones musicales a partir de la audición y transcripción.

\section{Representaciones pre figurativas, figurativas y formales}

Jeanne Bamberger $(1982,1988,1991)$ desarrolló una serie de estudios a partir de las representaciones espontáneas realizadas por niños y adultos con y sin conocimiento musical formal. En sus estudios los niños debían: escuchar un patrón rítmico que era palmeado por el investigador (ver figura 2.6), luego imitar palmeando ese ritmo y finalmente escribirlo para poder recordarlo o mostrarlo a alguien que no estuviera presente. El análisis de las estrategias contempló tanto el estudio de las producciones como también el estudio de los procesos implicados, lo cual le permitió a los autores, acceder a los aspectos del ritmo a los cuales la notación refería, de un modo más preciso.

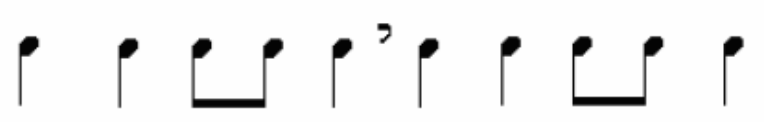

Figura 2.6. Patrón rítmico utilizado en los estudios de Bamberger (1982)

De acuerdo con la tipología de las estrategias utilizadas en las notaciones, la autora definió 3 categorías que denominó: (i) pre-figurativas, (ii) figurativas y (iii) formales o métricas.

\section{Representaciones pre-figurativas}

Las representaciones pre-figurativas son aquellas que ponen el foco en la acción y los movimientos vinculados a la ejecución, correspondiéndose con las representaciones denominadas por Goodnow (1977) como "acciones equivalentes". Estas representaciones, si bien reflejan los movimientos, no proporcionan información suficiente para identificar las características del ritmo palmeado. Fueron realizadas 
con mayor frecuencia por los niños de 3 a 5 años de edad e incluían tres tipos (PF1, PF2 y PF3), tal como se observa en la figura 2.7 .

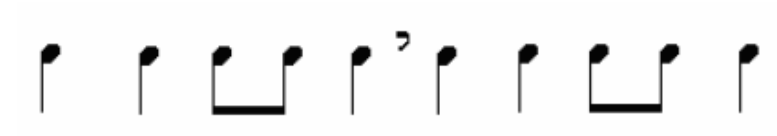

PF1 PF2 PF3

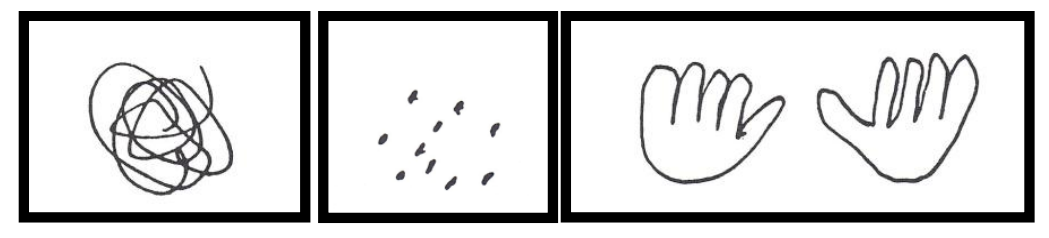

Figura 2.7. Patrón rítmico utilizado en los estudios de Bamberger (1982) y representaciones pre-

figurativas (PF) tipo 1, 2 y 3 (PF1, PF2 y PF3)

Quienes dibujaron garabatos rítmicos (PF1) tendían a reflejar los movimientos continuos del propio cuerpo al hacer el ritmo, así, como explica Bamberger (1982) sus representaciones correspondían a externalizaciones estáticas de su propio “conocimiento en acción". La autora observó que los niños, aun dibujando movimientos continuos, tendían a registrar en cada gesto circular un pulso. No obstante, no podían diferenciar entre los sonidos discretos y el movimiento continuo para producirlos. En esta etapa, las representaciones muestran el proceso de palmear pero no es posible identificar en ellas rasgos del ritmo.

Por otra parte, se encuentran los puntos dispuestos en grupos (PF2). En el modo en que realizaban la notación de observó que los niños también registraban sus movimientos como lo hacían en el garabato, pero esta vez de un modo diferente. Al percutir el ritmo sobre el papel, el lápiz cumplía una doble función de instrumento de ejecución y de medio para registrar el ritmo. La notación resultante contenía tantas unidades como cantidad de eventos tenía el ritmo pero la relación temporal entre los mismos no era representada. Asimismo, se podía considerar que los puntos no referían tanto a los eventos sino que reflejaban el hecho de ejecutar el ritmo sobre el papel. 
Finalmente, quienes dibujaron las manos (PF3) tendían a representar el objeto con que se hacía el ritmo (manos) antes que los eventos que ellas hacían (sonidos). Si bien estos dibujos son totalmente diferentes de los garabatos y puntos, todos ellos muestran diferentes maneras en que los niños ponen en el papel su propia experiencia corporal.

\section{Representaciones figurativas}

Las representaciones figurativas implican una comprensión global de la música, involucran respuestas intuitivas y tienden a hacer foco en los agrupamientos (ver figura 2.8). A diferencia de los garabatos, Bamberger explica que estas representaciones muestran un importante nivel de desarrollo que puede evidenciarse en: (i) el número correcto de eventos, (ii) la organización de la escritura de manera lineal, con dirección de izquierda a derecha y (iii) la notación de dos figuras (agrupamientos) claramente articuladas. La autora explica que es posible que el desarrollo que evidencian las representaciones en estas edades sea consecuencia de la escolarización de los niños.

Dos tipos de representaciones figurativas son analizadas (F1 y F2) tal como se observa en la figura 2.8. En la primera (F1) se observa que la línea iterada se corta dando lugar a dos figuras (o agrupamientos) iguales. A su vez, cada figura contiene 5 unidades que corresponden a los 5 eventos, aunque representados de manera continua. El proceso es diferente al que utilizaron quienes realizaron la percusión sobre el papel, dado que al observar el proceso queda en evidencia que los niños mueven el lápiz de forma continua pero escribiendo cada uno de los eventos con un trazo en una dirección diferente. Aun cuando esta notación muestra claramente el agrupamiento del ritmo palmeado en dos gestos, no alcanza a capturar las variaciones internas de cada grupo.

A diferencia de las notaciones tipo PF1 y F1 que eran continuas, en la representación figurativa F2 cada evento está separado en una unidad escrita. Asimismo, se registra la diferencia entre los movimientos que son más lentos (o temporalmente más lejanos) con círculos grandes y los que son más rápidos (o temporalmente más cercanos) con círculos pequeños. En la representación figurativa F2 también se observan los dos agrupamientos que se corresponden con la repetición del patrón rítmico y, a su vez, dos agrupamientos internos en cada uno, que se corresponden 
con los movimientos lentos (sonidos largos) y los movimientos rápidos (sonidos cortos).

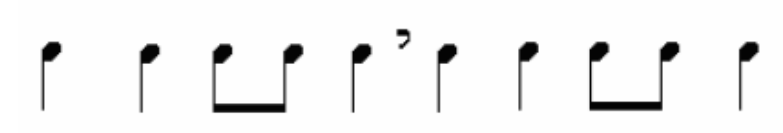

F 1

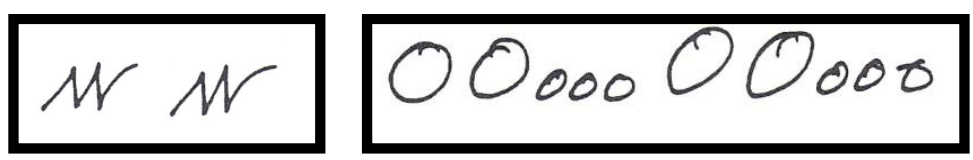

Figura 2.8. Patrón rítmico utilizado en los estudios de Bamberger (1982) y representaciones figurativas $(F)$ tipo 1 y 2 (F1 y F2)

Sin embargo, la relación entre el tamaño de los círculos y la duración no es en todos los casos correcta. El evento 5, que es representado con un círculo pequeño, es igual a los eventos 1, 2, 6 y 7, representados con círculos grandes. Aun cuando esta notación presenta esas diferencias, Bamberger se detiene a analizarla por tratarse de una notación que se encontró no sólo en los niños de esas edades, sino también en adultos no entrenados musicalmente. La autora se pregunta, entonces: ¿qué incide en nuestra percepción para entender al evento 5 diferente a los eventos 1, 2, 6 y 7; y a su vez igual a los eventos 3, 4, 8 y 9? Al describir su grafía, uno de los niños explicó: "puedes ver que hay 2 y luego 3 palmadas, los tres círculos pequeños van rápido y van juntos" (Bamberger 1982, p.201).

La autora explica que, quienes hacen notaciones del tipo de F2, están representando no sólo los eventos locales, individuales y discretos, sino también la idea de agrupamiento de sus propias acciones. Los límites iniciales y finales del agrupamiento se generan por los cambios en el ritmo. Así, los eventos 3, 4 y 5 forman un grupo o figura donde el límite inicial esta dado por el cambio de marcha, que pasa de lento a rápido, y el evento 5 es el límite final del agrupamiento que está dado por un nuevo cambio de marcha, en este caso de rápido a lento. Bamberger explica que, así como las formas que están próximas tienden a verse como una unidad formando una gestalt visual, eventos que se producen próximos en el tiempo, tienden a percibirse como una unidad, formando una gestalt temporal. 
Las representaciones figurativas difieren de las pre-figurativas fundamentalmente en dos aspectos: (i) la tipología de los elementos graficados, esto es, mientras que en las pre-figurativas los elementos son las acciones, en las figurativas los elementos refieren a las acciones; (ii) las representaciones contienen no sólo los dos agrupamientos, sino además aspectos de la organización interna de cada uno, describiendo la organización del ritmo.

\section{Representaciones formales o métricas}

Las representaciones formales refieren a aquellos aspectos de la música que pueden ser cuantificados (medidos o contados) como son las alturas, las duraciones, o la métrica. Aspectos de la música que se corresponden con las propiedades que son captadas por la notación musical.

Tres tipos de representaciones formales o métricas son analizadas (M1, M2 y M3) tal como se observa en la figura 2.9. La representación de tipo M1 comprende aspectos métricos iniciales. Como explica la autora, aquí los niños, que fueron observados durante el proceso de realización de sus grafías, contaban la cantidad de eventos y luego los disponían en sucesión sin agruparlos y sin diferenciarlos bajo ningún aspecto. A diferencia de las representaciones figurativas, aquí no hay agrupamiento, sólo se traduce la cantidad de sonidos sin expresar las diferencias en el movimiento del ritmo.

La autora explica que estas representaciones, a diferencia de las anteriores “muestran evidencia de una creciente capacidad de reflexión y distanciamiento de la experiencia inmediata" (1982, p. 203), están más alejados de las acciones mismas e implican mayor grado de abstracción respecto de las figurativas.

La representación de tipo M2 presenta una clasificación de las duraciones relativas: los eventos con mayor duración se dibujan con formas más grandes y los eventos de menor duración se dibujan con formas más pequeñas. Cada evento, y así cada elemento escrito, está clasificado con respecto a la duración con independencia de los agrupamientos. Este tipo de representación requiere la habilidad para comparar eventos que forman parte de diferentes grupos y que, por lo tanto, están separados en el tiempo y surge como consecuencia de un pensamiento más abstracto. 

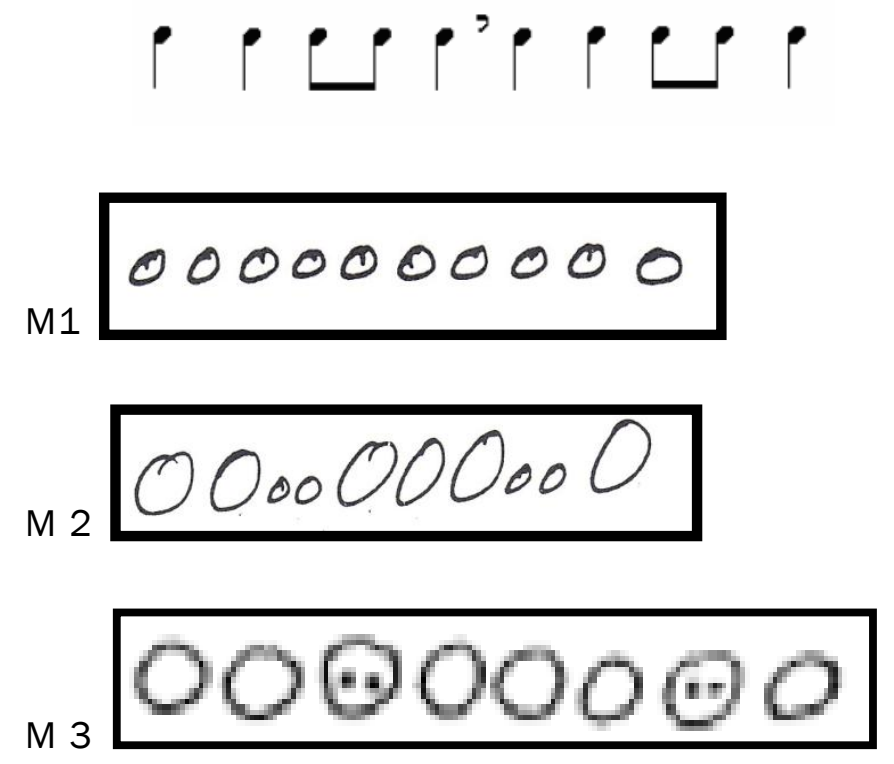

Figura 2.9. Patrón rítmico utilizado en los estudios de Bamberger (1982) y representaciones formales o métricas (M) tipo 1, 2 y 3 (M1, M2 y M3)

Las representaciones formales están caracterizadas por una reflexión en la clasificación de eventos en contraste con la atención en la función de las acciones, como así también, explica Bamberger, mayor coherencia y objetividad que incluso, a veces, difuminan distinciones intuitivas importantes (como los agrupamientos)

A diferencia de la representación de tipo M2, donde los eventos están clasificados en relación a su duración relativa, en M3 la duración de cada evento es medida con referencia a una unidad de tiempo que aparece graficada con los círculos grandes. Esa unidad de medida es el pulso subyacente. Allí se observa que, cuando los eventos se corresponden con esa unidad de tiempo, su representación coincide con el elemento graficado, mientras que, cuando los eventos son más rápidos, el círculo grande representa el pulso de base y los dos puntos pequeños los eventos contenidos en ese pulso con una relación de 2:1. Esta representación muestra un completo desarrollo de la métrica que se corresponde, como lo explica Bamberger, con el comienzo de organización de un sistema simbólico, un sistema de escritura que refiere a los eventos y a sus relaciones.

Así, a través de los ejemplos presentados podemos evidenciar una trayectoria evolutiva que parte de las representaciones pre figurativas, donde los elementos 
graficados corresponden a las acciones mismas de producirlos, luego las figurativas, las cuales refieren a esas acciones, y finalmente las formales, en las cuales se observa la construcción de un "esquema de pensamiento" que le permite organizar esas acciones.

La autora explica que, en esta trayectoria evolutiva, los diferentes modos de conocimiento antes que reemplazarse se complementan entre sí contribuyendo uno al otro, antes que desplazándose. En tal sentido, Musumeci (2000) explica que el conocimiento figurativo no es una forma preliminar de conocimiento sino un fundamento del conocimiento formal en su doble acepción de base y justificación, ya que las representaciones formales se nutren de las representaciones figurativas.

Posteriormente, Rena Upitis (1987b) replicó los estudios realizados por Bamberger en niños de 7 a 12 años, pero además de transcribir el ritmo propuesto, solicitó a los niños que realizaran actividades como leer y palmear ritmos escritos, percutir y escribir diferentes pulsos, e identificar auditivamente ritmos. Los resultaron indicaron que los niños tendían a representar aspectos más o menos figurativos de acuerdo a la tarea que se les solicitaba.

\section{Representaciones enactivas, icónicas y simbólicas}

Los niveles de pensamiento esquematizados por Bruner (1973) han inspirado muchas de las explicaciones vertidas en los estudios sobre las notaciones musicales. Bruner definió tres tipos de procesos representacionales: enactivo, icónico y simbólico. Las representaciones enactivas son aquellas basadas en acciones motoras, por ejemplo, podemos representarnos ciertos sucesos como "hacer un nudo" por las acciones que el hecho de hacerlo requiere. Las representaciones icónicas son aquellas basadas en dibujos o imágenes, en este caso, tanto un dibujo del nudo (en un papel) como su imagen mental serían modos icónicos de representación. Y por último, las representaciones simbólicas son aquellas que utilizan formas simbólicas como el lenguaje (palabras, letras u otros símbolos).

Bruner explica que, las descripciones lingüísticas son arbitrarias, podemos tener la imagen de un suceso que hemos experimentado, tanto como las acciones necesarias para realizarlo pero podemos no conocer un modo simbólico para representarlo. Para utilizar un medio simbólico debemos tener el dominio de ese sistema simbólico lo 
cual requiere conocer sus reglas de organización y de conversión. El autor considera que el desarrollo de los procesos de representación no implica una secuencia de etapas, sino un dominio progresivo de estas tres formas de representación y de su traducción parcial de un sistema a otro. Así, las representaciones enactivas resultan las más iniciales, las icónicas suponen cierto grado de abstracción y las simbólicas suponen mayor grado de abstracción e incluso conocimiento específico, y cada modo de representación ofrece nuevas posibilidades. Durante el desarrollo cognitivo, antes que remplazar un modo por otro, se produce un proceso acumulativo. Incluso, como explica Bamberger (1991), nuestra capacidad para cambiar el foco puede acompañarse de la posibilidad de elegir entre los diferentes modos de representación el más adecuado o incluso coordinarlos.

Los estudios realizados por Davidson y Scripp (1988, 1989) sobre las representaciones musicales de los niños han tomado como punto de partida los procesos representacionales iniciales descriptos por Bruner para explicar las características de las notaciones realizadas a partir de la audición de estímulos musicales. Los autores han considerado representaciones enactivas a aquellas que captan la acción de la obra, donde la sensación del pulso o del ritmo se ve reflejada en los movimientos de la mano de quien realiza la notación y que dan como resultante gráfica garabatos en los cuales el niño es poco lo que puede leer con posterioridad. Las representaciones icónicas corresponden a aquellas que están basadas en imágenes, las cuales suelen estar vinculadas con diferentes aspectos de la música: su texto, su línea narrativa o su pulso rítmico. Y finalmente, las representaciones simbólicas son aquellas representaciones basadas en sistemas de lenguaje que se corresponden con las notaciones que utilizan sistemas simbólicos para registrar relaciones rítmicas o tonales.

Davidson y Scripp (1988) realizaron un estudio longitudinal, con el fin de observar la trayectoria evolutiva de las representaciones musicales espontáneas realizadas por niños entre los 5 a los 7 años de edad. Los autores observaron que, de manera progresiva, las representaciones tendían a capturar una creciente cantidad de componentes de la melodía: su estructura, el número de notas, el pulso, el agrupamiento del ritmo, el contorno y las alturas. Para ejemplificar la trayectoria de desarrollo presentaron las grafías realizadas por una niña a los 5, 6 y 7 años (ver 
figura 2.10) al escribir un fragmento melódico perteneciente al final de la canción popular "Row, row, row your boat".
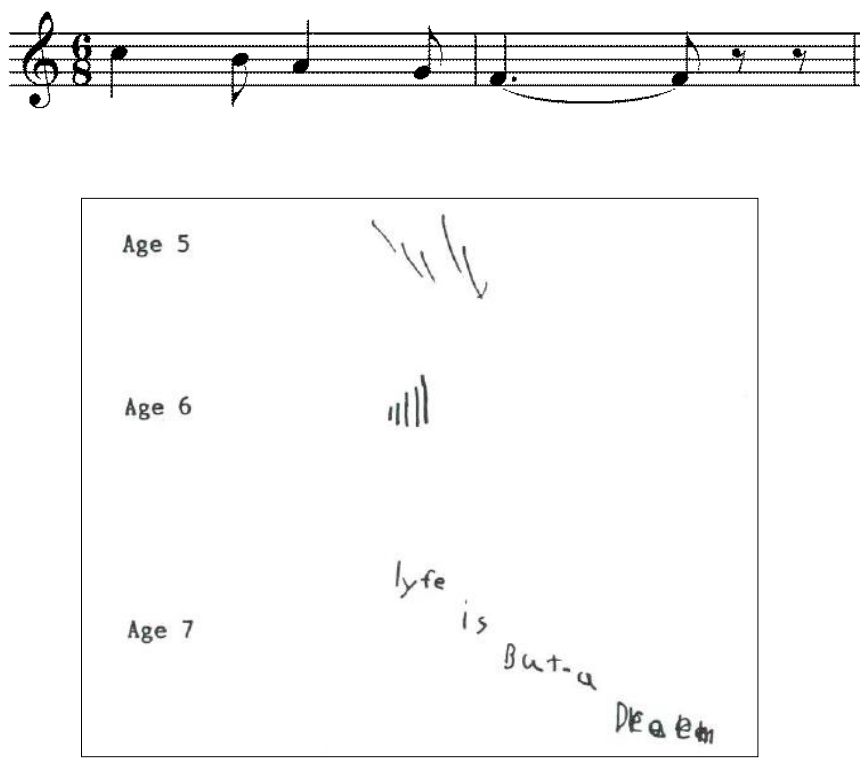

Figura 2.10. Transcripción del fragmento final de la canción popular "Row, row, row your boat" $y$ representaciones espontáneas realizadas por una niña (Davidson y Scripp, 1988, p.197)

Los autores observan que, a la edad de 5 años, la niña representa de un modo enactivo sólo los agrupamientos rítmicos del fragmento, que describe como "notas rápidas y lentas". Más tarde, a los 6 años, la niña transcribe líneas que representan el contorno melódico de la frase: "las líneas pequeñas son las notas más agudas". Finalmente, a los 7 años de edad, su representación sugiere al mismo tiempo los agrupamientos rítmicos y el contorno melódico de la canción, considerando que utiliza guiones para indicar los agrupamientos rítmicos y la disposición de las palabras en una pendiente para indicar el contorno melódico. Los autores advierten que, tal como lo hicieron otros sujetos en el mismo estudio, el ejemplo permite evidenciar el modo en que, entre los 5 y los 7 años, los niños son capaces de representar diferentes rasgos de la música de manera creciente y articulada, revelado que son capaces de combinar aspectos del ritmo y las alturas. 
A lo largo de este capítulo se planteó que las unidades del sistema de notación musical: el compás, la célula rítmica, el acorde y la nota; podrían pensarse de modo análogo a las unidades del lenguaje verbal: la oración, la palabra y el grafema; en el sentido que ambas no presentan un problema de delimitación en la escritura. Sin embargo, y a diferencia del lenguaje verbal, la delimitación de estas unidades desde el análisis por audición, no ha sido problematizada en el desarrollo de habilidades de lectoescritura musical.

En relación con el proceso de alfabetización, Emilia Ferreiro sostiene que los sujetos elaboran hipótesis acerca del modo en que funciona el sistema de escritura a través del análisis de sus representaciones, sin embargo, en la escritura musical, en general los sujetos no tienen oportunidades de hipotetizar los principios de su funcionamiento ya que las partituras no suelen formar parte del entorno y generalmente el contacto con ellas está reservado sólo para quienes estudian música en los ámbitos de enseñanza formal. Por lo tanto, el estudio de las estrategias iniciales de alfabetización musical ha sido abordado a partir del análisis de las grafías espontáneas realizadas por niños y adultos sin conocimientos musicales específicos a partir de la audición y transcripción de diferentes estímulos. Es decir que, a diferencia del lenguaje verbal, donde se han estudiado las diferentes hipótesis que desarrollan los niños acerca del funcionamiento de la escritura, en la escritura musical se ha indagado el modo en que los sujetos transcriben espontáneamente un estímulo.

Tanto los trabajos de Bamberger (1982), que indagaron las representaciones a partir de un estímulo rítmico palmeado; como los estudios de Davidson y Scripp (1988, 1989), que analizaron las representaciones de un fragmento melódico conocido; han coincidido en establecer una trayectoria de desarrollo. Una trayectoria planteada como madurativa y comprendiendo básicamente 3 etapas. En una etapa inicial los sujetos expresan las acciones motoras, a las cuales los autores denominan garabatos rítmicos y representaciones enactivas respectivamente. Luego establecen un modo de representación que refiere a imágenes, aunque Bamberger lo consideró como parte de las representaciones pre-figurativas y Davidson y Scripp lo denominaron representaciones icónicas. Y por último, ambos describen el desarrollo de las representaciones simbólicas como punto de llegada. Sin embargo, ambos enfoques 
contienen un aspecto no previsto y que será abordado en esta tesis: ninguno de ellos problematiza la nota como unidad de análisis desde la audición.

Los autores no contemplan esta variable en su análisis y por lo tanto los estímulos que utilizan proporcionan cierto andamiaje a los sujetos para poder acceder a las notas perceptuales de un modo más inmediato. Por ejemplo, la utilización de texto en los trabajos de Davidson y Scripp podría favorecer una segmentación en sílabas, así como la ejecución "en vivo" del ritmo palmeado que utiliza Bamberger podría favorecer una segmentación del diseño en los movimientos que lo componen. En la trayectoria de desarrollo planteada por los autores mencionados, los sujetos acceden a la nota, como unidad de representación mínima, de un modo natural y espontáneo, sin intervención, y transitan de manera continua de las representaciones figurativas o enactivas e icónicas, es decir aquellas que hacen foco en los significados sentidos, globales y holísticos, a las representaciones simbólicas, representadas con elementos discretos.

Si atendemos a las consideraciones que plantea el enfoque de la lingüística, tal como se desarrolló en el Capítulo 1, las unidades de escritura, no presentan un correlato directo con las unidades perceptuales. Por el contrario, la escritura impone sus propias restricciones al lenguaje oral para su organización y representación. Por lo tanto resultaría ingenuo concebir que, en el desarrollo de la notación musical, los sujetos accedan a las unidades de escritura desde la percepción de un modo espontáneo, y que los principios de organización de la escritura (que fue originalmente construida para comunicar enunciados) tengan un correlato con la experiencia de audición.

En el análisis por audición, los sujetos podrían configurar unidades perceptuales y principios de organización diferentes a los propuestos por el sistema de notación musical convencional. Por lo tanto esta tesis se propone indagar la realidad perceptual de la nota como unidad mínima de segmentación y analizar las diferentes unidades perceptuales utilizadas por niños y adultos en diferentes tareas que demanden la segmentación del discurso, con el objeto de avanzar en el estudio de las representaciones musicales tomando como punto de partida el problema de la definición de las unidades perceptuales y operativas del pensamiento musical. 



\section{SEGUNDA PARTE: EVIDENCIA EMPÍRICA}





\section{Capítulo 3: La influencia del conocimiento de la notación musical en la identificación de la nota como unidad perceptual}

A partir de las discrepancias encontradas, en el contexto de las instancias iniciales de lectoescritura musical en la educación formal de adultos, entre la cantidad de notas escritas en las melodías y la cantidad de notas esperada, se desarrolló este primer trabajo con la finalidad de indagar la vinculación entre la habilidad para acceder a estas unidades y el conocimiento de la notación musical.

La hipótesis que se somete a verificación aquí sostiene que, las personas que se inician tempranamente en prácticas musicales sistemáticas basadas en la notación musical identifican la nota como unidad de análisis porque sus experiencias musicales se han sistematizado a partir de la agregación y/o combinación de unidades de este nivel como nivel básico. Por el contrario, quienes desarrollan más extensamente experiencias musicales ágrafas, es decir que no se basan en el manejo y las categorías del código de notación convencional, configuran un nivel básico que no se corresponde con el nivel de discretitud de la nota.

En este estudio, que será considerado Estudio 1, se propone analizar la incidencia del conocimiento del código de escritura musical en la identificación del número notas percibidas en fragmentos melódicos por parte de estudiantes de música adultos.

\section{Metodología}

\section{Sujetos}

Participaron en esta investigación, 62 estudiantes de música del Ciclo de Formación Musical Básica de las carreras del Departamento de Música de la Facultad de Bellas Artes, Universidad Nacional de La Plata, con edades comprendidas entre los 18 y 22 
años. Todos ellos se encontraban cursando las primeras clases en la Universidad al momento de administrarse la prueba. 26 estudiantes (42\%) no habían aprendido el sistema de notación musical mientras que 36 estudiantes (58\%) sí lo conocían. Sin embargo, todos ellos tenían práctica en algún instrumento. Así, antes de su ingreso a la universidad, 18 estudiantes (29\%) habían aprendido a tocar un instrumento "leyendo la notación musical", y 44 estudiantes (71\%) habían aprendido a tocar un instrumento "de oído". De este modo el conjunto de sujetos se distribuyó en 3 grupos: (1) sujetos que aprendieron a tocar de oído y no sabían leer música hasta su ingreso a la universidad; (2) sujetos que aprendieron a tocar de oído, y luego aprendieron a leer música previamente al ingreso a la universidad; (3) sujetos que aprendieron a tocar leyendo y por lo tanto sabían leer música previamente a su ingreso a la universidad. La muestra quedó segregada en tres grupos: grupo $1(n=26)$, grupo 2 $(n=18)$ y grupo $3(n=18)$.

\section{Estímulo}

Con motivo de estudiar el problema en condiciones ecológicas de audición, los estímulos utilizados corresponden a fragmentos seleccionados de la ejecución de una obra musical real: Los Miserables de Alan Boublil y Claude-Michel Schönberg (1987) dirigida por Cameron Mackintosh ${ }^{3}$.

Se seleccionaron 20 fragmentos de la obra, los cuales presentan una melodía cantada con acompañamiento instrumental donde la línea vocal se destaca claramente en la textura, y el texto de la voz cantada en inglés no refuerza la segmentación en sílabas. Cada fragmento comprende entre 9 y 15 notas y dos unidades morfológicas con una relación antecedente-consecuente. Se estimó que, independientemente a la cantidad mayor o menor de notas comprendidas en cada uno, los fragmentos presentaban dificultad equivalente a los fines de la tarea a realizar.

Cada fragmento se grabó tres veces intercalando una pausa entre cada una de las repeticiones. Cada pausa presentaba la misma duración del fragmento.

\footnotetext{
3 Se adjunta en el Apéndice la transcripción y grabación de los fragmentos seleccionados para este
} estudio. 


\section{Procedimiento}

La tarea consistió en escuchar tres veces cada fragmento e imitar cantando con el objetivo de memorizar cada uno, utilizando las pausas para ello. Luego de cantar el fragmento 3 veces, para cada ejemplo los sujetos recibían de entre las siguientes posibilidades: (i) contar la cantidad de sonidos de la melodía4; (ii) caracterizar el tempo; (iii) caracterizar la relación entre las dos unidades que presentaba el fragmento (repetición, variación o cambio). Aunque la primera consigna era la que interesaba a los fines de esta investigación, las restantes fueron incluidas a los fines de garantizar que los sujetos contaran las notas a partir de la memoria del fragmento, evitando que se predispusieran a contar las notas simultáneamente a la audición del fragmento. Por lo tanto se estimaron sólo las respuestas ofrecidas para esa tarea que corresponde a 9 de los 20 fragmentos.

Los sujetos debían volcar su respuesta en una planilla. Dado que la muestra estaba formada por sujetos que no manejaban el código de notación musical, en la consigna se utilizó la expresión "sonidos" en lugar de "nota” para evitar la connotación relativa a la escritura, asimismo se realizó en el inicio del test una actividad a modo de aprestamiento.

Al finalizar el test, se solicitó a cada uno de los sujetos que completara un breve cuestionario relativo a su formación musical, dominio del código de notación y estimación de la autoeficacia en diferentes tareas vinculadas a la lectoescritura musical.

La realización del test demandó alrededor de 15 minutos y se realizó de manera colectiva.

\footnotetext{
4 En las consignas que forman parte de los estudios que comprenden los capítulos 3, 4 y 5, se utilizó el término sonido para referir a la unidad de segmentación o nota perceptual con la finalidad de suscitar respuestas espontáneas evitando connotaciones con conceptos musicales específicos. En tal sentido, se consideró que este término se encuentra más directamente identificado con la noción de unidad idiosincrática.
} 


\section{Resultados}

Cada sujeto debió contar sonidos (notas) en 9 fragmentos melódicos. La cantidad de notas proporcionada para cada ejemplo se analizó en relación a la cantidad de notas esperada para cada uno. Así, se consideró que la cantidad de notas identificada podía ser igual (correcta), mayor (error por exceso) o menor (error por defecto) a la cantidad esperada. El gráfico de la figura 3.1 permite observar la distribución de los 3 tipos de respuesta.

Tan solo en la mitad de los fragmentos musicales presentados (51\%) los sujetos contaron igual cantidad de notas en relación a la cantidad de notas esperada. Por lo tanto, en la otra mitad, los sujetos contaron diferente cantidad de notas (por exceso o por defecto). En este último caso, los sujetos tendieron con más frecuencia a contar menor cantidad de notas.

\section{Tipo de respuesta}

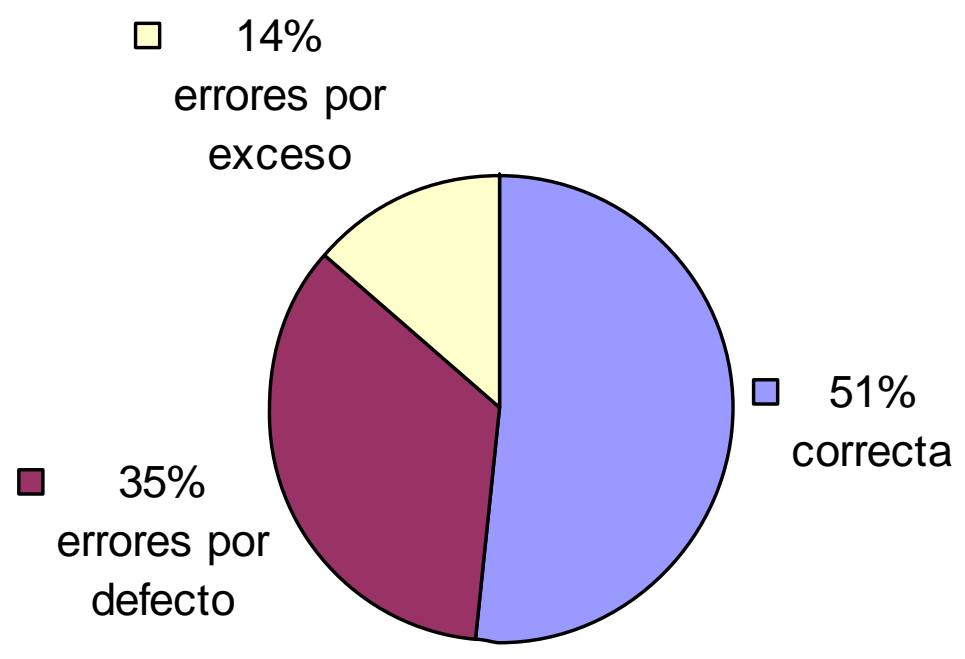

Figura 3.1. Distribución global de las respuestas de los sujetos (en porcentajes)

Luego se contó la cantidad de respuestas incorrectas de cada sujeto. El gráfico de la figura 3.2 presenta la distribución de los sujetos según la cantidad de errores. Se observa una distribución tipo normal con un alto porcentaje de sujetos que cometieron entre 3 y 6 errores. Asimismo se observa que ningún sujeto obtuvo el puntaje óptimo de 0 error y, del mismo modo, ningún sujeto erró los 9 items. La 
media de la cantidad de respuestas incorrectas fue de 4,6. Se observa que un alto porcentaje de sujetos no lograron resolver adecuadamente la mitad de los ejemplos.

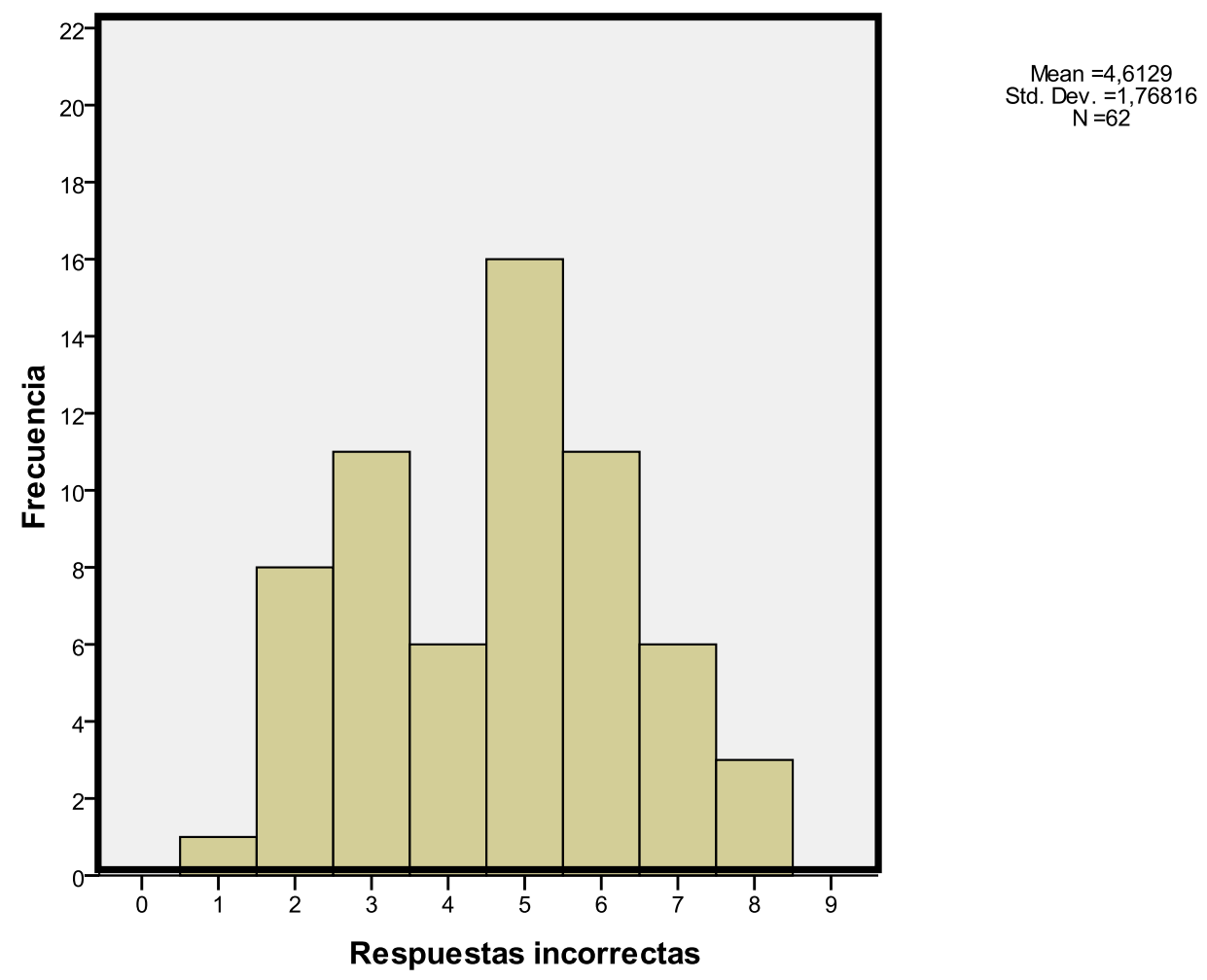

Figura 3.2. Distribución de las frecuencias de sujetos por cantidad de ítems incorrectos, en porcentajes

En la figura 3.3 se presenta un análisis descriptivo para las respuestas incorrectas obtenidas en los sujetos que conformaban cada grupo. Los sujetos del grupo 1 que corresponde a quienes desarrollaron prácticas musicales desde la audición y no aprendieron el código de escritura musical convencional obtienen la media más alta $(\dot{x}=5,5)$, es decir que es el grupo que más errores cometió. Le sigue el grupo 2 ( $\dot{x}=$ 4,28) y finalmente el grupo $3(\dot{x}=3,67)$ obtiene la media más baja, es decir que, quienes desarrollaron prácticas instrumentales desde la audición y no aprendieron a leer música presentaron más errores que quienes desarrollaron prácticas instrumentales desde la audición y luego aprendieron a leer música. 


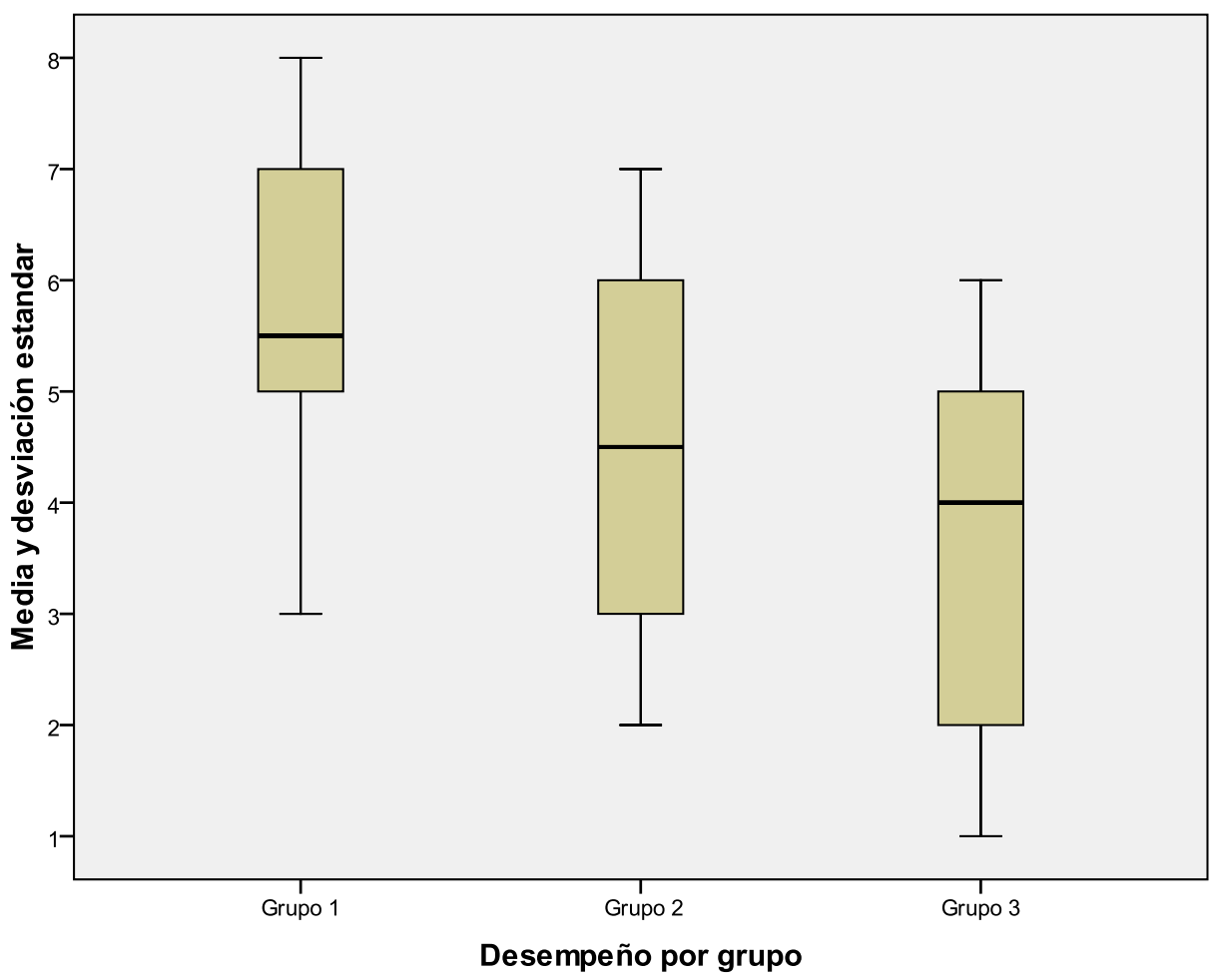

Figura 3.3. Media y desviación estándar de cada grupo

Finalmente, un ANOVA de un factor indicó que las diferencias entre las medias de los tres grupos resultaron altamente significativas $\left(F_{[2-59]}=7.486 ; p=.001\right)$ Un análisis pos-hoc (HSD de Tukey) indicó que la diferencia entre el grupo 1 y 3 resultó altamente significativa $(p=.001)$ y la diferencia entre los grupos 1 y 2 arrojó una significación marginal $(p=.042)$, mientras que la diferencia entre los grupos 2 y 3 no fue significativa.

\section{Discusión}

La presente investigación se propuso indagar en qué medida la naturaleza de la experiencia musical podía incidir en la habilidad para identificar y contar notas perceptuales en una melodía. Para ello se seleccionaron 9 fragmentos melódicos y se solicitó a los sujetos que contaran los sonidos articulados en la melodía. Las respuestas dadas fueron analizadas en términos de correctas e incorrectas (por exceso o por defecto) y se analizó la cantidad de respuestas correctas en los 3 grupos de sujetos que conformaron la muestra. 
En principio los datos permiten afirmar que la nota no resulta una unidad fácilmente discernible en el fluir del discurso musical. Tan sólo la mitad de las respuestas dadas resultaron correctas. En el caso de las respuestas incorrectas, de acuerdo con el gráfico de la figura 2 , un $85 \%$ de los sujetos $(N=53)$ tuvo en sus 9 respuestas, entre 3 y 8 incorrectas. Es decir que, la dificultad se extendió a la mayoría de los sujetos.

Contar sonidos articulados en una melodía, implica segregar el discurso en notas perceptuales. Estas unidades se corresponden con las unidades de escritura, es decir, con las notas gráficas. Sin embargo, la nota, no tiene entidad en sí misma, sólo cobra sentido en el fluir de la melodía. Como lo propusieron los psicólogos de la Gestalt, la totalidad es percibida como algo más y distinto de la suma de las partes, es por ello que no percibimos conjuntos de elementos, sino formas o unidades de sentido estructuradas. En el mismo sentido, la melodía es percibida como una configuración y no como una sucesión de notas, y por lo tanto, como lo indican los resultados, acceder a esas unidades podría implicar una habilidad con un alto grado de abstracción.

La diferencia entre la media del grupo 1, conformado por sujetos que no conocían el sistema de notación musical, con los grupos 2 y 3 , de sujetos que si lo conocían, estaría dando cuenta de dos modos diferentes de pensar la melodía en relación con la experiencia musical adquirida: una por agregación de unidades (grupo 2 y 3 ) y otra como imagen o configuración más holística (grupo 1).

De acuerdo con el primer modo de pensar la melodía, quienes han desarrollado experiencias musicales iniciales vinculadas con el código de escritura musical convencional, ya sea porque han construido sus prácticas de ejecución desde la lectura o porque han accedido al aprendizaje del código en algún momento anterior de su desarrollo musical, las han construido por agregación y combinación de unidades comunicadas a través de la escritura (notas). Por lo tanto para estos sujetos analizar la melodía al nivel de esas unidades es un proceso familiar. Para estos sujetos la unidad de notación tiene una gran influencia en sus unidades de percepción y de acción (a cada nota escrita le corresponde una acción en la ejecución). La enseñanza de la música en los ámbitos formales favorece este modo de hacer y pensar la música. 
De acuerdo con el segundo modo de pensar la melodía, quienes han desarrollado experiencias musicales a partir de prácticas que no se basan en la lógica notacional, desde la imitación o bien utilizando cifrados o tablaturas, la nota, no constituye una entidad en sí misma. En algunas prácticas musicales resulta posible abordar la ejecución sin pensar necesariamente en el nivel de la nota, como por ejemplo en la ejecución por rasgueo de la guitarra, donde para cada signo escrito corresponde una acción en el instrumento pero el resultado musical no es una nota sino un conjunto de notas. Posiblemente, para estos sujetos, la melodía sea una entidad que se captura a través de atributos más globales y de manera holística.

Para la resolución del test los sujetos debían contar los sonidos a partir de la memoria de los fragmentos, y es posible también, que los criterios de literalidad en la copia cantada también sean diferentes en uno y otro grupo. Mientras que, para los sujetos que integraban el grupo 2 y 3 , repetir cantando una melodía implica articular con precisión cada una de las notas que la conforman porque es la agregación de tales notas lo que la caracterizan e identifican, para quienes integraban el grupo 1 repetir cantando una melodía podría implicar una aproximación a través de rasgos de otra naturaleza (direccionalidad, movimiento, etc.) más general y menos articulada. En este sentido, para los sujetos que leen y escriben música el concepto de literalidad es también al nivel de la nota.

Si la conciencia fonémica es la habilidad para oír, identificar, producir y manipular los sonidos individuales (fonemas) del lenguaje hablado, podríamos considerar que la diferencia en el desempeño entre el grupo 1 y los grupos 2 y 3 , se debe a que quienes conocen el código de notación poseen una mayor conciencia de las notas perceptuales como unidades constitutivas de la melodía. Y esa conciencia podría manifestarse tanto en la manera de contar como en la manera de reproducir lo escuchado, mientras que, para aquellas personas que no conocen el código de notación musical, la melodía se comprende desde rasgos más holísticos que, no necesariamente implican el nivel de la nota como unidad de análisis. 


\section{Capítulo 4: La unidad espontánea de análisis musical por audición en niños de 6 años}

En el Estudio 1, presentado en el capítulo precedente se proporcionó evidencia acerca de la relación entre la habilidad para segmentar el discurso en notas y el conocimiento de la notación musical. Como se observó, los sujetos cuyas prácticas musicales estaban basadas en la lectura tuvieron respuestas más ajustadas en cuanto la cantidad de notas percibidas, respecto a los sujetos que habían desarrollado experiencias musicales a partir de prácticas no basadas en la notación musical.

Por tratarse de adultos alfabetizados, podría considerarse que, aunque estos sujetos no tenían dominio del sistema de notación musical, todos ellos habían desarrollado la capacidad para segmentar la corriente sonora en unidades menores a las unidades de sentido, al menos en el dominio del lenguaje. Así, con el objetivo de analizar las unidades espontáneas utilizadas por sujetos sin conocimiento de los sistemas de escritura, tanto musical como del lenguaje, este trabajo se desarrolló con niños de 6 años en proceso de alfabetización.

Por otra parte, de acuerdo con los trabajos reportados en la literatura sobre el desarrollo de las representaciones espontáneas, a la edad de 6 años, los niños estarían en condiciones de representar cada uno de los eventos expresados en un estímulo (ver Capítulo 2). Sin embargo, es importante considerar que, si bien los estudios realizados por Bamberger (1991) han permitido reflexionar acerca del modo en que se configuran las representaciones figurativas y formales, los estímulos utilizados consistían en ritmos percutidos con palmas, es decir, en estímulos en los cuales no intervenían los numerosos factores que modelan la experiencia de audición musical. Estudiar las unidades mínimas de análisis a partir de la audición de un fragmento musical real, interpretado por la orquesta, podría derivar en nuevas posibilidades de análisis ya que, los atributos expresivos involucrados en la ejecución musical podrían colaborar en la percepción de la melodía como una configuración 
dinámica. Es por ello que, en la tarea de identificar las notas perceptuales a partir de estímulos musicales reales, se estima que los sujetos reflejen en sus respuestas una organización diferente respecto a las representaciones propuestas por Bamberger.

Este estudio, en adelante Estudio 2, se propone analizar las unidades utilizadas por niños sin conocimiento de la lectoescritura del lenguaje, para analizar y describir un fragmento musical (instrumental-orquestal) a partir de la audición. Se estima que la descripción de las particularidades de las respuestas pueda arrojar luz sobre el proceso cognitivo que lleva a considerar la nota perceptual como unidad mínima de la configuración melódica.

\section{Metodología}

\section{Sujetos}

Participaron del estudio 5 niños de 6 años, sin embargo aquí serán reportados los resultados de 4 de ellos, ya que el caso restante se seleccionó para un estudio más profundo que será presentado en el capítulo siguiente (razón por la cual no se trata en este capítulo). Los niños que participaron estaban iniciando el 1er grado de la Educación Primaria y no tenía conocimientos musicales específicos. En el contexto de esta investigación serán denominados como: Lucio, Santiago, Santino y Francisco.

\section{Estímulo}

Se utilizó el fragmento inicial del 1er Movimiento de la Sinfonía $N^{\circ} 5$ de Ludwig van Beethoven (compases 1-4)5, interpretada por la Orquesta Sinfónica de Londres dirigida por Alfred Scholz. La melodía del fragmento se transcribe en la figura 4.1.

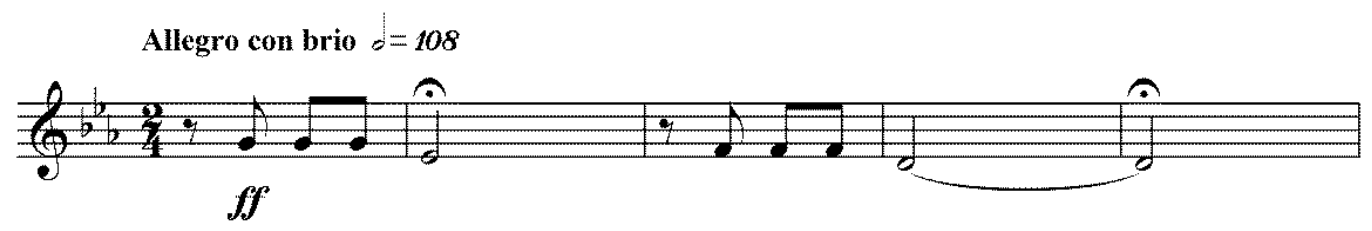

Figura 4.1. Melodía del fragmento inicial del $1^{\text {er }}$ Movimiento de la Sinfonía № 5 de Beethoven.

\footnotetext{
${ }_{5}^{5}$ Se adjunta en el Apéndice la grabación del fragmento de Beethoven.
} 


\section{Procedimiento}

Se realizaron entrevistas individuales, una entrevista para cada sujeto, con una duración de entre 5 y 10 minutos. En las mismas, se solicitó a los niños participantes que escucharan el fragmento, contaran la cantidad de sonidos que tenía y escribieran esos sonidos como palitos. Una vez realizada esa tarea se solicitó que cantaran el fragmento mientras señalaban las unidades graficadas. A partir allí, se desarrolló una estrategia metodológica por indagación con la finalidad de producir cambios en la unidad utilizada para la segmentación, cuando ésta no era la nota perceptual. Se propusieron diferentes consignas y/o se formularon interrogantes, con la finalidad de: (i) recoger evidencia acerca de la unidad a la cual atendían o el criterio que utilizaban y (ii) producir cambios en la unidad de análisis adoptada, cuando la misma no tenía el nivel de la nota.

Durante la entrevista se sugirió cantar, contar con los dedos, escribir, señalar en la transcripción cantando, etc. La modalidad del investigador en las entrevistas fue participativa y las entrevistas fueron filmadas.

\section{Resultados}

A partir de la consigna inicial de contar la cantidad de sonidos que el fragmento presentaba, los sujetos contaron de manera espontánea cuatro sonidos (Lucio, Santiago y Santino) y diez sonidos (Francisco). Sin embargo, los que contaron cuatro sonidos no lo hicieron del mismo modo: Lucio contó cuatro sonidos de corrido, Santiago contó uno chiquito, uno grande, otro chiquito, otro grande; Santino contó dos y dos, mientras que Francisco contó cinco y cinco.

A partir del análisis de las entrevistas, se advirtieron algunas particularidades de las unidades a las que cada sujeto se refirió. Aquí se desarrollan y analizan cada una de las entrevistas.

\section{Lucio}

Lucio contó inicialmente cuatro unidades y luego dibujó cuatro palitos (figura 4.2). Sin embargo, al solicitarle que escuchara nuevamente el fragmento y señalara por dónde iba, primero escuchó el fragmento y a continuación explicó: “¿viste que dice 
como na na na na?, bueno, en una dice na, como una na, entonces ese es uno, después el que sigue, el que sigue y el que sigue" (Aquí, cada uno de los "na" es hablado, no cantado).

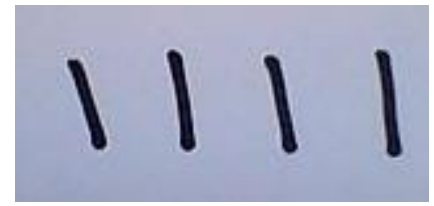

Figura 4.2: representación gráfica de Lucio correspondiente al fragmento inicial del $1^{\text {er }}$ Movimiento de la Sinfonía № 5 de Beethoven.

La explicación de su grafía puso en duda la unidad a la cual se había referido inicialmente, ya que, si bien en un principio dijo que el estímulo tenía cuatro sonidos (y por lo tanto podía considerarse que contó unidades con una dimensión mayor a la nota) en esta explicación, precedida de su propia escritura, parecía estar contando unidades correspondientes a la nota.

Para indagar acerca de la tipología de las unidades graficadas e intentar producir cambios en la resolución de la tarea, se intervino de la siguiente manera:

I: Escuchemos la música otra vez y después la cantas.

Escucha el fragmento y luego lo canta.

I: Entonces, ¿todo eso son cuatro sonidos?

L: ¡ $A$ Ah, no! son seis.

l: ¿Cómo los contás?

Canta el fragmento y se detiene cada dos sonidos, en esas pausas cuenta con los dedos y en voz alta.

L: na na, uno dos, na na, tres, na na, cuatro cinco, na na, seis.

I: Entonces podés contar cuatro y también podés contar seis, ¿no? ¿Y cómo eran 4 ?

Canta los primeros cuatro sonidos.

L: Ahí son cuatro.

I: ¡Pero ahí no termina! ¿La escuchamos una vez más?

Escucha el fragmento 
L: Si, son ocho.

I: ¿Cómo sería entonces?

Canta los primeros cuarto sonidos

L: Ahi son cuatro.

Canta los siguientes cuatro sonidos

L: Son cuatro más, son cuatro y cuatro, son ocho.

Lucio no accedió espontáneamente a la nota como unidad de análisis, sin embargo, a partir de los interrogantes formulados durante la entrevista, el niño fue descubriendo nuevos modos de pensar la tarea. Inicialmente representó cuatro unidades que podían comprenderse como unidades más amplias que la nota. Aun cuando, al explicar las unidades graficadas, cantó solamente los primeros cuatro sonidos del estímulo, lo hizo utilizando una sílaba para cada uno y contó cuatro. A partir de allí, las unidades graficadas inicialmente cobraron una nueva dimensión. Estimamos que, tanto el texto adjudicado, el cual comprendía una sílaba para cada nota, como su propia escritura, lo condujeron a enfocar el problema desde un pensamiento más abstracto, favoreciendo la identificación de notas perceptuales como unidades de análisis.

Sin embargo, cuando le solicitamos escuchar y cantar el estímulo completo, Lucio contó seis unidades (agrupando los sonidos 3-4 en una unidad y 7-8 en otra). Al explicar el conteo advertimos que podría comprenderse como una combinación entre el criterio anterior, según el cual había contado notas perceptuales, y el criterio inicial, según el cual había graficado cuatro unidades, donde las mismas bien podían representar los grupos 1-2, 3-4, 5-6 y 7-8. Finalmente, cuando le pedimos que explicara cómo era cuando contaba cuatro unidades, Lucio volvió al nivel de la nota y contó ocho sonidos organizándolos en dos unidades mayores: cuatro y cuatro.

En el desarrollo de la entrevista se observó que el niño, en orden a redefinir el problema, conforme a dar respuesta a los interrogantes y valiéndose de la escritura, fue produciendo cambios en sus unidades de análisis hasta finalmente estimar la nota perceptual. 


\section{Santiago}

Santiago escuchó el ejemplo y dibujó cuatro palitos. Las unidades graficadas presentaban algunas diferencias, tal como él describió: "un palito chiquito, uno grande, otro chiquito y otro grande" (figura 4.5).

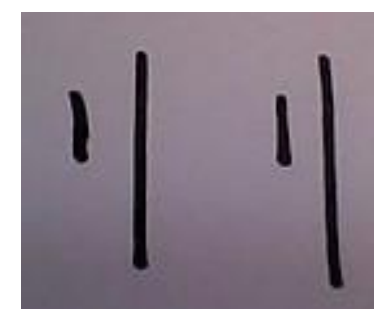

Figura 4.5. Representación gráfica de Santiago correspondiente al fragmento inicial del $1^{\text {er }}$ Movimiento de la Sinfonía № 5 de Beethoven.

En la grafía se observó que el niño, no sólo representó las unidades identificadas, sino que además, representó las relaciones que estableció entre esas unidades, aunque su descripción no fue del todo precisa para describirlas: "los grandes son como fuertes... y los chiquitos son como comunes".

Para indagar acerca de la tipología de las unidades graficadas e intentar producir cambios en la resolución de la tarea, se intervino de la siguiente manera:

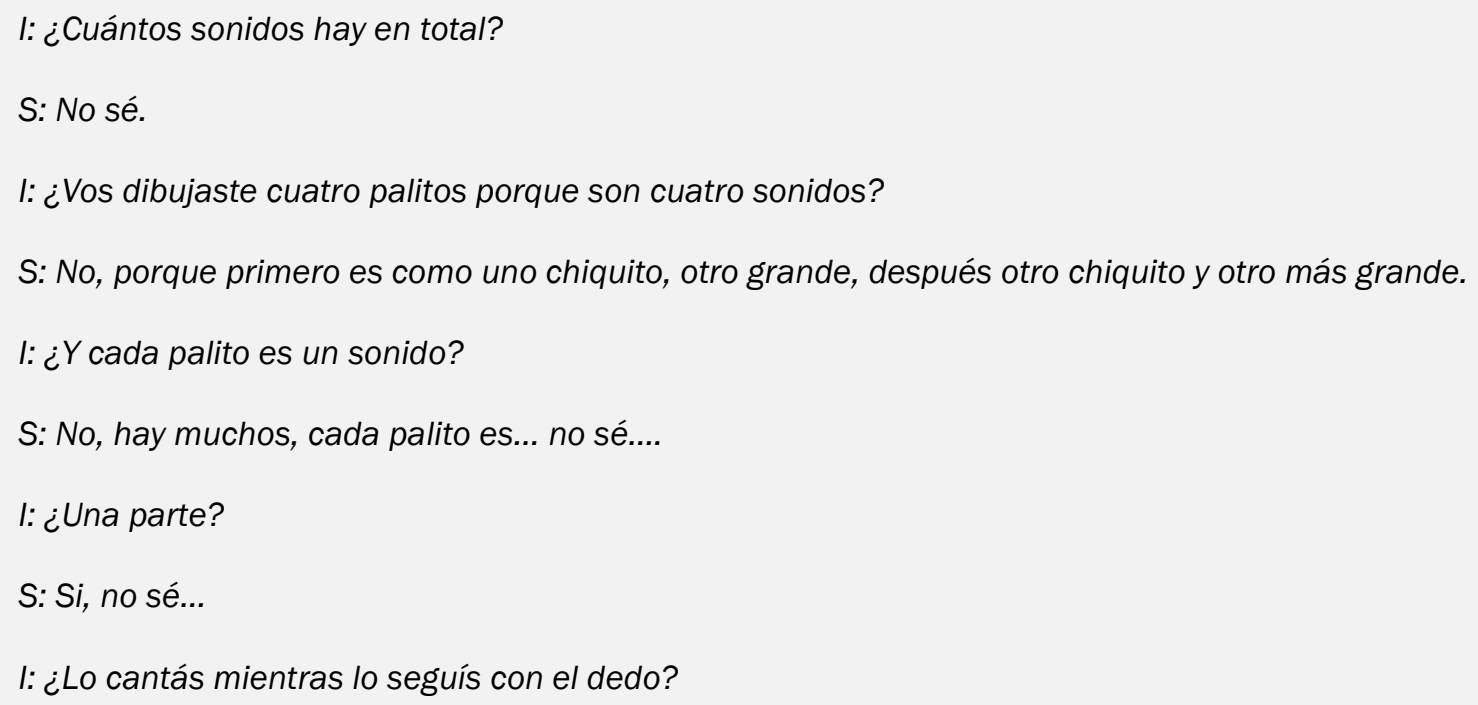


Canta señalándola grafía completa, sin deslizar el dedo por el papel.

I: ¿Y por qué hay unos grandes y otros chiquitos?

S: Y, porque los grandes son como fuerte,

I: ¿El último es grande no?

S: Si, porque es más fuerte.

I: ¿Y los chiquitos?

S: Esos son más chiquitos, son como comunes...

Santiago consideró una unidad de notación que no se correspondía con su propia unidad de percepción. De acuerdo con su explicación, advertimos que el niño adoptó un criterio bajo el cual anotó unidades que representaban más de un sonido, aunque no pudo acceder a cada uno de ellos. Los diferentes interrogantes no produjeron cambios en el análisis, por lo tanto no se pudo advertir el nivel de acceso que podía tener a unidades menores que las representadas.

\section{Santino}

Santino contó los sonidos con los dedos, dos sonidos con una mano y dos sonidos con la otra mano, dijo: "dos y dos", y en su transcripción realizó dos palitos en un renglón y dos palitos en el renglón de abajo (ver figura 4.6). Al solicitarle que lo cantara señalando la transcripción, Santino cantó y señaló el primer palito para las notas 123 , el segundo palito para la nota 4, el siguiente palito para las notas 567 y el último palito para la nota 8 .

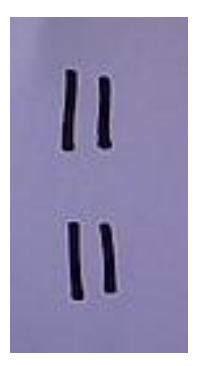

Figura 4.6. Representación gráfica de Santino correspondiente al fragmento inicial del $1^{\text {er }}$ Movimiento de la Sinfonía № 5 de Beethoven. 
Considerando que el niño cantó el fragmento tal como se transcribe en la figura 4.7, las unidades contadas podrían corresponderse con el pulso de base, aunque sin contemplar las pulsaciones subyacentes en los sonidos largos, o bien podría estar agrupando alturas o duraciones por proximidad siguiendo los principios de la Gestalt.

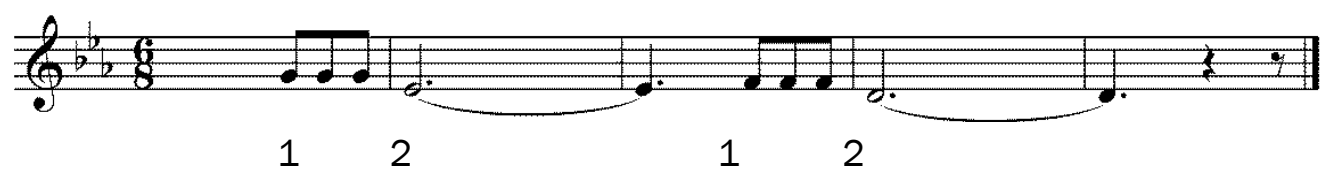

Figura 4.7. Transcripción de la melodía de Beethoven tal como la cantó y contó Santino.

Durante el conteo se observó que Santino cantaba el fragmento produciendo un énfasis en la primera y cuarta nota de cada motivo. Si bien se formularon algunas preguntas tendientes a producir cambios en la unidad de análisis, como por ejemplo, le preguntamos cuántos sonidos había cantado al señalar el primer palito, el niño no modificó el conteo y siguió contando como un único sonido allí donde cantaba las alturas repetidas. Todo ello puso en evidencia, que la nota no resultaba una unidad accesible para el niño.

\section{Francisco}

La cantidad de unidades que contó Francisco surgió de la combinación de unidades equivalentes a la nota más una unidad (en cada motivo) que se correspondía con el énfasis que él mismo producía al cantar el fragmento. Francisco cantó el fragmento produciendo un énfasis durante la prolongación del último sonido de cada motivo y en coincidencia con un beat, tal como se transcribe en la figura 4.3.

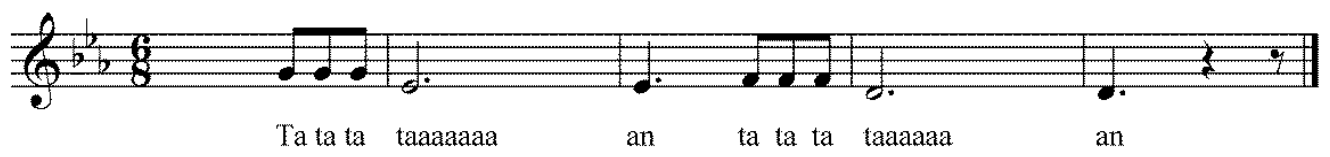

Figura 4.3. Transcripción de la melodía de Beethoven cantada por Francisco

Francisco contó cinco y cinco sonidos, luego escribió, separados por un espacio, cinco y cinco palitos (figura 4.4). 


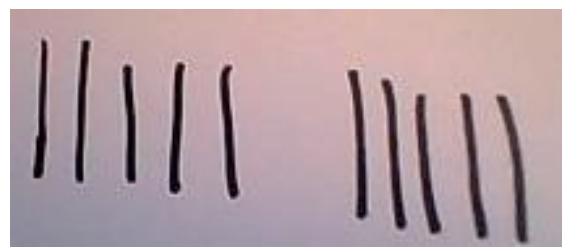

Figura 4.4. Representación gráfica de Francisco correspondiente al fragmento inicial del $1^{\text {er }}$ Movimiento de la Sinfonía N 5 de Beethoven.

Cuando se solicitó que cantara señalando con el dedo en la escritura, lo hizo siguiendo el mismo criterio que cuando había cantado: señalando el palito 5 y el 10 en cada énfasis que él mismo producía al cantar al final de cada motivo, dotando así de entidad sonora al beat del final de cada uno.

A pesar de que se propusieron diferentes consignas tales como atender especialmente al último sonido de cada grupo o cantar señalando, Francisco no modificó sus unidades de conteo. Para él, a diferencia de los otros niños, la unidad de análisis resultaba menor que la nota misma.

\section{Discusión}

Este estudio se propuso analizar las unidades de análisis espontáneas identificadas a partir de la audición de un fragmento musical por niños de seis años de edad sin conocimientos musicales específicos y en proceso de alfabetización. Con el objetivo de identificar los criterios implicados en la selección de las unidades se desarrollaron entrevistas individuales durante las cuales el investigador asumió un rol participativo formulando interrogantes con el objetivo de inferir los criterios que cada niño estaba poniendo en juego para la resolución de la tarea. Asimismo, estimando que los niños no accederían inicialmente a las notas perceptuales como unidades de análisis y con la finalidad de inducirlos al análisis del fragmento musical en notas perceptual, se desarrolló una estrategia metodológica por indagación, donde a través de diferentes consignas propuestas durante la resolución de la tarea se intentó producir cambios en la selección de la unidad de análisis establecida.

Los resultados permitieron considerar que la nota no resultaría una unidad espontánea ya que ninguno de los niños entrevistados contó ocho sonidos a partir de la consigna inicial. Los sujetos contaron diferente cantidad de sonidos, pero además 
todos ellos dieron una organización a esas unidades contadas estableciendo jerarquías que estarían indicando que cuentan al tiempo que comparan y organizan las unidades. Esa organización en jerarquías tendría dos niveles. Un nivel básico, donde la unidad de análisis podría vincularse con diferentes criterios: proximidad de alturas, duraciones similares, pulsos, entre otras. En tal sentido, por ejemplo, Santiago graficó las cuatro unidades que identificó, con palitos de diferente tamaño, representando las diferencias y similitudes entre las unidades de este nivel. Y un nivel supraordinado donde los sujetos estarían reflejando sus agrupamientos en dos motivos. Estas unidades fueron traducidas a la escritura de diferentes maneras: con una separación en el eje vertical (Santino) o en el eje horizontal (Francisco).

Por otra parte, Lucio fue el único niño que tuvo diferentes respuestas a lo largo de la entrevista, los otros niños conservaron su segmentación espontánea inicial tanto en la identificación como en la transcripción. Pero además, en la entrevista de Lucio se observó particularmente cómo las consignas y la propia escritura lo fueron orientando a focalizar en las notas perceptuales. En este sentido, como considera Emilia Ferreiro (2002), la escritura provee el punto de apoyo para la reflexión y objetivación del lenguaje en unidades de análisis. El proceso de escribir ayudó a Lucio a posicionarse ante el lenguaje de un modo diferente porque le permitió exteriorizar la organización que él mismo había atribuido y luego, a partir de ello y de las nuevas consignas, reflexionar sobre la vinculación entre la música y esas unidades. Todo ello favoreció un proceso de abstracción que derivó en la selección de la nota perceptual como unidad de análisis.

Otra particularidad se observó en la entrevista a Francisco, quien dotó de entidad sonora al beat del final de cada motivo mostrando que su noción de sonido era aun menor que la nota perceptual. Su unidad de análisis no se correspondió con la unidad de acción, aún cuando él finalmente lo traduce a una acción, sino con una unidad de percepción que construyó en vinculación con la configuración psicológica de la estructura métrica. En este sentido es interesante observar que Francisco estaría construyendo su concepto de sonido y en él estarían interviniendo no sólo los sonidos articulados sino los énfasis percibidos.

En tal sentido, Blanche-Benveniste sostiene que "para una persona acostumbrada a reflexionar solamente sobre su lengua escrita, toda diversidad le resulta sospechosa, mientras que para una persona que no sabe escribir, la diversidad es la regla" (2002, 
p.28). Francisco no conoce los principios que rigen la escritura, percibió un énfasis en un determinado lugar del discurso y este énfasis también alcanzó el estatus de sonido. Si consideramos que el oyente puede contar espontáneamente las notas como unidades equivalentes, estaríamos desestimando la idea de que el oyente no percibe todas las notas iguales (por el peso tonal o métrico) y que, en tanto no conoce la escritura, no conoce sus principios de objetivación.

Como se observó en este trabajo, los niños que desconocen la notación musical no utilizan las categorías que proporciona la escritura para pensar la música, en tanto que consideran unidades de análisis diferentes a la nota que pueden resultar tanto mayores, como menores, que la nota. En el caso de Francisco, la unidad era inferior a la nota, ya que contaba como unidad un énfasis que él mismo producía sobre el sostén de una nota que ya había contado, es decir que contaba dos notas donde se escribiría una. En el caso de los otros niños, la unidad considerada inicialmente era mayor a la nota, incluyendo dos o tres notas en algunas de las unidades identificadas y graficadas. En todos los casos la diferencia entre la unidad seleccionada y la unidad que establece el sistema de notación musical surge a partir de la diversidad de componentes que entran en juego durante la audición musical. Incluso, se observó que, a pesar de la simplicidad de la escritura propuesta para la resolución de la tarea, que consistía en utilizar palitos, los niños incorporaron indicaciones, tales como separaciones o diferentes tamaños, para representar atributos de la música que, aunque no están comprendidos en las categorías de la notación musical, resultaron relevantes en el análisis por audición. 



\section{Capítulo 5: El conocimiento de la notación musical y la identificación de la nota como unidad de análisis. El caso de una niña violinista}

Como hemos visto en el Capítulo 2, numerosas investigaciones en pedagogía y psicología de la música han estudiado el desarrollo de las representaciones gráficas espontáneas realizadas por niños y adultos a partir de diferentes estímulos musicales, ya sea ritmos palmeados (Bamberger 1982; Upitis 1987), canciones populares (Davidson y Scripp, 1988, 1989, 1992) o composiciones propias (Barret 1997). En general, esos estudios han coincidido en estimar que la edad y el conocimiento musical serían factores determinantes en la selección de atributos expresados y el modo en que los mismos son organizados.

Los trabajos de Bamberger (1982) y los estudios de Davidson y Scripp $(1988,1989)$ coinciden en considerar que el desarrollo de las representaciones surge como un proceso madurativo. En la trayectoria de desarrollo planteada por los diferentes autores, los sujetos acceden a las notas perceptuales como unidades espontáneas de representación. Sin embargo, tenemos evidencia para considerar que esto no siempre ocurre o bien que, al menos, no ocurre cuando el estímulo corresponde a un fragmento de una obra musical sin texto (ya que el texto condiciona la selección de unidades de segmentación, especialmente en el español, donde la sílaba corresponde a una unidad de segmentación que es de acceso espontáneo).

En el Estudio 2 (Capítulo 4) se observó que niños de seis años sin conocimiento de la notación musical y sin desarrollo de habilidades musicales específicas, no identificaron la nota perceptual como unidad constituyente en un fragmento musical de manera espontánea. Es relevante determinar si esta capacidad se encuentra asociada a un insuficiente desarrollo en el dominio de la música estudiando desempeños de niños con habilidades musicales desarrolladas. 
Asimismo, es preciso conocer la incidencia que el conocimiento del sistema de notación musical tiene en la habilidad para atender a las notas perceptuales como unidades de análisis. Por esta razón, el objetivo de este estudio es indagar la adquisición de tal habilidad en una niña violinista de seis años de edad, con un gran desarrollo del lenguaje musical basado en una intensa práctica instrumental precoz, a partir de una serie de entrevistas realizadas durante su proceso de alfabetización y el conocimiento del sistema de notación musical.

En cada una de las entrevistas se propuso realizar diferentes tareas como cantar, contar y analizar sonidos, escribir, imaginar tocando, entre otros. Estas tareas no estaban previamente protocolizadas, sino que, de acuerdo a las estrategias utilizadas o las explicaciones dadas por la niña, se proponían nuevas consignas para intentar producir cambios en la unidad de análisis, ya sea a partir de la formulación de nuevas preguntas o la explicitación de algún aspecto no previsto. Era preciso conocer si para la niña, la nota era una unidad accesible, aunque no la hubiera utilizado desde un principio para resolver la tarea. Las diferentes intervenciones tenían la finalidad de poner en evidencia la conciencia de las notas perceptuales como unidades constitutivas del discurso musical.

\section{Metodología}

Se desarrolla aquí un estudio de caso que es abordado a partir del análisis de cinco entrevistas realizadas a una niña de seis años.

\section{Justificación del caso de estudio}

Camila tiene seis años y toca el violín desde los cuatro. Sus padres tocan viola y clarinete en la orquesta, en su casa hay ensayos y se dictan clases. Camila aprendió a tocar el violín copiando a su mamá, ha dado conciertos acompañada por piano y en grupos de cuerdas. Todas las canciones que toca en el violín las aprendió por imitación y de oído. Su mamá explicó que suelen valerse de las digitaciones o los nombres de las notas para aprender las melodías de memoria.

Por otra parte, Camila ha finalizado el preescolar en una institución que desarrolla un proyecto experimental, en el cual la ejecución instrumental forma parte de la enseñanza curricular, allí Camila aprende a tocar guitarra y flauta, también por 
imitación. En esta institución educativa, la lectoescritura no es contenido del nivel, por lo tanto Camila tampoco sabe leer y escribir el lenguaje verbal. Sólo escribe su nombre, y a veces, salteando o repitiendo letras.

Camila participó en el estudio anterior en el cual, niños de seis años debían contar sonidos en un fragmento musical (Capítulo 4). En esa oportunidad descontábamos que el nivel de acceso a la nota sería para ella, una habilidad resuelta. Sin embargo Camila mostró un desempeño similar al de niños sin conocimientos musicales específicos. Se seleccionó entonces el caso para profundizar el estudio acerca del acceso a la nota como unidad perceptual y operativa del pensamiento desde una metodología por indagación en una niña que, sin conocer el sistema de notación musical, tiene un gran desarrollo del lenguaje musical.

\section{Estímulo}

Se utilizó un fragmento inicial del 1 er Movimiento de la Sinfonía $N^{\circ} 5$ de Ludwig van Beethoven, interpretada por la Orquesta Sinfónica de Londres dirigida por Alfred Scholz. El fragmento se transcribe en la figura 4.1 (Capítulo 4).

\section{Procedimiento}

Se llevó a cabo una metodología por indagación a partir de una serie de 5 entrevistas no estructuradas realizadas durante el lapso de seis meses. La Entrevista 1 se desarrolló a partir del análisis por audición del fragmento inicial del 1er Movimiento de la Sinfonía $N^{\circ} 5$ de Beethoven. El propósito de esta entrevista era generar cambios en las unidades utilizada por la niña en el marco de un estudio anterior en el cual, al solicitarle que contara la cantidad de sonidos que tenía el mismo fragmento, había dado por respuesta "dos y dos". Se esperaba observar si la niña podía acceder a la nota perceptual como unidad de análisis, aunque no la había estimado inicialmente.

A partir de los resultados obtenidos en esa primera entrevista se diseñaron cada una de las siguientes. Asimismo, el plazo de tiempo transcurrido entre las entrevistas derivó de los saberes que la niña fue adquiriendo durante cada período, tales como el desarrollo de la escritura alfabética y finalmente el aprendizaje del sistema de notación musical. 
Las primeras tres entrevistas se realizaron en el plazo de dos meses, todas ellas en instancias previas al ingreso de Camila a la Escuela Primaria. Hasta entonces la niña sólo sabía escribir su nombre, incluso repitiendo u omitiendo letras. Mientras tanto, las melodías que tocaba en el violín las aprendía "de oído" o por imitación y no sabía leer en el pentagrama.

\section{Desarrollo y análisis de las entrevistas}

A continuación se transcriben algunos fragmentos de cada una de las entrevistas realizadas y se analizan aspectos vinculados con las unidades de análisis, los atributos implicados, la relación entre esas unidades y la escritura, entre otros.

\section{Entrevista 1:}

Inicialmente propusimos a Camila escuchar un fragmento del $1^{\mathrm{er}}$ Movimiento de la Sinfonía $N^{0} 5$ de Beethoven con la consigna de contar los sonidos y dibujarlos con palitos, la niña escuchó el fragmento y luego se desarrolló el siguiente diálogo:

\section{C: ¡Lo conozco!}

Cuenta con los dedos mientras canta el fragmento de corrido en tiempo real:

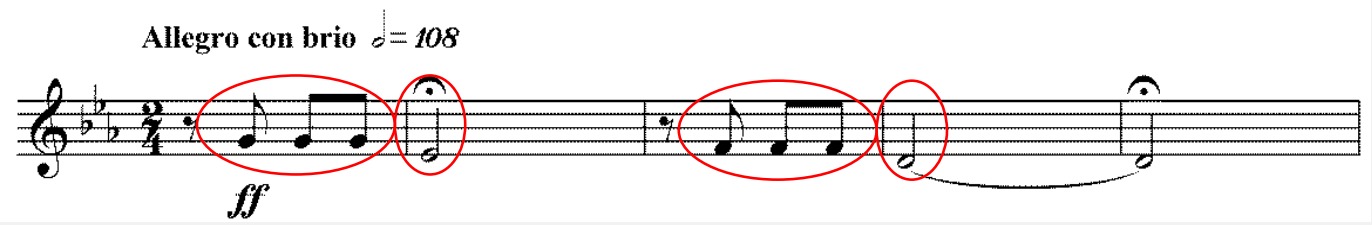

C: tiene dos y dos.
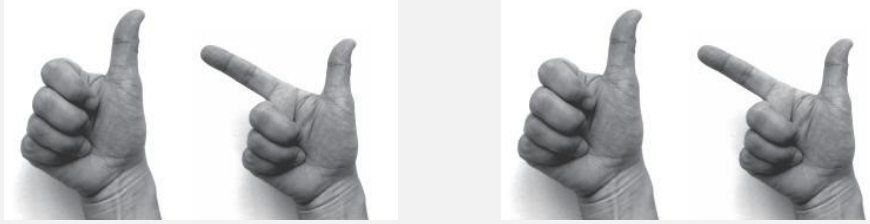
Dibuja:

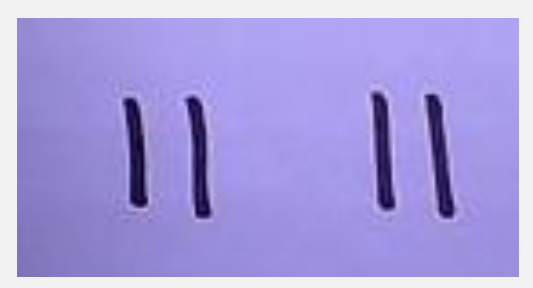

I: Te voy a pedir que cantes y señales lo que escribiste.

Canta mientras señala en su anotación:

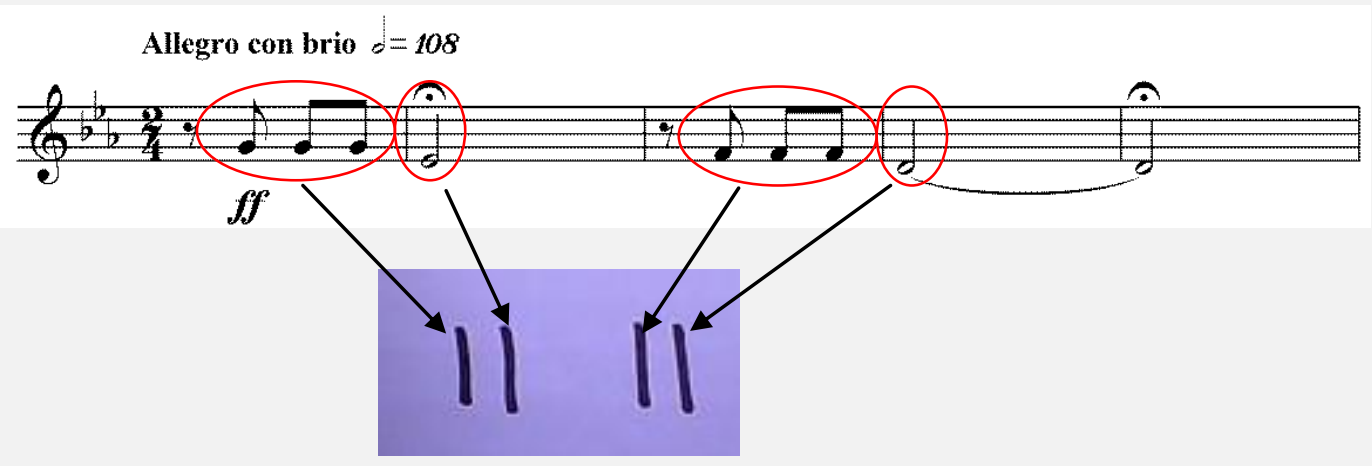

I: ¿Cuántos sonidos tocarías para ejecutar ese fragmento en el violín?

Canta en un tempo un poco más lento, mientras va contando con los dedos

C: Ocho. Cuatro y cuatro

I: ¿Y por qué habrás contado primero dos y dos y después cuatro y cuatro?

No puede explicarlo.

I: A mi parecer, utilizaste un palito para los tres primeros sonidos.

Canta todo el fragmento

C: Porque esos están más juntos

Canta “la la la" (pausa) "laaaaaa", contando nuevamente con los dedos dos.

I: ¿Los tres primeros sonidos son iguales?

C: ¡No! ¡Son distintos!. El primero más bajito, el segundo más fuerte y el último el más fuerte.

I: ¿Podrías cantarlos?

Canta los primeros cuatro sonidos mientras señala el primer palito.

I: Creo que ahí cantaste más sonidos, ¿cómo serían sólo los primeros tres?

Camila canta nuevamente los primeros cuatro sonidos. 
C: Ahí son tres.

I: ¿Y en el violín?, ¿esos tres sonidos se tocan con el mismo dedo?

C: No sé, para saberlo necesito el violín

ENTREVISTA 1: 6 años y 1 mes

Dos aspectos fueron analizados en esta entrevista: por un lado, las unidades de análisis utilizadas a partir de la audición y la imaginación de la ejecución en el violín; y por el otro, la relación entre esas unidades y la notación realizada.

\section{Las unidades de análisis}

En la primera parte de la entrevista observamos que Camila contó 4 unidades al tiempo que las agrupó. Contó: pulgar (1), índice (2), pulgar (3), índice (4), que agrupó en dos más amplias: pulgar-índice (1), pulgar-índice (2). Aun cuando no contó las unidades de corrido, cada vez que asignó un dedo estaba dando cuenta de una nueva unidad en un nivel básico.

En ese nivel básico, las cuatro unidades podrían corresponderse con diferentes criterios de agrupamiento: (i) sonidos cortos y sonidos largos, donde los sonidos cortos formarían una misma unidad por oposición al sonido largo, es decir que el cambio de duración sería el criterio percibido; (ii) unidades de tiempo o pulsos, donde el primer pulso correspondería a los sonidos 1,2 y 3 , el siguiente pulso correspondería al sonido 4, una pausa o silencio separaría esas dos unidades (recordemos que la partitura señala un calderón en la $4^{\text {ta }}$ nota), un nuevo pulso para los sonidos 5, 6 y 7, y un último pulso para el sonido 8; (iii) diferentes alturas, ya que el fragmento comprendía cuatro alturas diferentes.

Si bien el criterio utilizado podría ser alguno de los mencionados, o bien una combinación de ellos, lo cierto es que Camila no utilizó el nivel de la nota como unidad mínima de análisis. Asimismo, resulta oportuno observar que el criterio que subyace en este nivel básico, no corresponde a un principio de proximidad temporal, ya que los primeros cuatro sonidos presentan la misma separación temporal. Tampoco se corresponde con los principios descriptos en la teoría de Lerdahl y Jackendoff (1983), de acuerdo a los cuales, no habría separación entre el sonido 3 y 
4. Estos dos criterios más bien podrían incidir en el nivel de organización que estableció por encima de ese nivel básico.

Camila no contó cuatro unidades de corrido, como sería: pulgar, índice, mayor, anular (1 23 4), sino que contó: pulgar (1), índice (2), pulgar (1), índice (2), asignando el mismo dedo (pulgar) para la primera y tercera unidad, como así también para la segunda y cuarta (índice). Al volver a empezar, estaría dando cuenta del establecimiento de relaciones entre esas unidades y al mismo tiempo de la identificación de dos unidades más amplias, dos unidades que, a su vez, contienen dos unidades cada una. Camila contó unidades al tiempo que estableció relaciones entre las mismas. Este criterio de organización jerárquica quedó explícito cuando, luego de contar con los dedos, explicó: "son dos y dos".

Luego, la niña dibujó dos palitos y, más alejados, dos palitos más. Al hacerlo, organizó su notación de derecha a izquierda (recordemos que Camila sabe escribir el nombre y lo hace de izquierda a derecha). Pero no sólo representó el eje temporal en el espacio, sino que, además utilizó la separación espacial para representar una separación perceptual entre las primeras dos unidades y las dos siguientes. Si consideramos que el eje temporal está representado de izquierda a derecha y que, entre los palitos 1 y 2 hay mayor cercanía que entre los palitos 2 y 3 , podríamos suponer que la distancia entre ellos representa la distancia temporal entre esas unidades. Pero también, esa distancia podría representar la separación entre los dos objetos: si hay dos cosas, se escriben separadas. Finalmente cantó el fragmento señalando lo que escribió y quedando en evidencia que el primer y tercer palito representaba unidades mayores a la nota.

Con la consigna de contar cuántos sonidos debería tocar para poder ejecutar ese fragmento en el violín, el problema a resolver tomó una nueva dimensión. A partir de esta nueva consigna, Camila cantó la melodía y al hacerlo, por primera vez cantó en un tempo más lento, mientras contaba con los dedos. Contó de corrido ocho sonidos utilizando ocho dedos diferentes. Sin embargo dijo: "cuatro y cuatro". Es decir que, contó las unidades y nuevamente, y las agrupó. Podemos observar que Camila se vale de su experiencia musical para imaginar un correlato corporal de esa melodía y ese correlato se da al nivel de la nota. Asimismo, en términos de Bamberger, persisten los rasgos figurativos en la descripción, ya que la descripción se organiza en dos grupos. 
Cuando le preguntamos a la niña por qué había contado la primera vez dos y dos, y luego cuatro y cuatro, ella no pudo explicarlo. Esta pregunta, de todas maneras, resulta difícil de contestar ya que describir o explicitar los criterios utilizados en cada segmentación implica un ejercicio de metacognición, al que una niña de esta edad puede acceder con dificultad. Aunque no pudo explicarlo, quedó en evidencia que Camila consideró diferentes atributos para definir su unidad de segmentación. La niña pudo acceder a diferentes atributos y considerarlos como parámetros para establecer el nivel básico de su categorización de evento. Puede observarse cómo la categorización fue redefiniéndose de acuerdo con la naturaleza de la actividad realizada.

Si bien la nota perceptual no surgió espontáneamente como unidad de análisis, resultó una unidad accesible para la niña al pensar el mismo diseño melódico desde la ejecución, es decir al imaginarse tocando el fragmento en su instrumento. Camila utiliza los números de los dedos o los nombres de las notas para aprender sus melodías en el violín, por lo tanto su experiencia de ejecución tiene un correlato con la nota como unidad operativa. Esta experiencia le proporcionó la conciencia de esa unidad como unidad constitutiva del discurso y por lo tanto la niña accedió a esas unidades al pensar la melodía desde un dominio más directamente vinculado a su experiencia musical.

\section{Las unidades perceptuales y la notación}

Finalmente, y con el objeto de analizar el diseño melódico al nivel de la nota, le explicamos que, posiblemente en su notación inicial estaría utilizando el primer palito para dibujar los primeros tres sonidos tocados. Esta suposición derivó del modo en que ella misma relacionó las unidades escritas con las unidades cantadas cuando le solicitamos inicialmente que cantara señalando lo que había anotado. Aquí Camila, como dijimos antes, cantó el fragmento y agregó: "porque esos están más juntos" y luego explicó la diferencia entre esos tres sonidos: "El primero es más bajito, el segundo es más fuerte y el último es el más fuerte”. A continuación señaló el primer palito que había dibujado y cantó los primeros cuatro sonidos. Le pedimos que cantara esos primeros tres sonidos nuevamente y Camila, sin advertirlo, volvió a cantar los cuatro sonidos. 
La niña describió tres sonidos en cuanto a su sonoridad (el primero, el segundo y el último) pero al ejemplificarlo cantando no pudo aislar esa unidad. También es posible que sus descripciones: "porque esos están más juntos" o bien, "el primero es más bajito, el segundo es más fuerte y el último es el más fuerte" aludieran de un modo holístico a los cuatro sonidos y que su necesidad por explicar tres sonidos surgiera como consecuencia de nuestra consigna y no de su posibilidad de análisis.

Por lo tanto, se observa que si bien por momentos la niña parece estimar la nota perceptual como unidad de análisis, esta unidad no aparece claramente delimitada y por lo tanto no puede acceder operativamente a cada una de ellas.

\section{Entrevista 2}

A partir del conflicto advertido en el final de la Entrevista 1, donde se observó que la niña no accedía a la nota como unidad operativa ya que, al solicitarle que cantara sólo las primeras tres notas, tendía a cantar el motivo completo, se diseñó una tarea que presentaba un conflicto al nivel de la nota. Para ello se elaboró un estímulo musical grabado, similar al fragmento inicial del 1 er Movimiento de la Sinfonía $N^{\circ} 5$ de Beethoven (Estímulo 1) pero, en este caso, el diseño (Estímulo 2) comprendía una nota más por motivo (ver figura 5.2) y fue interpretado en piano.
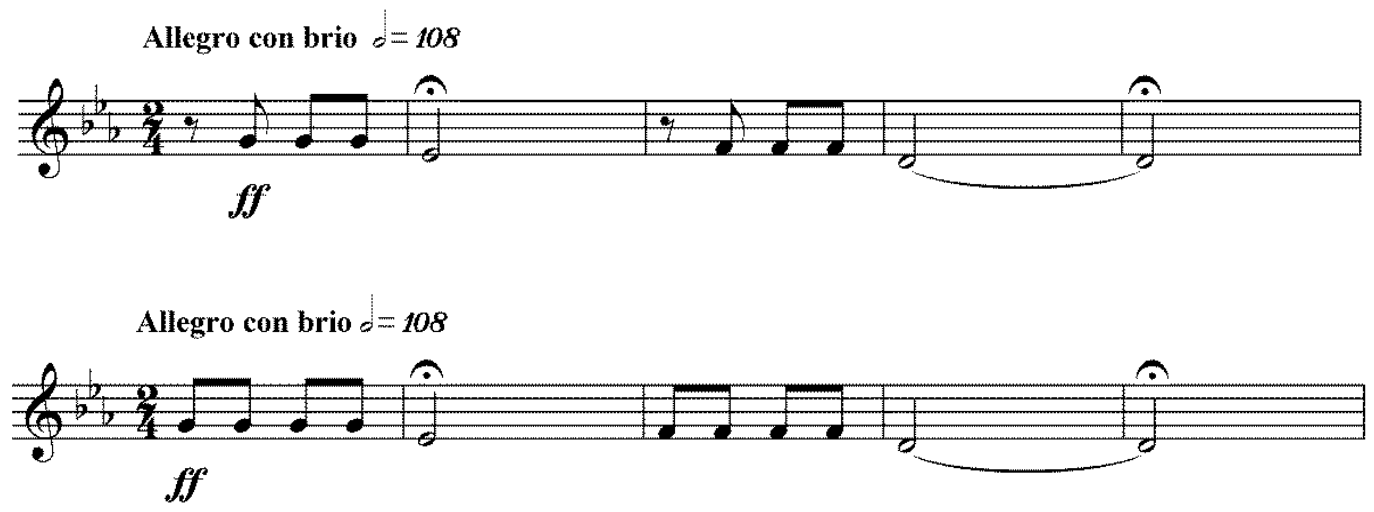

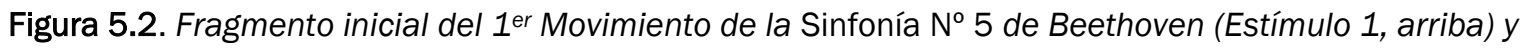
variación del mismo interpretado en piano (Estímulo 2, abajo)

En la entrevista se propuso focalizar la atención en la diferencia entre los estímulos con el fin de problematizar la nota perceptual como unidad de análisis. 
En primer lugar preguntamos a Camila si recordaba el fragmento musical que habíamos escuchado en el primer encuentro (Estímulo 1). Como la niña no lo recordaba le proporcionamos su anotación inicial para observar si esa representación le ofrecía suficiente información para poder cantar el diseño. Sin embargo esto no ocurrió. Camila recordaba haber realizado esa anotación pero la misma no le proporcionó información suficiente para poder recuperar la melodía.

Posteriormente le solicitamos a la niña escuchar una melodía grabada (Estímulo 2) con la consigna de corroborar si se trataba de la misma melodía a partir de la cual se había desarrollado la entrevista anterior. A continuación el diálogo que se desarrolló:

I: Vamos a escuchar una melodía y te voy a pedir que me digas si es la misma que escuchamos la vez pasada.

Camila escucha el Estímulo 2.

C: ¡Si, es esa! Pero la vez pasada la tocaba la orquesta, y ahora la toca el piano.

I: Bien, escuchemos entonces la de la orquesta, ¿es la misma?

Escucha el Estímulo 1.

C: Si, es la misma.

I: Fijate que no es exactamente la misma. Vamos a escuchar una vez cada una y quiero que encuentres una pequeña diferencia.

Escucha ambas melodías.

C: la del piano hace más veces y la de la orquesta hace menos.

I: ¿Cómo es eso?

No puede explicarlo.

I: Escuchemos las dos y me decís cuántas veces hace cada una.

Escucha el Estímulo 2

C: Creo que es tres.

Escucha el Estímulo 1.

C: Creo que es dos.

I: ¿Podrías cantar la del piano? 
Canta la melodía del piano (Estímulo 2)

I: ¿Y la de la orquesta?

Canta la melodía de la orquesta (Estímulo 1)

I: ¿Podrías escribirlas? ¿Cómo sería una y como sería la otra?

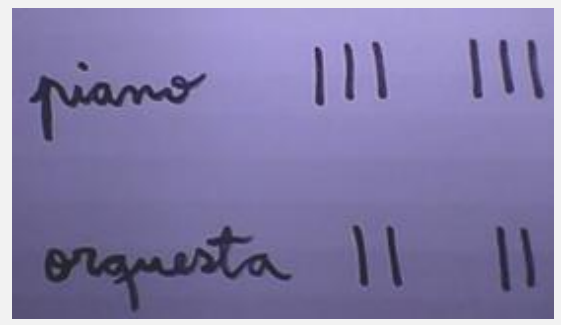

I: ¿Podrías cantar cada una siguiendo con el dedo lo que escribiste?

Sigue con el dedo la notación que hizo para el piano mientras canta la melodía de la orquesta (Estímulo 1) pero no advierte el error. Luego sigue con el dedo la anotación que hizo para la orquesta, se queda pensando, no puede cantarla.

C: No me acuerdo cómo era la de la orquesta.

Escuchamos nuevamente ambas melodías, las repite cantando. Cuando le pido que las cante señalando las anotaciones se confunde y tiende a cantar siempre la versión de la orquesta, para ambas escrituras.

ENTREVISTA 2: 6 años $Y 2$ meses

Dos aspectos fueron analizados en esta entrevista, por un lado la problematización de la literalidad de los estímulos al nivel de la nota y por el otro la vinculación entre las unidades de análisis y las unidades de la notación.

\section{Focalizando el análisis al nivel de la nota}

Cuando le propusimos a Camila escuchar y comparar ambos fragmentos la niña los identificó como "el mismo", aunque reconoció la diferencia tímbrica. Luego, cuando le pedimos que identificara similitudes o diferencias la niña explicó que la melodía del piano hacía más veces y la orquesta hacía menos veces. Es decir que, advirtió la diferencia en la cantidad de sonidos pero definió esa diferencia de un modo global, sin contar las unidades, simplemente "hace más" o "hace menos".

Luego, cuando le solicitamos que contara cuántas veces hacía cada una, la niña no utilizó los dedos para contar mientras escuchaba o mientras cantaba, tal como lo había hecho en la entrevista anterior, simplemente escuchó la melodía del piano y 
dijo "creo que es tres", escuchó la melodía de la orquesta y dijo "creo que es dos". Su modo de definir esa diferencia fue a partir de un cálculo estimado, un cotejo por aproximación. Camila advirtió que la diferencia entre ambos diseños estaba en la cantidad de veces, aunque no precisó la medida objetiva de cada una.

\section{Las unidades de análisis y la notación}

Camila escribió tantos palitos como unidades de análisis identificó: tres y tres para la melodía del piano, dos y dos para la melodía de la orquesta, a su vez cantó indistintamente una y otra. Sin embargo, cuando intentó vincular las unidades graficadas con las unidades perceptuales no consiguió hacerlo. Recordaba y cantaba con precisión cada una de las melodías pero se confundía cuando intentaba recuperarlas desde la escritura.

Por lo tanto, se advierte que las unidades escritas, no sólo no le aportaban información relevante para recomponer el diseño, sino que además, cada unidad graficada no representaba una unidad perceptual claramente delimitada.

\section{Entrevista 3}

A partir de los resultados obtenidos en la Entrevista 1, donde también se observó que imaginar la ejecución en el instrumento incidió en la selección de la unidad de análisis ya que, con la consigna de contar cuántos sonidos debía tocar para poder ejecutar ese fragmento en el violín, la niña cantó ocho sonidos; en la Entrevista 3 se propuso centrar la tarea en la ejecución y transcripción del fragmento inicial del 1 er Movimiento de la Sinfonía $N^{0} 5$ de Beethoven. Para ello se propuso a Camila tocar la melodía en el violín aprendiéndola "de oído" y luego escribirla para poder recordarla o para que alguien pudiera más tarde leerla y tocarla.

Inicialmente le preguntamos a la niña si recordaba la música de la entrevista pasada y como no la recordaba escuchamos nuevamente el fragmento y ella lo cantó. Luego, le solicitamos que "sacara de oído" la melodía en el violín y luego de algunos ensayos Camila tocó el fragmento completo. A partir de allí se desarrolló el siguiente diálogo: 
I: ¿Cómo podrías anotarla para recordarla o para que a alguien que la lee pueda tocarla?

Anota:

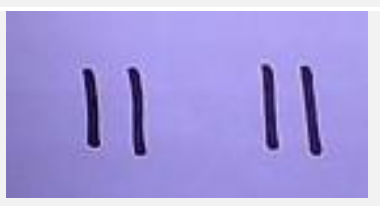

C: Porque son (cuenta con los dedos) uno, dos, tres, cuatro, hay cuatro, (canta) "ta ta ta ta", son dos cada uno, son cuatro (se enreda un poco)

I: Bueno, pero si alguien no sabe la melodía, lee lo que escribiste y puede tocar así (y toco una vez cada nota, una nota por cada palito anotado)

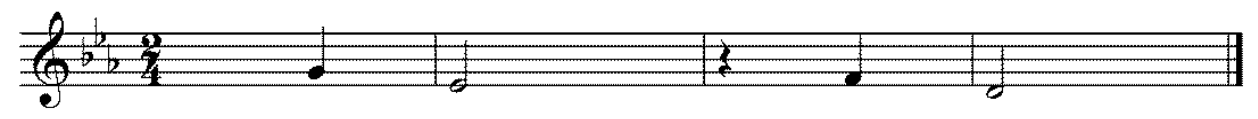

No le convence.

l: ¿Cómo podés escribirla para que alguien que lee toque la melodía tal como es?

Piensa y agrega tres palitos más en cada grupo, ahora queda:

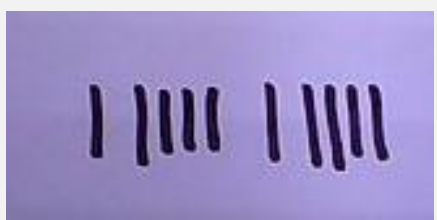

I: Explicame cómo sería

C: Puse tres palitos más en cada una porque me olvidé que hay que tocar tres veces acá (señala el sol) y tres veces acá (y señala el re).

I: Quien quiera leer lo que escribiste, ¿cómo tiene que hacer?

Toca la melodía.

I: ¿Y necesitarías decirle algo para que se dé cuenta cómo es que lo que escribiste se toca así?

C: No sé... y bueno, es más fácil que yo se la enseñe....

ENTREVISTA 3: 6 años y 3 meses

En esta entrevista se analizó particularmente la relación entre las unidades identificadas y los elementos graficados.

Camila escribió inicialmente dos y dos palitos para representar la melodía, sin embargo, cuando escuchó la ejecución, a la cual podría dar lugar su anotación (que 
comprendía sólo cuatro notas), advirtió que quedaban sonidos sin representar. Estos sonidos correspondían a las notas repetidas. Camila identificó los grupos de sonidos repetidos como faltantes, contó tres y tres, y los agregó a su anotación inicial, sin advertir que la primera vez que esos sonidos se ejecutan (el primero y el tercero) ya se encontraban representados en la anotación (ver figura 5.3).

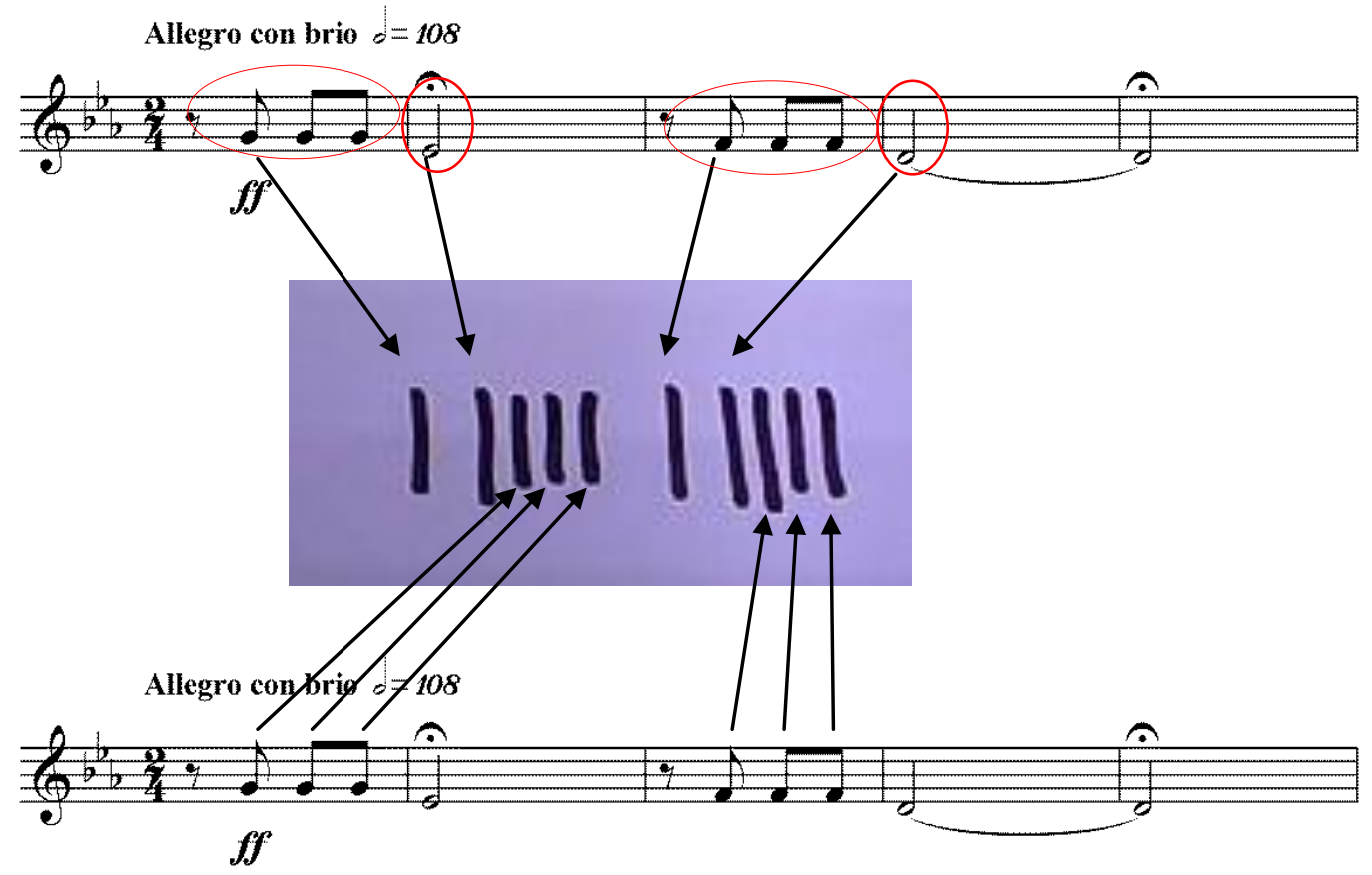

Figura 5.3: Relación entre las unidades graficadas por Camila y el ejemplo musical.

Su anotación contenía ahora cinco y cinco unidades graficadas. Pero estas unidades no se correspondían con diez sonidos, ni siquiera con diez acciones, simplemente surgían como consecuencia de incorporar unidades que respondían a diferentes criterios. Por un lado las unidades graficadas inicialmente (dos y dos) representaban unidades mayores a la nota perceptual, como se dijo antes, podrían corresponderse con diferentes criterios de agrupamiento: sonidos cortos y sonidos largos, unidades de tiempo o pulsos, diferentes alturas o una combinación de estos criterios. Pero, a su vez, las siguientes unidades que la niña incorporó a la anotación (tres y tres) se correspondían con notas perceptuales y surgían como consecuencia de la representación de acciones: "porque hay que tocar tres veces acá", aclara la niña. Así, su anotación final combinó distintos criterios de representación que dieron como resultado una sucesión de diferente tipo de unidades (grupos y notas). 


\section{Entrevista 4}

En la Entrevista 4 se propuso la resolución de la misma tarea pero transcurridos dos meses de realizada la Entrevista 3. En ese lapso Camila había comenzado la escuela primaria y había desarrollado habilidades de lectura y escritura, por lo tanto había desarrollado cierta habilidad para segmentar el continuo temporal en unidades de escritura al menos en el dominio del lenguaje. Así, cuando le preguntamos a la niña si estaba aprendiendo a escribir, contestó “me están enseñando las letras, puedo escribir mi nombre, el de mi hermano, el de mi mamá y el de mi papá”, entonces le preguntamos si podía escribir otro nombre, por ejemplo Irma y ella contestó "si, sé, empieza con la 'i', después la 'r', la 'm y la 'a'”.

Antes de comenzar la entrevista le preguntamos si recordaba la música que habíamos escuchado la última vez y que ella había tocado en el violín. La niña no la recordaba, entonces escuchó el fragmento, lo cantó, describió los instrumentos que formaban parte de la ejecución, y luego se desarrolló el siguiente diálogo:

\section{I: ¿Cuántos sonidos tiene?}

Cuenta con los dedos mientras canta el fragmento de corrido en tiempo real:

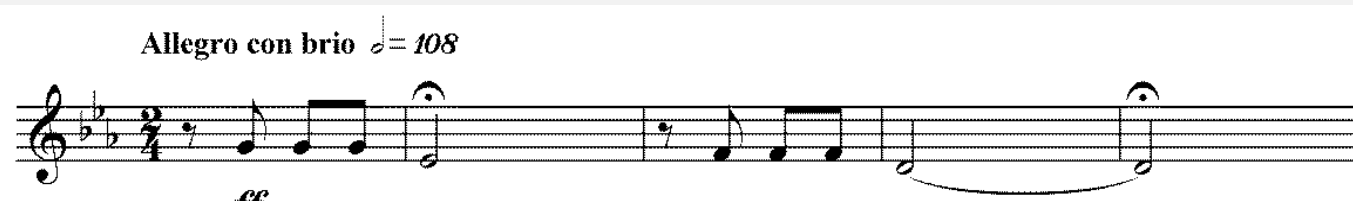

$$
f f
$$
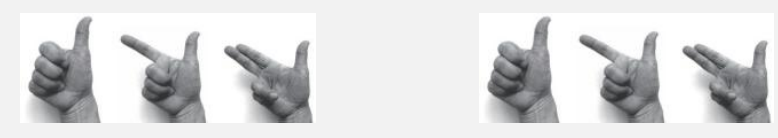

C: ¿Seis? Serian tres y tres.

I: ¿Lo escribís?

Dibuja:

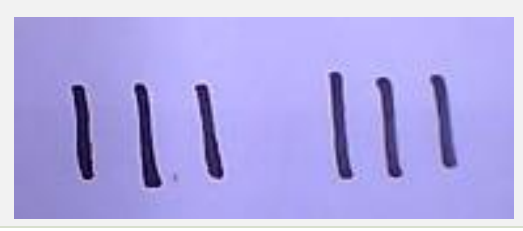


I: ¿Y qué los separa? ¿Por qué son tres y tres?

C: Es porque vuelve a empezar.

I: ¿Hace dos veces lo mismo?

C: Hace lo mismo pero me parece que con otras notas.

ENTREVISTA 4: 6 años y 5 meses

Camila contó tres unidades en cada motivo. Cuando lo hizo advirtió una clara correspondencia entre el conteo de la primera y tercera unidad de cada motivo y la nota de comienzo y final de cada uno, no así entre la segunda unidad que contó y las notas intermedias (segunda y tercera) de cada motivo (ver figura 5.4) donde el conteo no se correspondía directamente con ninguna de las dos notas intermedias.

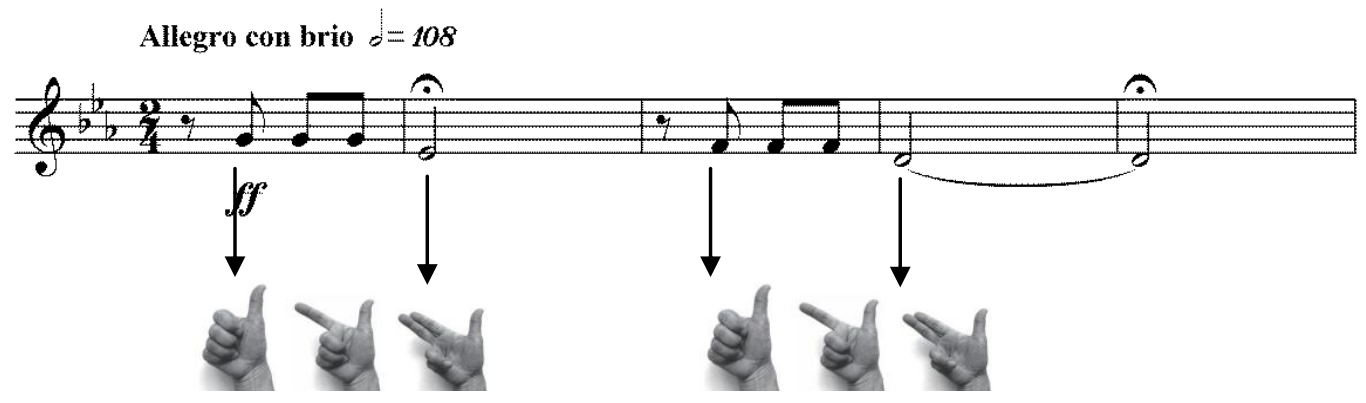

Figura 5.4: Correlación entre las unidades contadas por Camila y el ejemplo musical.

Esta entrevista se realizó luego de dos meses de la entrevista anterior con el fin de observar si algunos factores como: el acceso de la niña a la etapa alfabética en el desarrollo de la escritura, la práctica musical en su instrumento o bien la propia maduración durante este lapso de tiempo, tendría alguna incidencia en la selección de las unidades de análisis. Sin embargo, como podemos observar persiste la organización de las unidades en dos grupos, y la nota perceptual no surge como unidad de análisis y/o de escritura.

En esta entrevista Camila contó más unidades, contó seis, pero algunas de ellas parecerían no tendrían un correlato directo con las notas perceptuales, como es el caso de las notas 2 y 3,6 y 7 y las unidades que contó como dos en cada motivo. 


\section{Entrevista 5}

Finalmente la Entrevista 5 se realizó luego de dos meses de realizada la Entrevista 4. Si bien el desarrollo de la escritura del lenguaje se había consolidado para entonces, lo que marcó una clara diferencia entre las entrevistas anteriores y esta última fueron los progresos de Camila en la adquisición de la notación musical. Su mamá contó que Camila estaba aprendiendo a leer en el pentagrama y que algunas piezas las aprendía a partir de la lectura. Cuando preguntamos a la niña si sabía leer música en el pentagrama, ella dijo: "si, mi mamá me enseñó, el pentagrama me ayuda si me pierdo, pero si me dan una canción nueva la saco más fácil de oído".

La entrevista consistió en contar y escribir los sonidos del fragmento inicial del 1 er Movimiento de la Sinfonía $N^{\circ} 5$ de Beethoven y luego elegir, entre varias transcripciones en el pentagrama la más adecuada. Para ello se presentaron tres transcripciones diferentes, la primera (A) con una nota agregada en cada motivo, la segunda (B) con una nota omitida en cada motivo y la tercera (C) con la cantidad de notas adecuada (ver figura 5.5).
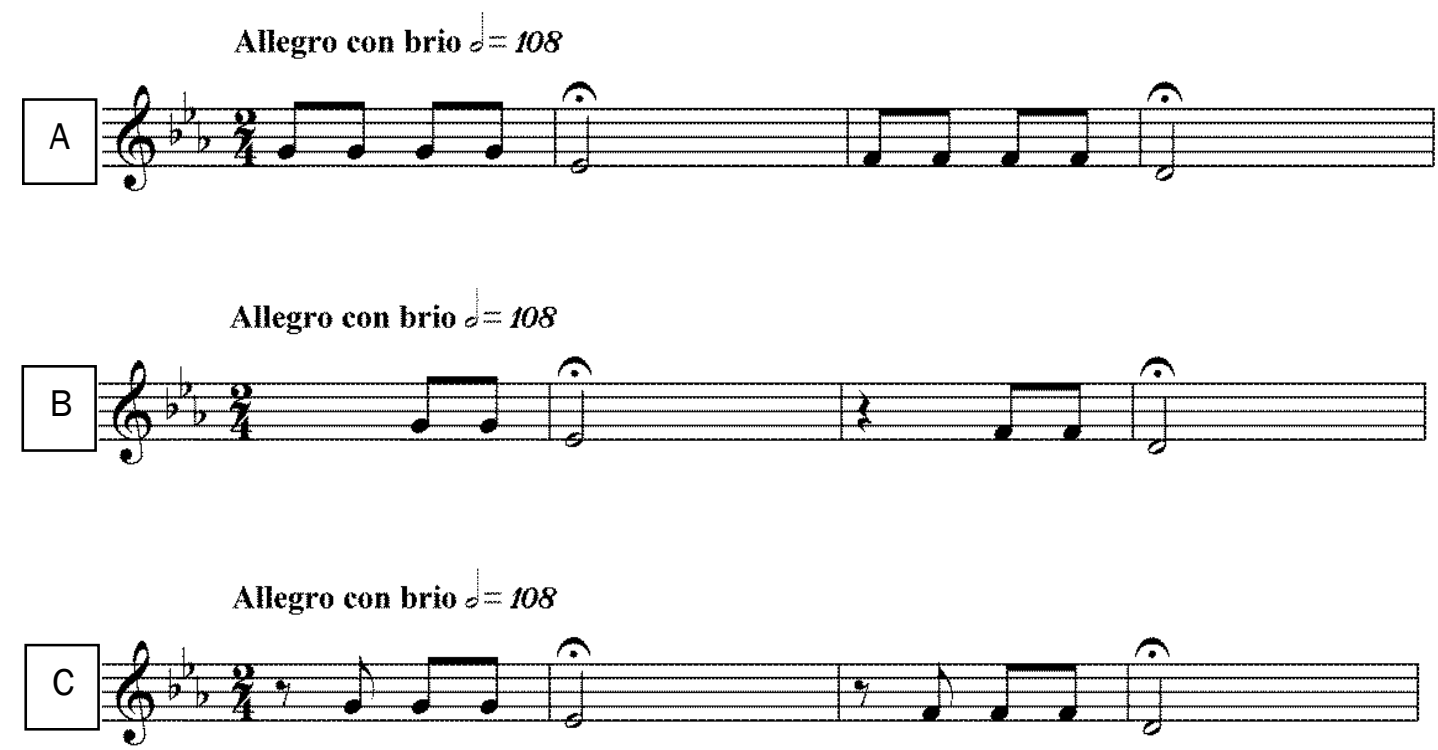

Figura 5.5: Diferentes transcripciones del fragmento inicial del 1er Movimiento de la Sinfonía $N^{\circ} 5$ de Beethoven: $A$ con agregado de notas, $B$ con omisión de notas y $C$ con la cantidad correcta de notas. 
Al iniciar la entrevista le preguntamos a Camila si recordaba la música que habíamos escuchado en los encuentros anteriores pero la niña no la recordaba. Le propusimos escuchar la melodía con la consigna de contar los sonidos y dibujarlos con palitos. A partir de allí se desarrolló el siguiente diálogo:

Camila escucha el fragmento y sin contar con los dedos ni cantar dice:

C: ¿Seis?

I: ¿Los escribís?

Camila va cantando mientras escribe, canta en un tempo lento, todos los sonidos con la misma duración, va escribiendo un palito por cada sonido (hace esto por primera vez en todas las entrevistas), escribe ocho palitos a la misma distancia.

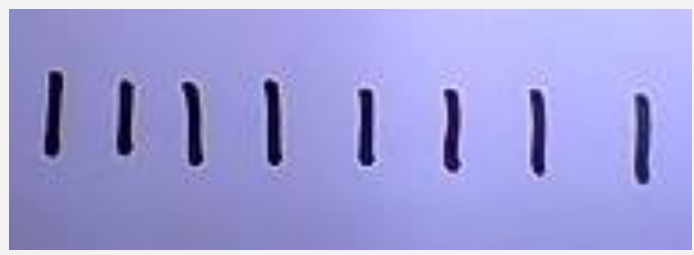

Camila cuenta los palitos escritos y dice:

C: Tiene ocho.

I: ¿Son ocho seguidos?

C: ¡No!, son cuatro y cuatro (y escribe una separación)

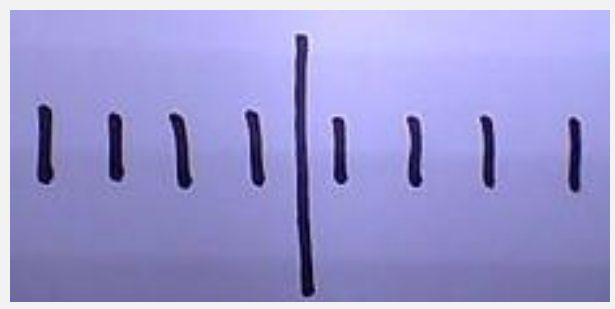

I: ¿Qué sería esa raya?

C: Es porque son dos compases.

Canta el primer motivo y dice:

C: Hasta ahí es un compás.

Canta el segundo motivo y dice:

C: Y ese es el otro compás. 
I: Tengo varias partituras y necesito que me digas si alguna de ellas corresponde a la melodía que escuchamos. ¿Será ésta? (Transcripción A).

Camila observa la transcripción, canta señalando nota por nota, cuando llega al segundo compás dice:

C: En ésta sobran notas, no es.

I: ¿Y ésta? (Transcripción B)

Camila observa la transcripción, canta señalando nota por nota, cuando llega a la blanca dice:

C: En ésta faltan notas.

I: ¿Y ésta? (Transcripción C)

Camila observa la transcripción, canta señalando nota por nota, cuando termina dice:

C: Acá las notas están bien, pero esta primera (señalando la primera corchea) está suelta y tendría que estar unida a las otras porque van las 3 seguidas.

Unimos con una fibra las tres primeras corcheas y dice:

C: Ahora sí, ahí está.

Señala con el dedo nota por nota mientras va cantando.

C: Ahora está bien.

ENTREVISTA 5: 6 años $y$ meses

Dos aspectos fueron analizados en esta entrevista, por un lado las unidades de análisis utilizadas y por el otro, la relación entre la notación musical y el diseño melódico.

\section{Las unidades de análisis}

Camila escuchó el diseño y contó inicialmente seis unidades. Sin embargo, este conteo inicial, lo hizo sin utilizar los dedos como mediadores y sin cantar el fragmento. La niña dio una respuesta inicial que parecería corresponderse con un conteo por aproximación, antes que con la selección de una unidad de análisis diferente.

Cuando solicitamos a la niña que escribiera los sonidos implicados, la niña cantó nuevamente el fragmento y aplicó una estrategia diferente a las utilizadas hasta 
entonces: cantó el diseño segmentándolo en unidades al tiempo que las escribía, graficó una unidad por cada unidad cantada, contó los elementos escritos y finalmente afirmó que eran ocho sonidos. Por primera vez, la correspon dencia entre las unidades escritas y las unidades de análisis, a partir de la audición, fue al nivel de la nota. Pero además, esta unidad apareció como único nivel de análisis: la niña ya no organizó las unidades jerárquicamente como lo había hecho hasta entonces (dos y dos o tres y tres), ahora eran ocho unidades igualables. El agrupamiento en cuatro y cuatro surgió a partir de la intervención del investigador antes que como consecuencia del conteo.

Es interesante observar que, para traducir tantas unidades como notas perceptuales tenía el fragmento, Camila cantó todos los sonidos con la misma duración, es decir, los igualó en condiciones de ejecución, al menos rítmicamente, lo cual se tradujo gráficamente también porque por primera vez escribió todos los sonidos a igual distancia. Ya no consideró la segmentación en dos motivos, tampoco los beat, las alturas o las duraciones diferentes, nada de ello incidió en la selección y en el criterio de representación de sus unidades. Ahora Camila conoce la notación musical y ésta le impone sus criterios de análisis, por lo tanto se trata de ocho unidades iguales.

A partir del conocimiento de la notación musical, Camila ha definido y delimitado la unidad de notación, ahora el correlato entre la unidad de análisis y la unidad de escritura se da al nivel de la nota. Conoce esta unidad y sus principios de objetivación, es por ello que desestima otros atributos y focaliza en la nota como unidad de análisis. Ahora canta el fragmento y representa a todas las unidades por igual.

\section{Relacionando la notación con el estímulo}

Camila señaló cada una de las nota en las diferentes partituras mientras cantaba el fragmento advirtiendo rápidamente la diferencia entre las transcripciones y el estímulo. La niña vinculó las unidades escritas con las unidades perceptuales, y ese correlato también se dio al nivel de la nota.

Finalmente observamos la persistencia de ciertos aspectos figurativos, especialmente cuando la niña separa las unidades graficadas en dos compases que refieren a los dos motivos, o bien cuando explica que, en la partitura, los primeros sonidos deberían ir unidos porque las tres corcheas van seguidas. En este sentido, como 
explica Bamberger (1991), es habitual que los lectores principiantes esperen encontrar los agrupamientos representados, de alguna manera, en la notación musical. Sin embargo, la escritura rítmica, las barras de compás, las armaduras de clave, es decir, la ortografía de la escritura musical, tiene principios diferentes que Camila irá configurando.

\section{Discusión}

En este trabajo se propuso indagar el uso de la nota como unidad operativa en el análisis de un fragmento musical por parte de una niña con un importante desarrollo de habilidades de ejecución instrumental durante el proceso de adquisición de la escritura del lenguaje y el aprendizaje de la notación musical. Se aplicó una metodología de entrevistas por indagación con el fin de observar los criterios subyacentes en la selección de unidades de análisis, las diferentes respuestas y estrategias utilizadas para resolver las tareas a partir de las intervenciones del investigador y el rol de la adquisición de la notación musical en la selección de unidades.

En las Entrevistas 1 a 4, la nota no surgió espontáneamente como unidad de análisis a partir de la audición. Si bien en la Entrevista 1, cuando le propusimos imaginar la ejecución del fragmento en el violín, la niña contó ocho unidades, luego no pudo aislar cantando las primeras tres, ni utilizar esas unidades para definir objetivamente la diferencia entre los estímulos presentados en la Entrevista 2. Por lo tanto, el acceso a las notas perceptuales parecería no relacionarse, al menos de modo directo, con las unidades o acciones implicadas en la ejecución.

Inicialmente Camila identificó cuatro unidades que contó como dos y dos. En el nivel superior, las dos unidades se correspondían con los motivos que presentaba el fragmento, mientras que el criterio subyacente para las unidades de nivel básico no apareció explícitamente en la descripción, bien podía relacionarse con atributos como la proximidad de alturas, similitud de duraciones o unidades de pulso. Aunque no sabemos cuál de esos criterios, incluso podría ser más de uno, estaría incidiendo en la selección de tales unidades, lo cierto es que las unidades contadas presentaban dimensiones diferentes: la primera y tercera comprendían tres notas, mientras que la segunda y cuarta coincidían con la nota. Es decir que, las unidades básicas de 
análisis fueron, indistintamente, notas y grupos. Este fue el primer aspecto que se problematizó en el desarrollo de las Entrevistas 1 y 2.

Cuando le explicamos a Camila, en el final de la Entrevista 1, que el primer palito podía corresponderse con tres sonidos, la niña hizo una descripción de las unidades en un nivel inferior al que había graficado: “El primero más bajito, el segundo más fuerte y el último el más fuerte" (Entrevista 1) pero luego no pudo cantar aislando sólo los primeros tres sonidos. Algo similar ocurrió en la Entrevista 2, cuando le solicitamos que explicara la diferencia entre los dos estímulos y la niña sólo pudo explicar la diferencia contando unidades de manera estimada.

Se observó que, por momentos, la niña estimó la nota perceptual, identificó que había más o menos notas, pero esta unidad no apareció claramente delimitada, por lo tanto no pudo acceder operativamente a cada una de ellas. Es interesante observar que este conflicto también se dio en uno de los niños del Estudio 2 (Capítulo 4). En ese estudio Santiago graficó cuatro unidades, luego explicó que cada palito se correspondía con muchos sonidos, pero no pudo acceder a cada uno de ellos para contarlos.

Para explicar la diferencia entre los estímulos de la Entrevista 2, Camila cambió la estrategia inicial al contar, no lo hizo como en la Entrevista 1, cantando al tiempo que utilizaba los dedos como mediadores, sino que, en la Entrevista 2, su respuesta fue inmediata luego de escuchar el ejemplo, sin cantarlo, dijo: "la del piano hace más veces y la de la orquesta hace menos" y al pedirle que contara cuántas veces hacía cada una, escuchó cada estímulo y agregó "creo que tres", "creo que dos" (Entrevista 2). Es decir, contó por aproximación.

En la Entrevista 3 se generó un nuevo conflicto en la unidad, esta vez en la relación entre las unidades de análisis y las unidades de escritura. En la intervención le explicamos a Camila que algunas unidades quedaban sin representar y al tocar el fragmento tal como ella lo había registrado, quedó en evidencia que había unidades faltantes. Aquí Camila advirtió que las notas repetidas no estaban representadas y las agregó a su grafía. Identificó como faltantes los grupos de tres notas repetidas, y sin modificar su escritura anterior, agregó a la misma tres elementos en cada motivo. La representación gráfica dejó en evidencia la superposición de criterios, nuevamente 
grupos y unidades. Ahora estaban todos los sonidos representados, pero la superposición de criterios daba como resultado más unidades que sonidos.

A partir de la respuesta dada en la Entrevista 3, donde la niña accedió a cada una de las notas que conformaban el fragmento, a pesar de la convivencia de diferentes criterios en su grafía, transcurridos dos meses, se repitió la actividad (Entrevista 4) para cotejar si la nota, como unidad de análisis, alcanzaba su campo de aplicación. Sin embargo, aun cuando la niña, hasta aquí, había accedido a estas unidades en diferentes oportunidades durante el desarrollo de las entrevistas anteriores, en la Entrevista 4, nuevamente, no la utilizó y contó "tres y tres" unidades.

El cambio en la selección de la unidad se produjo luego de que la niña adquiriera conocimiento acerca del sistema de notación musical, especialmente vinculado a su práctica instrumental. En la Entrevista 5 la niña ya había aprendido a leer en el pentagrama y a partir de esto se evidenció un cambio concluyente en la resolución de la tarea, tanto en la selección de la unidad de análisis por audición como en la estrategia para contar esas unidades.

En la Entrevista 5 le propusimos contar y escribir los sonidos que comprendía el fragmento y entonces la nota se impuso como unidad de análisis. La estrategia de resolución también tuvo un cambio sustancial, ahora la niña cantó el diseño segmentándolo en unidades iguales, es decir quitando el ritmo, al tiempo que las escribía. Graficó una unidad por cada unidad cantada, contó los elementos escritos y determinó que eran ocho sonidos. El conocimiento de la escritura la condujo a realizar segmentaciones que no había considerado hasta entonces. Además, la nota se impuso como único nivel de análisis: la niña ya no organizó las unidades jerárquicamente como lo había hecho hasta entonces (dos y dos o tres y tres), ahora eran ocho unidades igualables.

En la resolución de la tarea, se observó que la escritura cumplió una función diferente a la que había tenido en las entrevistas anteriores. Ahora, la escritura operó como mediador para pensar y resolver el problema, tal como ocurría antes con los dedos. Además, Camila estableció una relación de reciprocidad entre las unidades graficadas y las unidades perceptuales, la escritura no sólo le proporciona un medio para registrar las unidades sino que, además, ese medio le devuelve información sobre la música, la cantidad de unidades surge como consecuencia de contar las 
unidades en la representación gráfica. La escritura le garantiza el conteo de unidades porque cada uno de los elementos graficados guarda una relación con una unidad perceptual.

Operar con las notas como unidades de análisis de un modo flexible, aislarlas, compararlas, resulta ser una habilidad cognitiva particular. Como sostienen los estudios en psicolinguística (Scholes y Willis 1991; Olson 1994; Blanche Benveniste 2002), este tipo de habilidades se desarrollan con la lectoescritura. Como hemos visto en el análisis musical por audición, también el acceso a la nota como unidad operativa surge como consecuencia del aprendizaje del sistema de notación musical.

Durante el desarrollo de las primeras entrevistas Camila no conocía la notación musical, y entonces ¿Cuáles unidades debía escribir para que alguien pudiera recordar el fragmento? ¿Sus acciones? ¿Los agrupamientos? ¿Los beats? ¿Las alturas diferentes? Los criterios se entremezclaban. Hasta entonces, y como consecuencia de su conocimiento de la escritura de la lengua, lo único certero era la direccionalidad, los palitos iban de izquierda a derecha. Todo lo demás era la resultante de diferentes tentativas. Sin embargo, en la última entrevista la unidad de notación apareció claramente delimitada, el fragmento fue segmentado en notas perceptuales, estas unidades fueron igualadas en la ejecución del fragmento, cada una fue representada con una unidad de escritura y la resultante dio ocho palitos equidistantes, una representación similar a la representación M1 planteada por Bamberger (ver Capítulo 2) pero no como una representación espontánea que surge como consecuencia de un proceso madurativo, sino como la consecuencia de aplicar un principio teórico derivado del conocimiento del sistema de notación musical. 


\section{Capítulo 6: Conclusiones}

La nota es la unidad mínima de escritura musical y ha sido considerada como una categoría natural a la cual se accede de modo espontáneo. No obstante, esta tesis se propuso analizar la realidad perceptual de la nota como unidad operativa del pensamiento musical estudiando las unidades utilizadas por sujetos sin conocimiento de la notación musical en diferentes tareas que demandaran la determinación de unidades mínimas del discurso musical.

Para contextualizar el problema, en el Capítulo 1, se presentaron argumentaciones teóricas derivadas de la lingüística contemporánea, especialmente las planteadas por Claire Blanche-Benveniste y Marie-José Béguelin quienes asumen que las unidades como palabra, oración o grafema no presentan un problema de delimitación desde la escritura, pero que, su definición y delimitación desde la oralidad implica procesos cognitivos complejos que devienen con el desarrollo de la alfabetización. Desde esta perspectiva, se considera que las unidades de escritura mencionadas no guardan un correlato directo con las unidades perceptuales, y por lo tanto no se accede a ellas de modo espontáneo o como consecuencia de un proceso de maduración. Por el contrario, la habilidad para acceder a las unidades de segmentación resulta altamente dependiente del nivel de conceptualización del sistema de escritura y de sus componentes (Vernon y Ferreiro 1999).

La pedagogía y la tradición cognitivo-estructuralista de la psicología de la música, tal como se vio en el Capítulo 2, han considerado a los signos de escritura (y otros conceptos teóricos como el acorde o el intervalo) como unidades altamente compatibles con las propiedades y relaciones inherentes a la estructura musical, indagando los problemas vinculados a la percepción musical en términos de esas mismas categorías. Es por ello que, las investigaciones que abordaron el desarrollo de la notación musical a través del análisis de las grafías espontáneas, no han problematizado el acceso a la nota perceptual como unidad de análisis. Los estímulos utilizados, ritmos palmeados o fragmentos melódicos con texto, no permitieron poner 
en relieve este problema porque presentaban facilitadores para abordar la unidad: Ia explicitación de las unidades de acción en el ritmo y la separación en las sílabas del texto en el fragmento melódico. Así es que, en el contexto de esas investigaciones, las grafías realizadas por niños de 5 y 6 años, sin conocimiento del sistema de notación musical, mostraron coincidencia entre la cantidad de unidades graficadas y la cantidad de notas comprendidas en los estímulos musicales utilizados.

Asimismo, la pedagogía musical también sustentó sus prácticas y definió los contenidos iniciales de estudio bajo estas consideraciones. Un ejemplo de ello son las grafías analógicas que se utilizan frecuentemente para transcribir fragmentos musicales. Generalmente, en estas grafías la unidad de representación es la nota, dando por supuesto que el oyente accede a esa unidad de un modo espontáneo y que tiende a hacer foco en las relaciones (de altura, de duración, de sonoridad) que se establecen sobre ese nivel de análisis.

Ahora bien, si tal como sostienen los lingüistas, el conocimiento de la escritura impone restricciones en el modo en que percibimos y organizamos el lenguaje oral, resulta entonces ingenuo concebir que en el desarrollo de la notación musical los sujetos configuren un correlato perceptual de las unidades de escritura de modo espontáneo. Además, considerar que los atributos de la música que son representados en la notación, ya sea las notas o la métrica, son de acceso directo implica suponer que los principios de organización de la escritura tienen un correlato con la experiencia de audición, y que en tal sentido, la notación musical representa el modo en que percibimos la música. Estas consideraciones muestran puntos de encuentro con la perspectiva fonocéntrica del lenguaje (ver Capítulo 1), según la cual se considera que el conocimiento de la estructura de la lengua es anterior al hecho de representarla, en tanto que la evolución de la escritura consiste en encontrar los medios para traducir esa estructura en formas de escritura sin ambigüedades. Desde esta mirada, las unidades de la percepción, en nuestro caso las notas perceptuales, son anteriores al hecho de representarlas y por ello están en la conciencia del oyente aun cuando éste no tenga conocimiento del sistema de notación musical. En ese contexto la escritura simplemente da entidad a esos perceptos.

En el ámbito del lenguaje, la perspectiva fonocéntrica ha sido superada por una perspectiva autonomista que ha valorado la escritura como un medio lingüístico por derecho propio, que ejerce efectos decisivos en los procesos cognitivos vinculados 
con el habla, entendiendo que es a través de la escritura que el habla se convierte en objeto de pensamiento y análisis. Al respecto, David Olson (1994) explica que son los sistemas de escritura los que proporcionan los conceptos y las categorías para pensar el lenguaje oral y no a la inversa, ya que "la conciencia de la estructura lingüística es un producto del sistema de escritura, no una condición previa para su desarrollo" (1994, p.92). Asimismo, los estudios sobre el proceso de desarrollo de la escritura (Ferreiro 1982, 2000a, 2000b) indican que los sujetos no acceden espontáneamente a las unidades mínimas de escritura y que, para que se desarrolle la conciencia de tales unidades es necesaria una intervención la cual, generalmente, suele producirse en el inicio de la escuela primaria.

Entonces, a partir de los estudios empíricos que conformaron la tesis y a la luz de los resultados obtenidos, nos proponemos dar respuesta a los siguientes interrogantes: La nota como unidad de análisis ¿surge de modo espontáneo? ¿Es el conocimiento de la notación musical la condición de posibilidad de la conciencia de tales unidades? ¿Es necesaria una intervención para acceder a las notas perceptuales, como unidades básicas de análisis? Intentaremos dar respuesta a cada uno de ellos.

\section{La nota como unidad de análisis, ¿surge de modo espontáneo?}

En los estudios realizados con niños y utilizando un fragmento de una pieza orquestal, se observó que la nota perceptual no surgió como unidad de análisis de modo espontáneo. Como se vio en el Estudio 2 (Capítulos 4) y en el Estudio 3 (Capítulo 5), ninguno de los niños contó inicialmente 8 unidades, que correspondía al número de notas de del fragmento. A partir de la consigna dada, cada niño definió el propio alcance de la palabra "sonido", que pretendía sintetizar la idea de nota perceptual en la consigna dada y estableció sus criterios para contar. Las respuestas fueron variadas durante el desarrollo de las entrevistas, en algunos casos, el criterio fue cambiando y la unidad redefiniéndose.

De acuerdo con el criterio utilizado, la cantidad de sonidos resultó invariablemente diferente de la esperada. La diferencia se dio tanto por defecto como por exceso. Por ejemplo, en el Estudio 2 se observó que mientras algunos niños contaron "dos y dos" o "tres y tres", uno de ellos contó "cinco y cinco" como consecuencia de estimar también los énfasis que él mismo producía mientras cantaba el diseño. Por lo tanto, la unidad identificada por el oyente podría resultar tanto mayor como menor a la nota 
perceptual, lo cual conduce a estimar la dimensión de la nota como una propiedad convencionalizada en lugar de configurada a partir de su realidad perceptual.

En estos estudios también se observó en los niños la tendencia a organizar jerárquicamente los sonidos contados. Esta organización se evidenció tanto en las descripciones, por ejemplo: "son dos y dos", como también en las representaciones gráficas al dibujar dos sonidos arriba y dos más abajo. A partir de ello, se conjeturó que los sujetos estarían atendiendo conjuntamente a diferentes dimensiones del discurso. En el nivel superior las unidades mostraron correspondencia con los motivos del estímulo tal como lo predicen las teorías relativas al agrupamiento y la forma musical; mientras que, en el nivel básico, los sujetos definieron unidades que podían explicarse por diferentes criterios de segregación como la proximidad de alturas, la similitud de duraciones, las unidades de pulsos o bien el énfasis en la propia ejecución. Cada uno de estos criterios dio como resultado diferente cantidad de unidades (dos y dos, tres y tres, cuatro y cuatro, cinco y cinco). A su vez, se observó variabilidad en la dimensión de las unidades intersujeto ya que, para un mismo sujeto, una unidad podía corresponderse indistintamente con una nota, un grupo de notas (supra-nota) o bien una unidad inferior a la nota (sub-nota). Por ejemplo, uno de los niños del Estudio 2 (Capítulo 4) contó unidades que comprendían notas y sub-notas, mientras que otro sujeto en el mismo estudio contó unidades que correspondían a notas y supra-notas. Por lo tanto, se observó una gran variabilidad en la dimensión de la unidad de análisis.

A diferencia de los resultados reportados por Bamberguer, y Davidson y Scripp (Capítulo 2) que observaron que a partir de la edad de 5 años los niños tendían a representar gráficamente tantos elementos como eventos presentan los ejemplos, se observó que cuando se trata de un ejemplo musical real, los eventos, en tanto notas perceptuales, no aparecen claramente delimitados. En cambio, surgen otras unidades, especialmente aquellas relacionadas con el sentido musical tales como los agrupamientos que corresponden a los dos motivos o bien las unidades que se vinculan con atributos como la altura o la duración.

La delimitación de la nota, como unidad de acción tampoco parece encontrar un correlato en la percepción de modo directo. En tal sentido, la niña del Estudio 3 (Capítulo 5), que había utilizado en sus prácticas instrumentales los nombres de las notas o las digitaciones para aprender a tocar sus melodías, contó 8 unidades 
cuando pensó en la cantidad de sonidos que estarían implicados en su propia ejecución del fragmento, sin embargo luego no pudo acceder a ellos desde el análisis por audición y tampoco cantar aislando cada uno de ellos. Si bien la niña, utilizaba estas unidades en sus prácticas de ejecución, este conocimiento no fue transferible, de manera directa, al análisis por audición.

Por todo ello, proponemos que la nota perceptual no resulta una unidad de acceso espontáneo. Los sujetos tienden a configurar unidades diferentes a las notas perceptuales de acuerdo a los rasgos que estiman y los criterios que asumen.

\section{¿Es el conocimiento de la notación musical condición de posibilidad para la conciencia de tales unidades?}

Los resultados de los estudios reportados aquí permiten dar una respuesta afirmativa a este interrogante. En este sentido, el Estudio 1 (Capítulo 3) realizado en adultos mostró desempeños más ajustados, al contar las notas perceptuales en fragmentos melódicos memorizados, por parte de los sujetos que habían desarrollado habilidades musicales a partir de la lectura del sistema de notación musical, respecto de quienes habían desarrollado prácticas a partir de la audición o utilizando otros sistemas de escritura como las tablaturas o los cifrados.

Es interesante observar las similitudes que se plantean entre el Estudio 1 (Capítulo 3) y el estudio realizado por Read y sus colaboradores (ver Capítulo 1). Ambos estudios propusieron una tarea que demandaba a los sujetos acceder a las unidades mínimas de escritura desde un discurso oral. Mientras que, en el Estudio 1 los sujetos debían contar las notas perceptuales a partir de diseños melódicos previamente memorizados, en el estudio desarrollado por Read y sus colaboradores, los sujetos debían repetir una emisión eliminando o agregando un segmento inicial (un fonema). Particularmente, ambos estudios confrontaron los desempeños de dos grupos con características similares: el primer estudio, entre sujetos quienes habían desarrollado habilidades musicales a partir del sistema de notación musical y quienes habían utilizando cifrados y tablaturas; el segundo estudio, entre sujetos que utilizaban la escritura tradicional logográfica y otros que, además manejaban el sistema pinyin (que utiliza el alfabeto latino). Es decir, en ambos estudios todos los sujetos habían desarrollado habilidades para leer y escribir pero a utilizando diferentes sistemas de 
escritura, que no necesariamente implicaban la utilización de la unidad mínima que demandaba la resolución de la tarea (la nota perceptual o el fonema). En tal sentido, los resultados fueron similares. En relación a la música, haber desarrollado habilidades de lectura a partir de los cifrados y tablaturas no fue suficiente para acceder a las notas como unidades de escritura, del mismo modo que, en el lenguaje, haber desarrollado habilidades de escritura en un sistema logográfico no fue suficiente para acceder a los fonemas.

En tal sentido, así como en el lenguaje, aprender a leer en un sistema alfabético es condición de posibilidad para acceder a los fonemas como unidades de análisis desde la oralidad; del mismo modo, en la música, aprender a leer en el sistema de notación musical es condición de posibilidad para acceder a las notas perceptuales como unidades de análisis desde la oralidad.

Los resultados del Estudio 3 (Capítulo 5) fueron concluyentes en el mismo sentido. En las entrevistas realizadas a una niña con un gran desarrollo del lenguaje musical basado en una intensa práctica instrumental pero sin conocimiento del sistema de notación musical, observamos que las unidades de análisis por audición tendían a hacer foco en diferentes atributos y, a su vez, a organizarse jerárquicamente de acuerdo a los agrupamientos. En las primeras cuatro entrevistas la niña no contó notas perceptuales espontáneamente. Sin embargo, en la quinta entrevista, luego de la adquisición de la notación musical, la niña evidenció un cambio concluyente en la resolución de la tarea, tanto en la selección de la unidad de análisis por audición como en la estrategia para contar esas unidades. En esa entrevista la niña cantó y contó ocho unidades iguales desestimando todos los criterios que había considerado anteriormente.

A partir de estos resultados podemos considerar que la habilidad para contar unidades equivalentes a las notas no es una habilidad que se adquiera a partir de la exposición al lenguaje o como consecuencia de la maduración. Acceder a las notas perceptuales en una melodía requiere el desarrollo de la conciencia de tales unidades es decir, una habilidad análoga a la conciencia fonémica. Parafraseando a Cunningahm, podríamos definirla como la habilidad para oír, identificar, producir y manipular los sonidos individuales (notas perceptuales) del lenguaje musical. Al igual que en el lenguaje verbal, el desarrollo de la conciencia de estas unidades, parece estar íntimamente relacionado con el aprendizaje de la lectoescritura. 
Los resultados indican que el conocimiento del sistema de notación musical colabora en la identificación de las notas perceptuales como unidades de análisis. Estos resultados se orientan en la misma dirección que aquellos reportados por Robert Scholes y Brenda Willis en las pruebas de supresión de fonemas (Capítulo 1) y que condujeron a los autores a estimar que los fonemas serían un componente de la conciencia de la lengua que tiene un hablante sólo si éste sabe leer una escritura alfabética en su lengua. Del mismo modo, las notas perceptuales parecen ser un componente de la conciencia del lenguaje que tiene un sujeto especialmente si ha desarrollado habilidades musicales a partir de la lectura del sistema de notación musical.

\section{¿Es necesaria una intervención para acceder a las notas perceptuales, como unidades básicas de análisis?}

Como observamos en el Estudio 1 (Capítulo 3), donde los resultados más ajustados en la tarea de contar notas se obtuvieron en las personas que habían desarrollado habilidades musicales a partir del sistema de notación musical, y en el Estudio 3 (Capítulo 5), donde observamos que la niña accedió espontáneamente a las notas perceptuales como unidades de análisis una vez adquirido el conocimiento del sistema de notación, es posible concluir que aprender a leer en el sistema de notación musical proporciona la conciencia de la nota como unidad de análisis. Una vez que los sujetos conocen la unidad de escritura, hacen conscientes esas unidades como modelo de análisis. En tal sentido, y parafraseando a Jesús Alegría (1985), podemos decir que el oyente no llega espontáneamente a descubrir las notas perceptuales como unidades constitutivas de la música. Para que esto ocurra, una intervención externa es indispensable y esa intervención es generalmente el hecho de tener que aprender a leer el sistema de notación musical.

En el lenguaje musical, el conocimiento de la notación proporciona la conciencia sobre las notas como unidades constitutivas mínimas. Sin embargo, en el Estudio 2 (Capítulo 4) observamos que uno de los niños, accedió a la nota perceptual como unidad de análisis durante el desarrollo de la entrevista, aun cuando no conocía la escritura. El niño identificó y graficó primero cuatro unidades, luego seis y finalmente ocho. Aquí la naturaleza de la intervención no fue conceptual, a través del conocimiento del sistema de escritura, sino metacognitiva, a través de la explicitación 
de uno de los principios de representación empleados. En tal sentido, la entrevista funcionó como catalizador en el proceso y permitió que el niño fuera descubriendo unidades al interior de las unidades primeramente determinadas hasta finalmente contar ocho.

En la tercera entrevista del Estudio 3 (Capítulo 5) también se observó cómo el dispositivo de indagación funcionó como facilitador en el proceso de explicitación de las notas perceptuales, aun cuando la niña no había adquirido conocimiento de la escritura musical. En esta entrevista el investigador generó un conflicto al señalar que la unidad de análisis no se correspondía con la unidad de notación que la niña había utilizando. Esta falta de correspondencia quedó en evidencia cuando se ejecutó en el violín cuatro sonidos a partir de la lectura de las cuatro unidades graficadas. El investigador puso en evidencia la discordancia entre la unidad de representación utilizada por la niña y la nota perceptual como unidad de análisis: si cada palito debía representar un sonido entonces faltaban palitos. De este modo, se proporcionó la clave del sistema de notación musical. La intervención favoreció el insight de la correspondencia nota-palito. Podríamos considerar que esta intervención es similar a la que se requiere para pasar de una hipótesis de escritura silábica a otra alfabética, por ejemplo cuando la maestra le explica al niño que la sílaba MA tiene dos constituyentes. Aunque el niño aun lo analiza como un todo, para poder escribir y leer tendrá que acceder a otro nivel de análisis. Así, la niña advirtió la diferencia entre la unidad de transcripción y la unidad de análisis, cambió su criterio de selección y representación e incorporó tantas unidades gráficas como unidades faltantes advirtió. Sin embrago, en el proceso de acceder a la nota perceptual, la niña hizo un paso intermedio hacia la representación agregando tres palitos a cada uno de los grupos ya dibujados en su escritura. En esta etapa del proceso, la niña comprendió la clave, pero aun no advirtió que le quedaron representadas unidades con criterios diferentes.

En una entrevista realizada a uno de los niños participantes en el Estudio 2 (Lucio, Capítulo 4), quedó en evidencia, de modo más contundente, cómo un conjunto de intervenciones pueden funcionar como catalizador en el proceso de hacer conscientes las notas perceptuales aun cuando los sujetos no conocen el sistema de notación musical. Asimismo, se pone en evidencia la inestabilidad que tienen las notas perceptuales cuando aun no se ha desarrollado la escritura. 
En la entrevista presentada en el Estudio 2 (Capítulo 4), Francisco había segmentado el fragmento musical en "cinco y cinco" unidades contando, entre ellas, el énfasis que él mismo producía en una nota larga mientras cantaba. Por lo tanto, sus unidades de análisis incluían, básicamente, notas perceptuales. Sin embargo, dos años más tarde, el niño escuchó nuevamente el fragmento del 1er Movimiento de la Sinfonía $N^{0} 5$ de Beethoven con la misma consigna de contar los sonidos constituyentes de la melodía, cantó el fragmento y contó dos sonidos. A partir de allí, las intervenciones se dirigieron a procurar que el niño hiciera foco en unidades menores a las identificadas. Para ello le solicitamos que cantara el primer sonido que había contado (que correspondía al primer motivo), le preguntamos si dentro de ese "sonido" había otros sonidos más pequeños que lo conformaban, a lo cual el niño contestó afirmativamente, explicando que dentro de ese sonido había "muchos". Entonces, le preguntamos cuántos sonidos había dentro de ese fragmento que él había cantado, y el niño explicó que no podía separar eso porque era como todo un sonido largo.

Es decir que, si bien el niño había accedido, en la entrevista del Estudio 2 (Capítulo 4), a las notas perceptuales, identificando incluso unidades inferiores a la nota, ahora el mismo diseño se le presentaba de un modo diferente, como una configuración y por lo tanto, sus unidades constitutivas le resultaban inaccesibles.

En el contexto de esta nueva entrevista solicitamos al niño que escuchara nuevamente el fragmento con la consigna de atender a las unidades que contenía cada una de esas partes que había identificado. El niño contó primero cuatro y después cinco sonidos, y luego, en el desarrollo de la entrevista fue descubriendo nuevas unidades a partir de las intervenciones del investigador hasta que finalmente contó ocho unidades que se correspondieron con las notas perceptuales.

Retomando la pregunta inicial: ¿es necesaria una intervención para acceder a las notas como unidades básicas de análisis?, la respuesta es afirmativa. Ahora, esa intervención puede ser la adquisición del conocimiento del sistema de notación musical o bien la explicitación de sus unidades de análisis, tal como observamos en los sujetos que accedieron a las notas perceptuales a partir del proceso que tuvo lugar durante la entrevista. Esto es, por un lado hay un sistema de escritura formal, el sistema de notación musical, que al instalarse, conduce y al mismo tiempo condiciona al sujeto en la selección de las unidades mínimas; pero, por otro lado se 
observa también, que una intervención que explora y articula dispositivos que contribuyen a la segregación perceptual de las unidades logra, en principio, un resultado similar. Sin embargo, la diferencia entre ambas intervenciones debería ser estudiada con mayor profundidad, ya que, mientras que la primera permite fijar la unidad de análisis adquirida a partir de una unidad de representación gráfica, la segunda, permite identificar la unidad en el contexto del problema pero luego ésta no logra instalarse y consolidarse conceptualmente. Es por ello que, como vimos en el Estudio 3 (Capítulo 5), Camila accede a las notas perceptuales en la tercera entrevista como resultado de las intervenciones pero luego no utiliza esta unidad en el análisis de la entrevista siguiente, o bien, como vimos en el Capítulo 4, Francisco segmenta en unidades muy cercanas a las notas perceptuales y luego, en la entrevista relatada aquí, expresa que no puede acceder a unidades menores que los motivos.

Por lo tanto, si bien es necesaria una intervención para descubrir que el discurso musical puede ser segregado en notas perceptuales como unidades constitutivas, se requieren nuevas investigaciones para indagar las particularidades que cada intervención puede suscitar.

***

A la luz de las discusiones desarrolladas, es posible concluir que la música no es percibida espontáneamente con las categorías que propone la escritura, la melodía no es naturalmente segmentada en notas, la nota no es una unidad de acceso espontáneo. El sistema de notación musical no constituye una teoría de la audición, sino que es un sistema construido culturalmente, tal como lo es la escritura alfabética de una lengua, cuyas unidades de escritura son definidas de modo arbitrario. Sin embargo, este sistema de notación es la base para consolidar formas de audición que van a dominar el pensamiento una vez adquirida la lógica del sistema. Así, en acuerdo con Cook (1990) la teoría musical no constituye una teoría de la experiencia musical, sino una base para imaginar la musica a partir de ella.

Las notas, al igual que las letras, como unidades básicas de un sistema de escritura, están desprovistas de significado, es por ello que pueden ser conmutadas para formar ideas nuevas con nuevos significados. Acceder a esas unidades implica acceder a niveles que están por debajo del significado. Esto requiere, como explica 
Ferreiro, pasar de un "saber hacer con el lenguaje" a un "pensar sobre el lenguaje", lo cual implica niveles de objetivación y fragmentación diferentes de los que operan en la comunicación oral y para ello la escritura constituye una herramienta de gran utilidad. Para Ferreiro, “pensar sobre el lenguaje” supone aislar ciertas emisiones que, por el mismo hecho de ser aisladas se convierten en objetos opacos sobre los cuales es posible hacer comparaciones. Convertir el lenguaje en algo observable implica cierto nivel de conceptualización y la escritura colabora en este proceso haciendo conscientes diferentes aspectos del lenguaje y transformándolos en objetos de pensamiento y reflexión.

En la música, aislar las unidades del discurso que se corresponden con la escritura implica, además de delimitarlas, despojar a cada una de todos los atributos que le dan sentido, para quedarse sólo con aquella dimensión de la experiencia que está representada en la escritura. Contar la cantidad de notas percepuales implica igualar las unidades, aun cuando la tendencia, tal como observamos en las diferentes entrevistas, es a contar unidades y establecer relaciones entre ellas. Entonces, comprender la naturaleza del sistema de notación musical implica: (i) comprender que la escritura representa una unidad arbitraria que no se corresponde, necesariamente con las unidades de análisis espontáneas; (ii) comprender que todas las unidades son tratadas como equivalentes al nivel de la representación; (iii) comprender que ciertos elementos esenciales de la experiencia de audición no son retenidos en la representación y (iv) comprender que esos elementos que no son retenidos en la representación deberán ser luego reintroducidos en la interpretación de esta representación. 



\section{Referencias}

\section{Referencias bibliográficas}

Alarcos Llorach, E. (1968). Fonología española. Madrid: Gredos.

Alegría, J. (1985). Por un enfoque psicolingüístico de la lectura y sus dificultades. Infancia y Aprendizaje, 29, pp. 79-99.

Alegría, J. (2006). Por un enfoque psicolingüístico del aprendizaje de la lectura y sus dificultades -20 años después. Infancia y Aprendizaje, 29 (1), pp. 93-111.

Asociación Fonética Internacional. (2005). El Alfabeto Fonético Internacional Consultado en: http://www.langsci.ucl.ac.uk/ipa el 23/08/2013.

Ball, E. y Blachman, B. (1991). Does phoneme awareness training in kindergarten make a difference in early word recognition and developmental spelling? Reading Research Quaterly, 16, pp. 49-66.

Bamberger, J. (1982). Revisiting children's drawings of simple rhythms: A function of reflectionin-action. In S. Strauss (Ed.) U-shaped behavioral growth. New York: Academic Press. Pp. 191-226.

Bamberger, J. (1988). Les structurations cognitive de l'appréhension et de la notation de rthmes simples. En H. Siclair (comp.) La production de notations chez le jeune enfant: language, nombres, rythmes et mélodies. París: Presses Universitaires de France. Pp. 99-128.

Bamberger, J. (1991). The mind behind the musical ear. How children develop musical intelligence. Cambridge, Mass.: Harvard University Press.

Barrett, M. (1997). Invented notation: A view of young children's musical thinking. Research Studies in Music Education, 8, pp. 1-14.

Barret, M. (2005). Representation, cognition, and musical communication: invented notation in children`s musical communication. En D. Maill, R. MacDonald y D. Hargreaves (Eds.) Musical Communication. Oxford: University Press. Pp. 117-142. 
Béguelin, M. J. (2002). Unidades de lengua y unidades de escritura. Evolución y modalidades de la segmentación gráfica. En E. Ferreiro (comp) Relaciones de (in)dependencia entre oralidad y escritura.). Barcelona: Gedisa. Pp. 30-52.

Blanche-Benveniste, C. (1998). Estudios linguísticos sobre la relación entre oralidad y escritura. Barcelona: Gedisa, colección LeA, número 12.

Blanche-Benveniste, C. (2002). La escritura irreductible a un "código". En E. Ferreiro (comp) Relaciones de (in)dependencia entre oralidad y escritura. Barcelona: Gedisa. Pp 1530.

Blanche-Benveniste, C. y Chervel, A. (1974). L'othographe. París: Maspero.

Bloomfiel, L. (1933). Language. Nueva York: Holt, Rinehart \& Winston. [El lenguaje. Barcelona: Seix Barral, 1978.]

Bruner, J. (1973). Going Beyond the Information Given. New York: Norton.

Burcet, M. I. (2010). La unidad de pensamiento en la ejecución musical. En Favio Shifres (Ed.) Actas de la Segunda Jornada de Desarrollo Auditivo en la Formación del Músico Profesional, pp. 26-28.

Burcet, M.I. y Jacquier, M.P. (2007). El agrupamiento perceptual en conflicto con el código de escritura. En M. Espejo (Ed.) Memorias de las II Jornadas Internacionales de Educación Auditiva. Tunja, Colombia: UPTC, pp. 87-93.

Burcet, M.I. y Shifres F. (2011). Selección y uso de unidades musicales en una tarea de transmisión oral. En A. Pereira Ghiena; P. Jacquier; M. Valles y M. Martinez (Eds.) Musicalidad humana. Debates actuales en evolución, desarrollo y cognición e implicancias socioculturales. Buenos Aires: SACCoM, pp. 703-710.

Calero A. y Pérez R. (1993). Segmentación del habla y adquisición de la lectura. CL\&E, 18, pp. 431-453.

Carrillo, M. (1994). Development of phonological awareness and reading acquisition: a study in Spanish language. Reading and Writing: AnInterdisciplinary Journal, 6 (3), pp. 279 298.

Catach, N. (1988). Presentación. En N. Catach (comp) Hacia una teoría de la lengua escrita. Barcelona: Gedisa. Pp. 9-30. 
Colapinto, J. (2007). Onward and Upward with the Arts, When I'm sixty-four. En D. Remmick (ed.) The New Yorker, 4 de Junio de 2007. New York: Condé Nast Publications. Pp 5865.

Cook, N. (1990). Music, Imagination, and Culture. Oxford: Clarendon Press.

Cook, N. (2003). Music as Performance. En M. Clayton, T. Herbert y R. Middleton (Eds). The Cultural Study of Music. A Critical Introduction. New York y Londres: Routledge. Pp. 204-214.

Davidson, L., y Scripp, L. (1988). Young children's musical representations: Windows on cognition. En J. A. Sloboda, (Ed.) Generative processes in music: The psychology of performance, improvisation, and composition. Oxford: Clarendon Press. Pp. 195-230.

Davidson, L. y Scripp, L. (1989). Education and development in music from a cognitive perspective. En D. J. Hargreaves (Ed.) Children and the art. Milton Keynes: Open University Press. Pp. 59.86.

Davidson, L.; Scripp, L. (1991). Educación y desarrollo musicales desde un punto de vista cognitivo. En D.J. Hargreaves (Ed.) Infancia y educación artística. Madrid: Morata. Pp 80-111.

Davidson, L. y Scripp, L. (1992). Surveying the coordinates of cognitive skills in music. En R. Colwell (Ed.) Handbook of research on music teaching and learning. New York: Schimer Books. Pp 392-413.

Davidson, L.; Scripp, L. y Welsh, P. (1988). Happy Birthday: evidence for conflicts of perceptual knowledge and conceptual understanding. Journal of Aesthetic Education, 22 (1), pp. 65-74.

Defior, S. y Tudela, P. (1994). Effect of phonological training on reading and writing acquisistion. Reading and Writing: An Interdisciplinary Journal, 6 (3), pp. 299-320.

Desbordes, F. (1990). Idées romaines sur l'éscriture. Lille: Presses Universitaires de Lille. [Concepciones sobre la escritura en la antigüedad romana. Barcelona, Gedisa, 1995].

Deutsch,D. (1992). The Tritone Paradox: Implications for the Representation and Communication of Pitch Structures. En M. R. Jones y S. Holleran (Eds.) Cognitive Bases of Musical Communication. Washington: American Psychological Association. Pp. 115-138. 
Dowling, W. J. (1994). Melodic Contour in Hearing and Remembering Melodies. En R. Aiello (Ed.) Musical Perceptions. Oxford: University Press. Pp. 173-190.

Ehri, L. C. (1985). Effeccts of printed language acquisition on speech. En D. R. Olson, N. Torrance y A. Hildyard (comps.) Literacy, language, and hearning. The nature and consequences of Reading and writing. Cambridge: Cambridge University Press. Pp. 333-367.

Ferreiro, E. y Teberosky, A. (1979). Los sistemas de escritura en el desarrollo del niño. México: Siglo XXI.

Ferreiro, E. (1982). Los procesos constructivos de apropiación de la escritura. En E. Ferreiro y M. Gómez Palacio (eds.) Nuevas perspectivas sobre los procesos de lectura y escritura. México: Siglo XXI.

Ferreiro, E. (1997). Alfabetización, teoría y práctica. México: S. XXI.

Ferreiro, E. (2000a). Entre la sílaba oral y la palabra escrita. Infancia y Aprendizaje, 89, pp. 25-37.

Ferreiro, E. (2000b). L’écriture avant la lettre. Paris: Hachette.

Ferreiro, E. (2002). Escritura y oralidad: unidades, niveles de análisis y conciencia metalinguística. En E. Ferreiro (comp) Relaciones de (in)dependencia entre oralidad y escritura. Barcelona: Gedisa. Pp 151-171.

Ferreiro, E (2012). Consciência fonológica é pré-requisito para escrever? Publicado en http://revistaescola.abril.com.br/fundamental-1/emilia-ferreiro-conscienciafonologica-pre-requisito-escrita-745004.shtml consultado el 22 de Febrero de 2013.

Fromkin, V. y Rodman, R. (1988). An introduction to language. Nueva York: Holt, Rinehart y Winston.

Gaur, A. (1987). A history of writing. Londres: The British Library. [Historia de la escritura. Madrid: Ed Pirámide, 1989].

Goodnow, J. (1977). Children's drawing. London: Fontana Open Books.

Goody, J. (1977). The domestication of the savage mind. Cambridge MA: Cambridge University Press. [La domesticación del pensamiento salvaje. Madrid, Akal, 1985.] 
Goswami, U. y Bryant, P. (1990). Phonological Skills and Learning to Read. Londres: Earbaum.

Harris, R. (1986). The origins of writing. Londres. Duckworth

Hohn, W., Ehri, L. (1983). Do alphabet letters help prereaders acquire phonemic segmentation skill? Journal of Educational Psychology, 75, pp. 752-762.

Jiménez, J. (1992). Metaconocimiento fonológico: Estudio descriptivo sobre una muestra de niños pre lectores en edad preescolar. Infancia y aprendizaje, 57, pp. 49-66.

Kivy, P. (1995). Authenticities. Philosophical Reflections on Musical Performance. Ithaca and London: Cornell University Press.

Krumhansl, C.L. (1990). Cognitive Foundations of Musical Pitch. Oxford: University Press.

Lee, C.S. (1991). The Perception of Metrical Structure: Experimental Evidence and a Model. En P. Howell; R. West and I. Cross (Eds) Representing Musical Structure. London: Academic Press. Pp. 59-127.

Lerdahl, F. y Jackendoff, R. (1983). A Generative Theory of Tonal Music. MA: The Massachussets Institute of Technology.

Leroy-Boussion, A. (1975). Une habileté auditiva-phonétique nécessaire pour apprendre à lire: la fusion syllabique. Enfance, 2, pp. 165-190.

Liberman, A. M.; Cooper, F. S.; Shankweiler, D. P. y Studdert-Kennedy, M. (1967). Perception of the speed code, Psychological Review, 74, pp. 431-461.

Liberman, A. M. y Mattingly, I. G. (1989). A specialization for speech perception. Science, 234, pp. 489-494.

Liberman, I.Y.; Shankweiler, D.; Fisher, F.W. y Carter, B. (1974). Explicit syllable and phoneme segmentation in the young child. Journal of Experimental Child Psychology, 18, pp. 201-210.

Lundberg I. (1991). Phonemic awareness can be developed without reading instruction. En S. Brady y D. Shankweiler (Eds.) Phonological Processes in Literacy: A tribute to Isabelle Y. Liberman. Hillsdale, NJ: LEA. Pp 47-53. 
Lundberg, I.; Frost, J.; y Petersen, O. (1988). Effects of an extensive program for stimulating phonological awareness in preschool children. Reading Research Quaterly, 23, pp. 263-284.

Mattingly, I. G. (1972). Reading, the linguistic process, and linguistic awareness. En: J. F. Kavanagh \& I. G. Mattingly (Eds.). Language by ear and by eye: The relationships between speech and reading. Cambridge, MA: MIT Press. Pp. 133-147.

McCardle, P. y Chhabra, V. (2004). The voice of evidence in reading research. Baltimore: Paul Brookes Publishing.

Morais, J.; Cary, L.; Alegría, J. y Bertelson, P. (1979). Does awareness of speech as a sequence of phones arise spontaneously? Cognition, 7, pp. 323-331.

Morais, J.; Alegria, J. y Content, A. (1987). The relationships between segmental analysis and alphabetic literacy: An interactive view. Cahiers de Psychologie Cognitive European, 7, pp. $415-438$.

Musumeci, O. (2000). Una pedagogía musical cognitive. Actas de la III Conferencia Iberoamericana de Investigación Musical, pp. 97-102.

Musumeci, O. (2007): Adiós al dictado musical: propuestas cognitivas para una educación humanamente compatible utilizando música real. En M. Espejo (Ed.) Actas de la II Jornada de Educación Auditiva. Tunja: Facultad de Ciencias de la Educación, UPTC, pp. 125-167.

Naremore, R.; Densmore, A. y Harman, D. (2001). Phonological Awareness. Assessment and treatment of school-age language disorders a resourse manual. Canada: Singular, Thomson Learning.

Olson, D.R. (1994). The world on paper. Cambridge MA: Cambridge University Press. [EI mundo sobre el papel. Barcelona, Gedisa, 1998.]

Pontecorvo, C. (2002). Las prácticas de alfabetización escolar: ¿es aún válido el "hablar bien para escribir bien"?. En E. Ferreiro (Comp.) Relaciones de (in)dependencia entre oralidad y escritura. Barcelona: Gedisa, Colección LeA nº 21. Pp. 133-150.

Read, C. (1978). Children's awareness of language, with emphasis on sound systems. En A. Sinclair, R. J. Jarvella y W.J.M. Levelt (Eds.) The child's conception of language. New York: Springer. Pp. 65-82. 
Read, Ch.; Zhang, Y.; Nie, H. y Ding, B. (1986). The ability to manipulate speech sounds depends on knowing alphabetic spelling. Cognition, 24, pp. 31-44.

Real Academia Española. (2001). Definición de grafema. En: Diccionario de la lengua española (22. a ed.). Consultado en http://www.rae.es/rae.html el 20/05/2013.

Saenger, P. (1997). Space between words. The origins of silent Reading. Strandford, CA: Stanford University Press.

Saint Pierre, M. de la P. (2010). Factores psicológicos vinculados a la deserción y la retención estudiantil en el aprendizaje del lenguaje musical en el nivel universitario. En L. Fillottrani y A. Mansilla (Eds.) Tradición y Diversidad en los Aspectos Psicológicos, Socioculturales y Musicológicos de la Formación Musical. Buenos Aires: SACCoM, pp. 12-17.

Sampson, G (1985). Writing systems. Stanford, CA: Stanford University Press [Sistemas de escritura. Barcelona, Gedisa, 1997]

Saussure, F. de (1983) Course in general linguistics. Londres: Duckworth. (texto original publicado en 1916) [Curso de lingüística general. Buenos Aires, Losada, 1952]

Scholes, R.J. y Willis, B.J. (1987). Age and education inorla language skills. Developmental Neuropsychology, 3, (3 y 4), pp. 239-248.

Scholes, R.J. y Willis, B.J. (1991). Linguistic, literacy and the intensionality of Marshall McLuhan`s Western man. En D. R. OIson y N. Torrance (Eds.) Literacy and orality. Cambridge, MA: Cambridge University Press. Pp. 215-235.

Shifres, F. (2007). La educación auditiva en la encrucijada. Algunas reflexiones sobre la educación auditiva en el escenario de recepción y producción musical actual. En M. Espejo (Ed.) Memorias de las II Jornadas Internacionales de Educación Auditiva. Tunja: UPTC, pp. 64-78.

Shifres, F. (2009). Notas para un debate sobre el rol de la Audición Estructural en el desarrollo de las competencias auditivas de los músicos profesionales. En Actas de Músicos en Congreso 2009. Siglo XXI. Escenarios musicales en la educación. Pp. 138-148.

Shifres, F. (2013). Descripciones musicales. En F. Shifres y M. I. Burcet (Comp.) Escuchar y Pensar la Música. Bases Teóricas y Metodológicas. La Plata: EDULP. Pp. 67-96. 
Shifres, F. y Burcet, M.I. (2013). Escuchar y Pensar la Música. Bases Teóricas y Metodológicas. La Plata: EDULP.

Shifres, F y Holguín Tovar, P. (ed.) (en prensa). El desarrollo de las habilidades auditivas de los músicos. Teoría e investigación.

Signorini, A. (1998). La conciencia fonológica y la lectura. Teoría e investigación acerca de una relación compleja. Lectura y vida, 19 (3), pp. 15-22.

Sinclair, H. (1982). El desarrollo de la escritura: avances, problemas y perspectivas. En E. Ferreiro y M. Gómez Palacio (Eds.) Nuevas perspectivas sobre los procesos de lectura y escritura. México: Siglo XXI. Pp. 93-106.

Stambak, M. (1951). Le problème du rythme dans le développment de l'enfant et dans les dyslexies d'évolution. Enfance, 4, pp. 480-502.

Stanovich, K.; Cunningham, A. y Cramer, B. (1984). Assesing phonological awareness in kindergarten children: Issues of task comparability. Journal of Experimental Child Psychology, 38, pp. 175-190.

Stanovich, K.E. y Stanovich, P.J. (1995). How research might inform the debate about early reading acquisition. Journal of Research in Reading, 18 (2), pp. 87-105.

Togensen, J. K. y Mathes, P. (2000). A guide to understanding, assessing and teaching phonological awareness. Texas: Pro Ed.

Upitis, R (1992). Can I play you my song? The compositions and invented notations of children. Portsmouth: Heinemann Educational Books.

Upitis, R. (1987a). Toward a model for rhythm development. En J. C. Peery , I. W. Peery y T. W. Draper (Eds.) Music and child development. New York: Springer-Verlag. Pp. 54-79.

Upitis, R. (1987b). Children's understanding of rhythm: The relationship between development and music training. Psychomusicology, 7, pp. 41-60.

Vernon, S. (1997). La relación entre la conciencia fonológica y los niveles de conceptualización de la escritura. Tesis de doctorado. México: DIE/Cinvestav. Consultado en http://www.lecturayvida.fahce.unlp.edu.ar/ el 22/08/2013.

Vernon, S. y Ferreiro, E. (1999). Writing development: A neglected variable in the consideration of phonological awareness. Harvard Educational Review, 69 (4), pp. 395-415. 
Wason, R. W. (2002). Musica Practica: music theory as pedagogy. En Thomas, Cristensen (Ed.) The Cambridge History of Western Music Theory. Cambridge: University Press, pp. 46-77.

\section{Referencias musicales}

Boulil, A. y Schönberg, C.M. (1980). Los Miserables. En CD Original Broadway Cast Recording. Intérprete: Orquesta dirigida por Cameron Mackintosh (1986) New York: GEFEN Rocords.

Beethoven, L.v. (1805). Sinfonía $N^{0} 5$ en do menor, op 67. En CD The Best of Beethoven. Intérprete: Orquesta Filarmónica de Eslovaquia dirigida por Zdenek Kosler (1992) Quebec: Madacy. 



\section{Apéndice}

\section{Transcripción de los fragmentos de Los Miserables}

Transcripción de los fragmentos melódicos seleccionados de la obra Los Miserables de Alan Boublil y Claude-Michel Schönberg utilizados como estímulos en el estudio "La influencia del conocimiento de la notación musical en la identificación de la nota como unidad perceptual" (Capítulo 3)

1

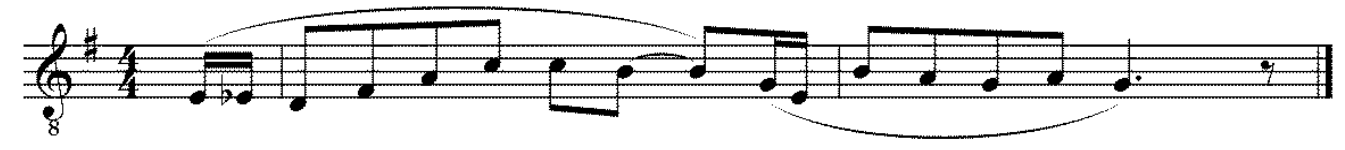

2

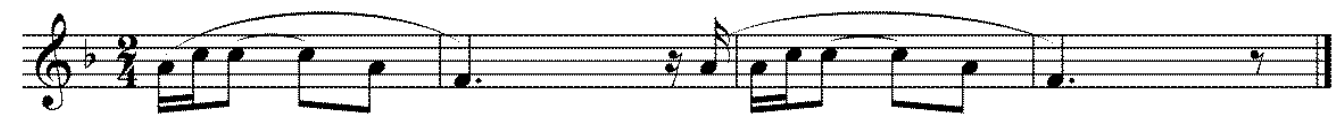

3

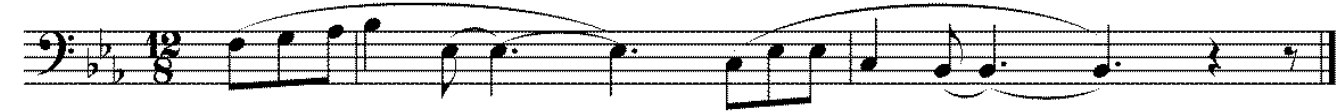

4

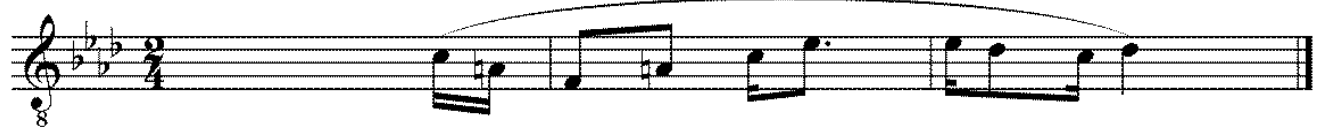

5

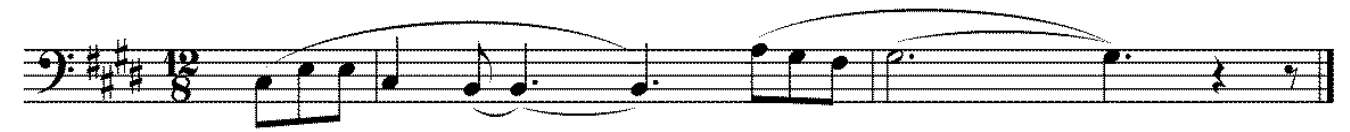

6

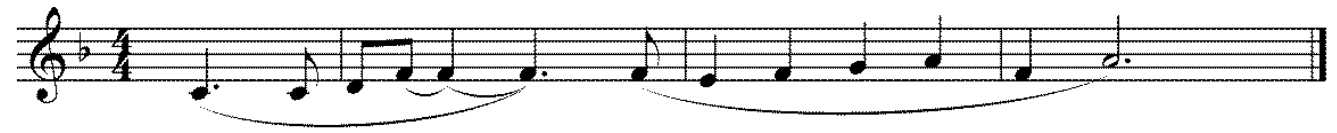

7
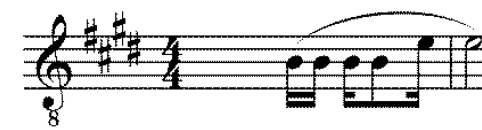


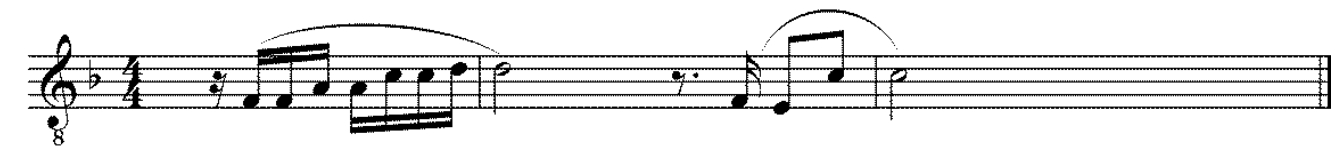

9

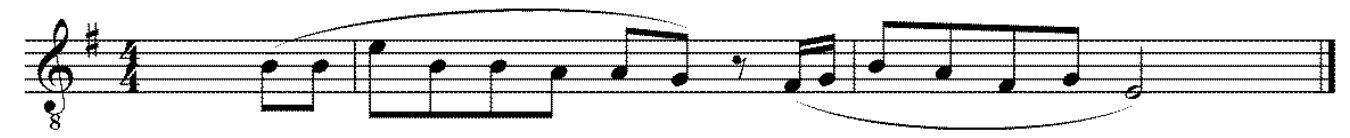

\section{Grabación de los fragmentos de Los Miserables}

Se adjunta en CD la grabación de los 9 fragmentos melódicos seleccionados de la obra Los Miserables de Alan Boublil y Claude-Michel Schönberg utilizados como estímulos en el estudio "La influencia del conocimiento de la notación musical en la identificación de la nota como unidad perceptual" (Capítulo 3).

\section{Grabación del fragmento de la Sinfonía N5}

Se adjunta en CD la grabación del fragmento inicial del 1 er Movimiento de la Sinfonía $\mathrm{N}^{\circ} 5$ de L.V. Beethoven, utilizado como estímulo en el estudio del Capítulo 4, "La unidad espontánea de análisis musical por audición en niños en proceso de alfabetización" y del Capítulo 5, "El conocimiento de la notación musical y la identificación de la nota como unidad de análisis. El caso de una niña violinista". 